Liebig, T. et al. (2012), "The labour market integration of immigrants and their children in Switzerland", OECD Social, Employment and Migration Working Papers No. 128, Directorate for Employment, Labour and Social Affairs, OECD Publishing

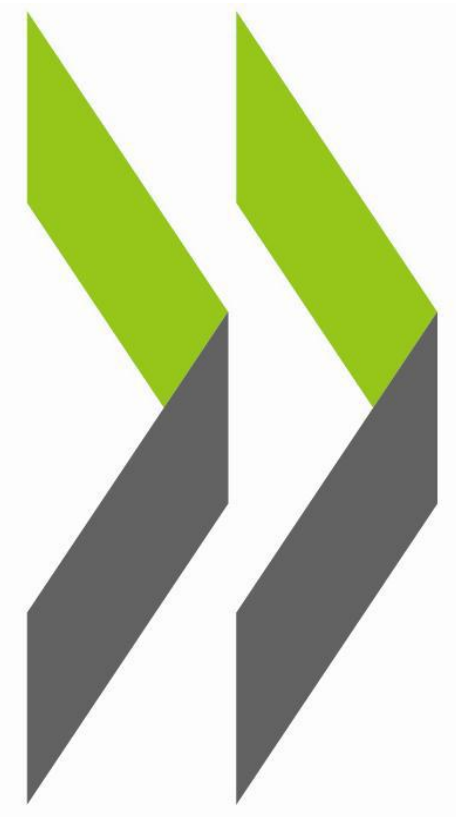

OECD Social, Employment and Migration Working Papers

\title{
The labour market integration of immigrants and their children in Switzerland
}

Thomas Liebig, Sebastian Kohls and Karolin Krause

128

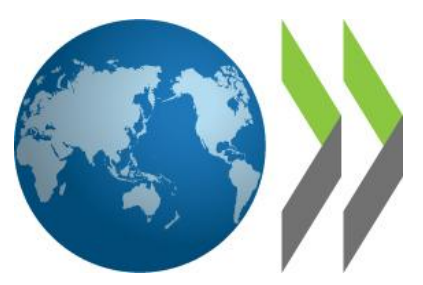


Organisation de Coopération et de Développement Économiques

Organisation for Economic Co-operation and Development

02-Feb-2012

DIRECTORATE FOR EMPLOYMENT, LABOUR AND SOCIAL AFFAIRS

English - Or. English

EMPLOYMENT, LABOUR AND SOCIAL AFFAIRS COMMITTEE

OECD SOCIAL, EMPLOYMENT AND MIGRATION WORKING PAPERS, $\mathrm{N}^{\circ} 128$

THE LABOUR MARKET INTEGRATION OF IMMIGRANTS AND

THEIR CHILDREN IN SWITZERLAND

Thomas Liebig, Sebastian Kohls and Karolin Krause

$J 13, J 15, J 21, J 124, J 61, J 7, J 8$

Translations in German and Italian of the executive summary, as well as of the assessment and recommendations, are to be found in Annex 2 and 3 , respectively.

"This document and any map included herein are without prejudice to the status of or sovereignty over any territory, to the delimitation of international frontiers and boundaries and to the name of any territory, city or area". 


\title{
OECD SOCIAL, EMPLOYMENT AND MIGRATION WORKING PAPERS
}

\author{
www.oecd.org/els/workingpapers
}

This series is designed to make available to a wider readership selected labour market, social policy and migration studies prepared for use within the OECD. Authorship is usually collective, but principal writers are named. The papers are generally available only in their original language - English or French - with a summary in the other.

Comment on the series is welcome, and should be sent to the Directorate for Employment, Labour and Social Affairs, 2, rue André-Pascal, 75775 PARIS CEDEX 16, France.

The opinions expressed and arguments employed here are the responsibility of the author(s) and do not necessarily reflect those of the OECD.

Applications for permission to reproduce or translate all or part of this material should be made to:

\author{
Head of Publications Service \\ OECD \\ 2, rue André-Pascal \\ 75775 Paris, CEDEX 16 \\ France
}

Copyright OECD 2010 


\section{ACKNOWLEDGEMENTS}

This report is the eleventh in a series of reviews of the labour market integration of immigrants and their children, following reviews of Australia, Austria, Belgium, Denmark, France, Germany, the Netherlands, Norway, Portugal and Sweden. It has been written by the International Migration Division of the OECD Directorate for Employment, Labour and Social Affairs under the supervision of Thomas Liebig. It has been produced jointly with Sebastian Kohls and Karolin Krause. Yassine Khoudja provided valuable statistical assistance. It also includes a contribution from Etienne Piguet (University of Neuchâtel).

The authors are grateful for the support and advice received from Jonathan Chaloff, JeanChristophe Dumont, Jean-Pierre Garson, Georges Lemaitre, John Martin, Stefano Scarpetta and Alfonso Sousa-Poza.

A draft of this report was presented and discussed at the OECD Committee for Employment, Labour and Social Affairs on 14 October 2011. The authors thank the participants of the Committee for valuable comments.

The preparation of this report would not have been possible without the support of the Swiss authorities, especially Kurt Rohner and Adrian Gerber and their respective teams from the Federal Office for Migration. The authors are also grateful to the Swiss Federal Statistical Office, in particular Alain Vuille and his team, as well as Sandra Hupka-Brunner and Thomas Meyer from the University of Basel, for their co-operation and for provision of the data. Finally, the authors thank all stakeholders met during the missions to Switzerland, for their valuable information and fruitful discussions.

\section{Contact:}

Thomas Liebig

International Migration Division

Directorate for Employment, Labour and Social Affairs

2, rue André-Pascal

F-75775 Paris Cedex 16

Tel. +33-1-45 249068

Thomas.Liebig@oecd.org

www.oecd.org/migration 
DELSA/ELSA/WD/SEM(2012)2

\section{EXECUTIVE SUMMARY}

Switzerland is among the OECD countries with the largest immigrant populations $-27 \%$ of the working-age population are foreign-born - and the issue of immigration is high on both the policy agenda and in the public debate. Given the numerous debates around this issue in Switzerland, one could be tempted to think that immigrants are less well integrated than in other countries.

The review shows that overall, integration works well in Switzerland. The labour market outcomes for the immigrant population as a whole are highly favourable in international comparison. Both immigrant men and immigrant women have higher employment rates than in other OECD countries.

The favourable picture is mainly attributable to the overall good labour market conditions in Switzerland and a specific mix of origin countries. The bulk of migrants (more than 60\%) have come from high-income OECD countries, more than half of whom from the neighbouring countries with which Switzerland shares the same national languages. Among the other immigrants, the majority are from the successor countries of the former Yugoslavia and from Turkey.

In recent years, following the gradual introduction of freedom of movement with the member countries of the European Union, Switzerland experienced an exceptionally large inflow of immigrants. About 5\% of the resident population consists of recent immigrants, defined as those immigrants with less than five years of residence. Most recent arrivals have again come from neighbouring countries, in particular Germany, and these migrants tend to have highly favourable labour market outcomes by all standard indicators.

Notwithstanding the overall favourable picture, less good outcomes are recorded for some migrant groups, such as, for example, immigrant women with young children. There are few integration measures for immigrant women and they often do not have access to the full range of active labour market policy tools. There are also some signs that the labour market participation of this group has declined in recent years.

Another group which has low employment rates, including in international comparison, are recent humanitarian migrants, who seem to have more difficulties in the Swiss labour market now than previous cohorts of humanitarian migrants. In contrast to other countries, Switzerland does not yet have a standardised integration programme for new humanitarian arrivals, which may have contributed to the low outcomes of this group. Given the positive experiences of OECD countries with structured integration programmes targeted at labour market integration, an introduction of these in Switzerland should be seriously considered.

The generally high employment rates for migrants in Switzerland have also been associated with a significant degree of over qualification for migrants with qualifications from non-OECD countries. These are strongly discounted on the Swiss labour market and there are few bridging courses available. In contrast to other OECD countries, there are also few mentorship or similar programmes in place which would provide immigrants with the necessary contacts with native-born Swiss and with employers, as well 
as knowledge about labour market functioning, both of which are important for access to higher-skilled jobs. Such tools should be provided more broadly, in co-operation with employers.

The federalist character of the country is clearly visible in integration policy, and different local and cantonal practices to promote integration have evolved. While this is in accordance with the principle of subsidiarity and may have contributed to tailor-made and flexible solutions for many migrants, it has also retarded the development of a federal integration policy. As a result, and in spite of considerable improvements over the past decade, the overall framework for integration is thus still underdeveloped. Federal integration policy is modest in comparison with the activities in other OECD countries, most of whom have smaller immigrant populations than Switzerland. Apart from some instruments such as basic language training financed by the Federal Office for Migration, only few integration measures directly targeted at immigrants are available throughout the whole of Switzerland. Indeed, the overall approach to integration in Switzerland is one of immigrants' inclusion in mainstream services, rather than providing targeted measures. To tackle the shortcomings of the current system, the Confederation, cantons and local authorities have recently come forward with a number of suggestions to improve the integration framework, and committed to enhanced funding for integration.

Integration measures at the cantonal level vary widely, partly reflecting the different size and composition of migrant populations. Although many cantons have stepped up their integration measures in recent years, this has often been done on a small-scale, project-type basis, and it is difficult to assess their effectiveness. Some minimum standards should be set by the Federal authorities to ensure that all immigrants get the measures which they need, regardless of the canton they live in.

Access to Swiss nationality is difficult for immigrants, due to exceptionally long duration-ofresidence requirements - 12 years for the ordinary procedure, the longest in the OECD - and the threetiered nature of citizenship acquisition, which involves federal, cantonal and municipal requirements. A reform of citizenship legislation is underway which would tackle some of the most important shortcomings of Swiss nationality law and enhance immigrants' mobility within Switzerland. Empirical evidence suggests that this could provide an important impetus for the integration of disfavoured immigrant groups.

Overall, labour market outcomes for children of immigrants are highly favourable in international comparison. This is partly attributable to good overall labour market conditions and other factors such as the strong role of apprenticeship, which seems to be a particularly beneficial school-to-work transition mechanism for children of immigrants. There are also some innovative programmes in place to prepare low-educated youth (among which children of immigrants account for a large part) for apprenticeship and these appear to have a beneficial effect.

However, children of immigrants whose parents are low-educated tend to have low educational outcomes, and growing numbers of these are now entering the labour market. The less favourable outcomes seem to be at least in part attributable to a lack of early childhood education, as the latter is not yet commonly available in Switzerland. A better and targeted early childhood education for children of immigrants at the critical ages of three and four, in conjunction with language stimulation, should be an urgent priority for policy.

One area in which Switzerland lags greatly behind other OECD countries is anti-discrimination measures. There is little awareness about this issue on the part of employers and it is absent from the public debate. Yet, research suggests that offspring of immigrants, in particular from the former Yugoslavia, with an otherwise equivalent $\mathrm{CV}$ have to submit up to five times the number of applications made by the children of natives in order to get invited to a recruitment interview. It is thus important to take appropriate action to reduce such inequities. 
All things considered, while overall Switzerland performs well in terms of the labour market integration of its immigrants in international comparison, there are several signs that the labour market outcomes of certain groups of immigrants are diverging, with some disfavoured groups running the risk of being left behind. It is thus important to take action now, while overall outcomes are still good. There is awareness of this, and action in the domain of integration has been stepped up on all three levels of government. Nevertheless, in many aspects the integration policies in Switzerland lag behind those in other OECD countries. To overcome these shortcomings and to ensure that outcomes are favourable for all migrant groups, a number of measures should be considered.

Key words: Integration, immigrants, labour market, Switzerland, skills, recognition, discrimination

\section{Summary of the main policy recommendations}

\section{A) Strengthen the overall framework for integration}

- $\quad$ Develop common minimum standards for integration measures that apply across all cantons.

- $\quad$ Facilitate the exchange of good practices between cantons and municipalities.

- $\quad$ Ensure that all immigrants in need of integration support have adequate access to it independent of their type of permit and of the type and scale of benefit receipt, including in particular immigrant women.

- $\quad$ Provide language training to all immigrants in need of this, adjusted to their skills and qualifications.

- Facilitate access to Swiss nationality, and reduce in particular cantonal and municipal residence requirements, to facilitate the geographical mobility of migrants.

- $\quad$ Raise awareness about the benefits which acquiring Swiss nationality entails for the better integration of immigrants and their children.

\section{B) Promote early labour market integration of humanitarian migrants}

- Strengthen the cantons' incentives for the rapid labour market integration of humanitarian migrants during the first five years of residence.

- Implement a structured integration programme for all newly-arrived humanitarian migrants (i.e., persons whose claim is recognised or who are on temporary protection), based on each individual's needs, with a clear focus on labour market integration.

- $\quad$ Better inform employers about the labour market access of persons with temporary protection status.

\section{C) Make better use of the skills of migrants}

- Make sure that the current focus on lesser-skilled employment for humanitarian migrants does not come at the detriment of making the best use of their skills.

- Make the available offers for the assessment and recognition of foreign qualifications better known to immigrants and raise awareness about the benefits which recognition conveys. 
Box 1. Summary of the main policy recommendations (cont.)

C) Make better use of the skills of migrants (cont.)

- Extend bridging courses and other support programmes to help immigrants with credentials from abroad to get into higher-skilled employment.

- $\quad$ Consider the careful extension of temporary wage subsidies for immigrants.

D) Put more effort into the early integration of the children of immigrants

- Enhance pre-school education and pay specific attention to increasing the participation of children of immigrants from disadvantaged background at the early ages of three and four.

- Strengthen language training for the children of immigrants, in particular at early ages.

- Investigate the reasons for the apparently low completion rates of apprenticeship by children of immigrants and take remedial action.

\section{E) Establish a strong framework for anti-discrimination}

- Outlaw discrimination in hiring based on Swiss nationality.

- Raise awareness about the issue of discrimination among employers and the society in general.

- Consider the introduction of more pro-active measures to tackle discrimination. 


\section{TABLE OF CONTENTS}

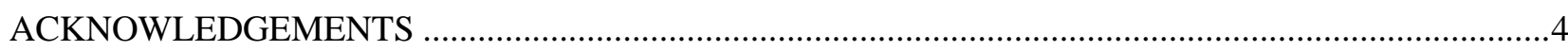

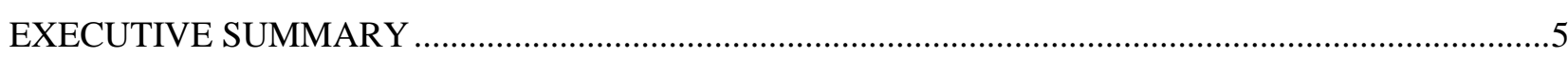

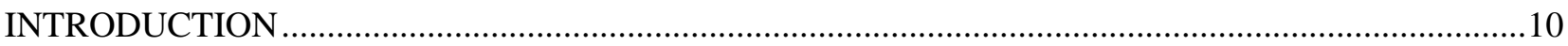

I. A FIRST GLANCE AT THE LABOUR MARKET OUTCOMES OF IMMIGRANTS AND THEIR CHILDREN IN INTERNATIONAL COMPARISON AND THEIR EVOLUTION OVER TIME ............12

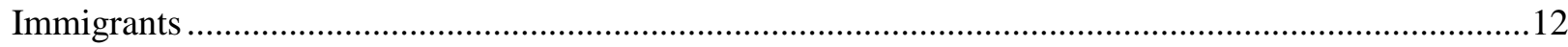

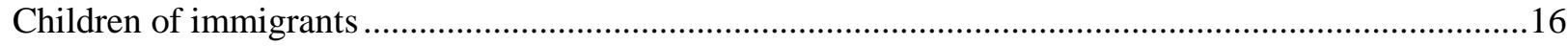

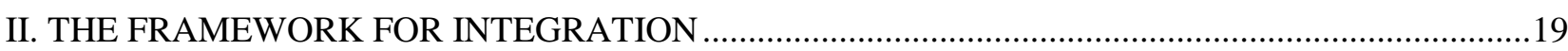

The evolution of immigration to Switzerland and the main migrant groups .........................................19

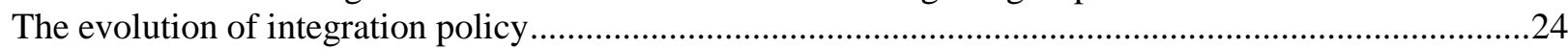

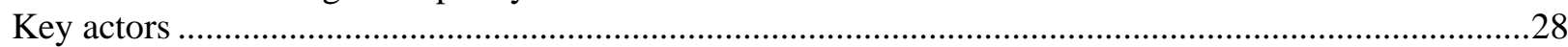

III. KEY ISSUES IN THE LABOUR MARKET INTEGRATION OF IMMIGRANTS.............................31

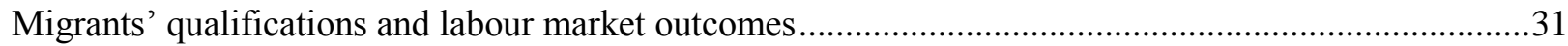

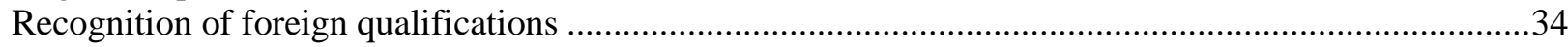

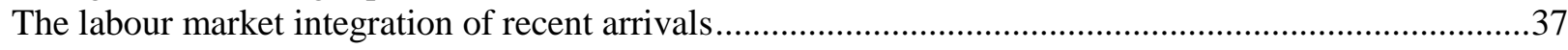

Immigrants' participation in active labour market policy measures .......................................................41

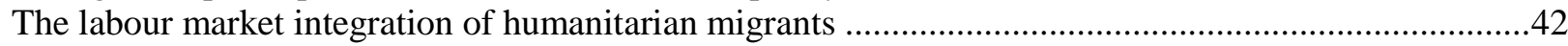

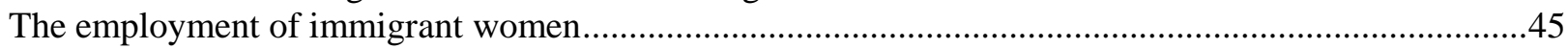

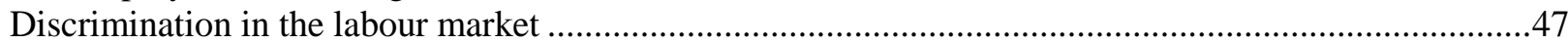

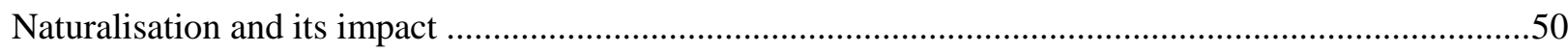

IV. THE LABOUR MARKET INTEGRATION OF IMMIGRANTS' OFFSPRING ….............................54

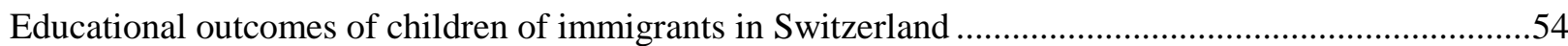

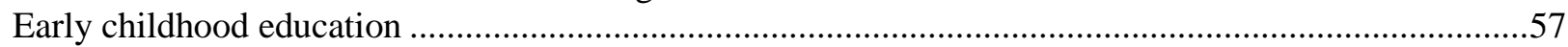

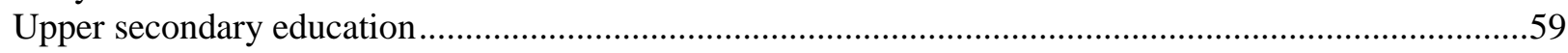

School-to-work transition and labour market outcomes ......................................................................66

Policy intervention to support the school-to-work transition.................................................................66

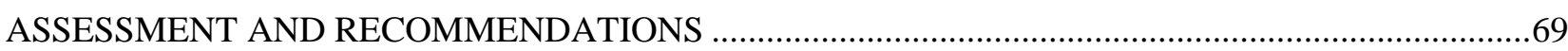

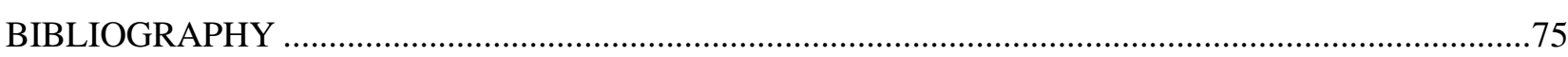

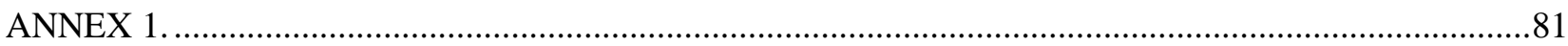

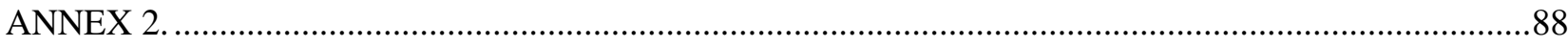

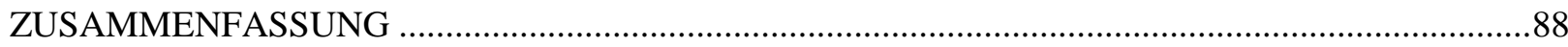

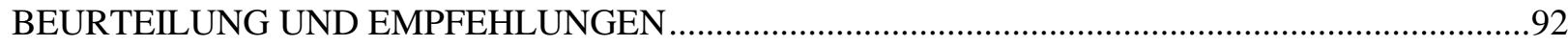

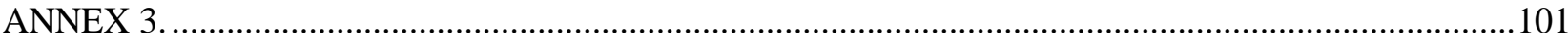

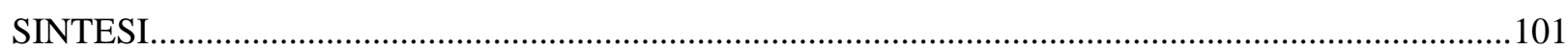

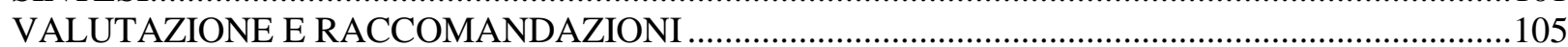


DELSA/ELSA/WD/SEM(2012)2

\section{THE LABOUR MARKET INTEGRATION OF IMMIGRANTS AND THEIR CHILDREN IN SWITZERLAND}

\section{Introduction}

1. With about $27 \%$ of its working-age population being foreign-born, Switzerland has - together with Australia and Luxemburg - one of the largest immigrant populations in relative terms in the OECD. This large share is the result of a longstanding migration history - already in 1970, more than $16 \%$ of Switzerland's population did not have Swiss nationality.

2. A distinguishing characteristic of the immigrant population in Switzerland is the strong concentration of immigrants from other European countries, in particular from neighbouring Italy, Germany and France, as well as by Portugal. Originally, the vast majority of immigrants came from Italy in 1960, 63\% of all foreigners were from that country. Over time, the immigrant intake has diversified to other Southern European countries, in particular the former Yugoslavia. ${ }^{1}$ More recently, following Switzerland's stepwise introduction of freedom of movement with the member countries of the European Union, there has been a large flow of immigrants from Germany. Today, almost $60 \%$ of the immigrant population are from countries of the European Economic Area. A further 17\% are from the successor countries of the former Yugoslavia.

3. Most migration to Switzerland has been labour migration and associated family flows. As a result, the labour market integration of immigrants was less an issue of public debate than the macroeconomic impact of immigration on wages and on structural change.

4. Over the past twenty years, following the fall of the Iron Curtain, Switzerland has also become one of the most important destination countries for humanitarian migration, and this has contributed to a further diversification of the migrant intake. Along with this diversification and the arrival of non-labour migrants from more distant countries, immigrants' labour market integration has gained importance in the public debate, although it remains less of an issue in Switzerland than in many other OECD countries with much smaller immigrant populations.

5. The labour market integration of immigrants also has to be analysed in the context of three key structural specificities of Switzerland. The first is the decentralised nature of policy-making with the strong involvement of three levels (federal, cantonal and local) and the linguistic heterogeneity of the country with four official languages (German, French, Italian and Rumantsch). The second is a flexible labour market with high labour market participation of both genders, low unemployment, high salary levels and relatively low net benefit replacement rates in comparison with other European OECD countries. Finally, Switzerland has a highly productive and internationalised economy, with one of the highest per capita GDP in the OECD, and exports accounting for more than $40 \%$ of this.

1 For the sake of convenience, the terms "ex-Yugoslavia" or "former Yugoslavia" are used in this document synonymously to refer to the former Federal Republic of Yugoslavia and its successor countries. Slovenia, which is a successor country but is now a member of both of the European Union and the OECD, is generally excluded from these figures. 
6. This report is structured as follows: Section I presents an overview of the key labour market outcomes of immigrants in Switzerland in international comparison, and their evolution over time. Section II sets out the framework for integration, that is, the evolution and current composition of the immigrant population, the main elements of integration policy, and the key stakeholders involved in the labour market integration of immigrants. Section III highlights some key issues in the integration of immigrants. Section IV reviews the labour market integration of the children of immigrants. The report ends with a summary and recommendations. 


\section{A FIRST GLANCE AT THE LABOUR MARKET OUTCOMES OF IMMIGRANTS AND THEIR CHILDREN IN INTERNATIONAL COMPARISON AND THEIR EVOLUTION OVER TIME}

\section{Immigrants}

7. Looking at the labour market outcomes of immigrants in international comparison, the first and salient observation is that the employment rates of immigrants are the highest in the comparison group, for both genders (Table 1). ${ }^{2}$ The situation is less positive with respect to unemployment - immigrants face between two and three times higher unemployment rates than the native-born. However, this has to be seen in the context of low overall unemployment in Switzerland which is, after Norway, the lowest in the comparison group.

Table 1: Labour force characteristics of immigrants and the native-born, aged 15-64, selected OECD countries, 2008/2009 average

\begin{tabular}{|c|c|c|c|c|c|c|c|c|c|c|c|c|c|}
\hline & & & \multicolumn{3}{|c|}{ Participation rate } & \multicolumn{4}{|c|}{ Employment rate } & \multicolumn{4}{|c|}{ Unemployment rate } \\
\hline & $\begin{array}{c}\% \text { of the } \\
\text { population } \\
\text { foreign- } \\
\text { born }\end{array}$ & $\begin{array}{l}\% \text { of the } \\
\text { foreign-born } \\
\text { from lower- } \\
\text { income } \\
\text { country }\end{array}$ & $\begin{array}{c}\text { Native- } \\
\text { born }\end{array}$ & $\begin{array}{l}\text { Foreign- } \\
\text { born }\end{array}$ & $\begin{array}{c}\text { Foreign- } \\
\text { born from } \\
\text { lower- } \\
\text { income } \\
\text { country }\end{array}$ & $\begin{array}{c}\text { Native- } \\
\text { born }\end{array}$ & $\begin{array}{l}\text { Foreign- } \\
\text { born }\end{array}$ & $\begin{array}{l}\text { Foreign- } \\
\text { born from } \\
\text { lower- } \\
\text { income } \\
\text { country }\end{array}$ & $\begin{array}{l}\text { Difference } \\
\text { NB-FB in } \\
\% \text {-points }\end{array}$ & $\begin{array}{c}\text { Native- } \\
\text { born }\end{array}$ & $\begin{array}{l}\text { Foreign- } \\
\text { born }\end{array}$ & $\begin{array}{c}\text { Foreign- } \\
\text { born from } \\
\text { lower- } \\
\text { income } \\
\text { country }\end{array}$ & $\begin{array}{l}\text { Difference } \\
\text { FB-NB in } \\
\text { \%-points }\end{array}$ \\
\hline \multicolumn{14}{|l|}{ Men } \\
\hline Austria & 16.4 & 49 & 81.2 & 81.0 & 81.0 & 78.5 & 73.7 & 71.5 & 4.8 & 3.4 & 9.0 & 11.6 & 5.6 \\
\hline Australia (1) & 28.1 & $\ldots$ & 83.8 & 80.5 & $\ldots$ & 79.7 & 76.1 & & 3.6 & 4.9 & 5.5 & 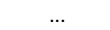 & 0.6 \\
\hline Belgium & 12.3 & 51 & 73.0 & 74.0 & 74.1 & 68.6 & 62.2 & 57.8 & 6.4 & 5.9 & 15.9 & 22.0 & 10.0 \\
\hline Canada (2) & 20.3 & $\ldots$ & 82.0 & 83.2 & $\ldots$ & 75.5 & 75.8 & $\ldots$ & -0.3 & 7.9 & 8.8 & $\ldots$ & 0.9 \\
\hline Denmark & 8.4 & 49 & 84.6 & 80.2 & 77.6 & 80.7 & 73.4 & 70.2 & 7.4 & 4.5 & 8.5 & 9.5 & 4.0 \\
\hline France & 11.9 & 66 & 75.1 & 77.2 & 76.4 & 69.6 & 66.9 & 64.3 & 2.7 & 7.4 & 13.4 & 15.9 & 5.9 \\
\hline Germany & 15.1 & & 82.2 & 82.6 & $\ldots$ & 76.4 & 72.0 & & 4.4 & 7.0 & 12.8 & $\ldots$ & 5.8 \\
\hline Netherlands & 12.2 & 76 & 85.8 & 79.9 & 79.1 & 83.4 & 73.9 & 72.4 & 9.5 & 2.8 & 7.6 & 8.5 & 4.8 \\
\hline Norway & 9.0 & 53 & 82.0 & 81.3 & 75.5 & 79.8 & 74.4 & 66.5 & 5.4 & 2.7 & 8.5 & 12.0 & 5.8 \\
\hline Sweden & 15.2 & 59 & 81.9 & 79.3 & 78.2 & 76.7 & 68.3 & 63.6 & 8.5 & 6.3 & 14.0 & 18.6 & 7.6 \\
\hline Switzerland & 27.2 & 33 & 87.6 & 88.9 & 87.8 & 85.4 & 83.9 & 80.1 & 1.5 & 2.5 & 5.6 & 8.8 & 3.1 \\
\hline $\begin{array}{l}\text { German Switzerland (3) } \\
\text { Romandy/ltalian }\end{array}$ & 24.8 & 49 & 88.9 & 89.3 & 86.9 & 87.1 & 84.7 & 80.9 & 2.4 & 2.0 & 5.2 & 7.1 & 3.1 \\
\hline Switzerland (3) & 33.5 & 33 & 84.0 & 88.1 & 86.0 & 80.5 & 82.4 & 77.4 & -1.9 & 4.3 & 6.6 & 10.2 & 2.3 \\
\hline United Kingdom & 13.7 & 63 & 81.9 & 83.2 & 80.9 & 75.8 & 76.9 & 73.8 & -1.1 & 7.5 & 7.6 & 8.9 & 0.1 \\
\hline United States & 16.7 & 89 & 77.4 & 86.0 & 86.3 & 70.5 & 79.1 & 79.0 & -8.6 & 8.6 & 8.0 & 8.5 & $(-0.6)$ \\
\hline Average (4) & 15.9 & 59 & 81.4 & 81.3 & 79.7 & 77.0 & 73.6 & 69.9 & 3.4 & 5.5 & 9.6 & 12.4 & 4.1 \\
\hline \multicolumn{14}{|l|}{ Women } \\
\hline Austria & 18.1 & 43 & 70.7 & 62.0 & 55.5 & 68.1 & 57.0 & 49.7 & 11.1 & 3.7 & 8.0 & 10.3 & 4.3 \\
\hline Australia (1) & 28.4 & $\ldots$ & 72.6 & 64.0 & $\ldots$ & 69.1 & 60.1 & $\ldots$ & 9.0 & 4.9 & 6.0 & $\ldots$ & 1.1 \\
\hline Belgium & 13.2 & 50 & 62.3 & 51.4 & 46.4 & 58.0 & 43.2 & 36.2 & 14.8 & 6.9 & 16.0 & 22.0 & 9.1 \\
\hline Canada (2) & 21.6 & $\ldots$ & 75.6 & 69.7 & & 71.2 & 63.7 & $\ldots$ & 7.5 & 5.8 & 8.6 & $\ldots$ & 2.8 \\
\hline Denmark & 9.7 & 51 & 78.3 & 66.8 & 60.7 & 75.1 & 60.9 & 54.5 & 14.2 & 4.2 & 8.9 & 10.3 & 4.8 \\
\hline France & 12.5 & 65 & 67.3 & 59.7 & 55.4 & 61.6 & 51.4 & 46.4 & 10.2 & 8.5 & 13.8 & 16.2 & 5.4 \\
\hline Germany & 16.0 & $\ldots$ & 72.9 & 62.3 & $\ldots$ & 68.0 & 54.5 & $\ldots$ & 13.5 & 6.6 & 12.5 & $\ldots$ & 5.9 \\
\hline Netherlands & 13.6 & 73 & 75.1 & 61.6 & 57.5 & 72.8 & 57.2 & 52.9 & 15.5 & 3.1 & 7.0 & 8.0 & 4.0 \\
\hline Norway & 9.7 & 59 & 77.1 & 72.3 & 68.1 & 75.4 & 68.3 & 63.4 & 7.1 & 2.2 & 5.5 & 7.0 & 3.3 \\
\hline Sweden & 17.4 & 57 & 78.6 & 67.6 & 63.7 & 73.7 & 58.3 & 52.0 & 15.4 & 6.2 & 13.7 & 18.4 & 7.5 \\
\hline Switzerland & 28.0 & 36 & 78.4 & 73.3 & 68.2 & 76.0 & 67.6 & 59.5 & 8.3 & 3.1 & 7.7 & 12.8 & 4.7 \\
\hline $\begin{array}{l}\text { German Switzerland (3) } \\
\text { Romandy/ltalian }\end{array}$ & 25.5 & 51 & 80.0 & 74.2 & 69.1 & 77.9 & 68.8 & 61.5 & 9.0 & 2.8 & 7.4 & 11.2 & 4.6 \\
\hline Switzerland (3) & 34.7 & 39 & 74.1 & 71.9 & 68.7 & 71.0 & 65.9 & 60.1 & 5.1 & 4.3 & 8.5 & 12.7 & 4.2 \\
\hline United Kingdom & 14.2 & 62 & 70.4 & 62.9 & 55.9 & 66.5 & 58.2 & 50.6 & 8.3 & 5.6 & 7.5 & 9.5 & 2.0 \\
\hline United States & 15.7 & 88 & 68.9 & 62.9 & 62.3 & 64.7 & 58.4 & 57.7 & 6.3 & 6.1 & 7.1 & 7.4 & 1.0 \\
\hline Average(4) & 16.8 & 59 & 72.9 & 64.3 & 59.4 & 69.2 & 58.4 & 52.3 & 10.9 & 5.1 & 9.4 & 12.2 & 4.3 \\
\hline
\end{tabular}

Notes: 1. Data refer to the average of January 2008 - June 2009. 2. For Canada, separate data for men and women were not available for the foreignborn from lower-income countries. 3. Data from the Swiss Labour Force Survey (Enquête suisse sur la population active (ESPA), Swiss Federal Statistical Office) 2008/2009. 4. The average refers to the unweighted average of all countries included in the table. Definitions of lower-income countries differ slightly between the ESPA and the European Labour Force Survey data. "Lower-income countries" refers to all countries other than OECD highincome countries.

Source: European Union Labour Force Survey, except Switzerland by regions (ESPA), United States (Current Population Survey March Supplement), Canada (Labour Force Survey) and Australia (Labour Force Survey).

The terms "employment rate" and "employment-population ratio" are used synonymously in this report. The comparison group includes OECD countries which also have large and longstanding immigrant populations, most of which have also been under review by the OECD (see footnote 1). 
8. To a large degree, these positive outcomes are attributable to the fact that the majority of immigrants - about two-thirds, the largest proportion in the comparison group - is from high-income OECD countries. ${ }^{3}$ The labour market outcomes of migrants from these countries tend to be better in most countries than those of other migrants (see also OECD, 2007; 2008b). This is attributable to a number of factors, such as the fact that migrants from lower-income countries are often humanitarian migrants. In addition, at the time of migration, the labour markets and education systems in these countries have often differed quite significantly from those found in high-income OECD countries. ${ }^{4}$

9. When looking only at immigrants from lower-income countries, the picture remains relatively favourable for men, whereas the labour market outcomes for women from these countries are broadly in line with those observed in other OECD countries with well-performing labour markets such as Denmark and Norway.

10. Table 1 also shows that the regional differences between the German- and French/Italianspeaking parts of Switzerland are not large. However, employment is higher and unemployment lower in the German-speaking part. This also holds for immigrants, but to a lesser degree. In addition, the share of immigrants from lower-income countries - mainly from the former Yugoslavia and from Turkey - is larger in the German-speaking cantons.

11. Analysis of the labour market integration of immigrants and their children over time is hampered by the fact that data on the labour force status of immigrants is only available from the labour force survey, which has only since 2003 regular information on the country of birth..$^{5}$ Indeed, when reference is made to "immigrants" in Switzerland, both administrative data and research and the public debate generally consider essentially the population with a foreign nationality (see Box 1).

\section{Box 1 Target population, data and research on the labour market integration of immigrants and their children in Switzerland}

In spite of the large immigrant share and the growing policy attention attached to immigrants' labour market integration in Switzerland, quantitative research on this issue has been rather scarce. One reason for this is the fact that both legal documents (such as the Ordinance on the Integration of Foreigners, OIE) and administrative datasets in Switzerland that provide information on the labour market integration of "immigrants" do not refer to the foreign-born population, but to foreign nationals. The reliance on the nationality criterion hampers international comparisons, as citizenship laws and citizenship take-up vary greatly between OECD countries.

Unless stated otherwise, "high-income countries" refers to high-income OECD countries (i.e., OECD other than Mexico and Turkey). "Lower-income countries" include all other countries of origin.

$4 \quad$ Note that the distinction between high- and lower-income countries conceals some heterogeneity within these groups. For example, as will be seen below, migrants from Portugal - a high-income OECD country - often face significant difficulties in labour market integration. This is partly attributable to their low education and has also been associated with poorer outcomes for their children (see also Fibbi et al., 2010).

5 Information on country of birth is also available for 1998 and 2001. However, until 2001, only 16000 households were surveyed in the Swiss labour force survey and the results for the immigrant population are not reliable. In 2001, the sample was increased to 35000 households. Since 2003, the survey has included a regular question on country of birth. In addition, again since 2003, an additional sampling of 15000 households in which the household head is a foreign national has been selected from the Central Information Service on Migration (Système d'information central sur la migration, SYMIC). Since 2010, the labour force survey has been conducted on a continuous basis, a shift which has been associated with a large further increase in the sample size (105 000 households plus an additional sample of 21000 foreign households). 


\section{Box 1 Target population, data and research on the labour market integration of immigrants and their children in Switzerland (cont.)}

Whereas citizenship in Australia, Belgium and Canada can be obtained only three years after immigration, Switzerland has a relatively stringent citizenship law which, in particular, does not envisage automatic citizenship for persons born in Switzerland to immigrant parents (see Section III below). Furthermore, naturalisation appears to be selective: individuals who acquire Swiss nationality tend to be higher educated and to have better labour market outcomes. This may lead to a situation in which integration figures for "foreigners" worsen, even though the actual integration results for the migrant population as a whole stay constant or even improve. In addition, because of Switzerland's long immigration history and the difficult access to citizenship, more than one out of five foreigners is a native-born offspring of immigrants. However, the issues involved are not the same for persons born and educated in the host country as for persons who have immigrated themselves, generally as adults, and who have acquired at least part of their human capital abroad. For these reasons, wherever possible, this document focuses on foreign-born persons and not on persons with a foreign nationality. Because of the size of the native-born offspring of immigrants, a separate section is devoted in this report to their integration.

The assessment of the labour market integration of immigrants in international comparison is also hampered by the fact that most immigrants have come from the European Economic Area (that is, the enlarged European Union, Norway, Iceland and Liechtenstein). Immigrants from these countries not only tend to have better labour market outcomes in most destination countries; they can also easily return to their origin countries in the case of unemployment and benefit from a number of favourable provisions regarding occupational mobility and recognition of their qualifications in Switzerland. Labour market integration is essentially viewed in Switzerland as being an issue for migrants from outside of the European Economic Area (EEA). For this reason, the main target population of this report tends to be immigrants from non-EEA countries and their children.

Data on the foreign-born used to be scarce, but here the situation has significantly improved over the past years. The Swiss Labour Force Survey regularly contains special migration modules. Such modules were included in 1998, 2001, 2003 and 2008. The most recent module also contains rich information on participation in integration services and the recognition of foreign qualifications and allows for an identification of the native-born children of immigrants. Since 2003, the survey has an oversampling of foreigners and includes information on the respondents' country of birth. Since 2009, the data from the labour force survey can also be linked with administrative data from the social insurance funds; retrospective data on this basis are available since 1999. However, information on the type of labour market integration measures in which an individual has participated is only available on a highly aggregated basis.

Switzerland has also participated in the 2003 Adult Literacy and Life Skills Survey (ALL). The Swiss sample included 1087 immigrants and a further 334 native-born persons with two immigrant parents, making it possible to conduct some basic analyses with this survey (see below).

The main longitudinal dataset in Switzerland is the Swiss Household Panel (Panel suisse de ménages, PSM). Established in 1999 with 5074 participating households, it contains information on a broad variety of integrationrelated issues, including background information on the respondents' parents. However, the small sample size and the attrition hamper the usability of this data source for a longitudinal analysis of immigrants' labour market integration. This has been gradually changing with the integration of the PSM in the EU Survey of Income and Living Conditions (EU-SILC). In 2011, a special module covers the intergenerational transmission of disadvantage.

Longitudinal analysis regarding the labour market integration of immigrants' offspring is possible through the TREE (Transition from Education to Employment) dataset. The dataset covers 5528 persons who participated in the 2000 PISA survey in Switzerland and has followed their school-to-work transition in eight annual waves until 2007, an additional wave was conducted in 2010. Since the dataset contains information on both education outcomes and the respondents' migration background, the longitudinal dimension of the integration of immigrants' offspring can be well studied. This dataset has been used in the analysis on the children of immigrants below.

A number of institutions and initiatives have recently provided impetus to research on immigrants' integration, although labour market integration has not always been the primary focus area. In 1995, the Swiss Forum for Migration and Population Studies was established at the University of Neuchâtel. The Forum conducts interdisciplinary research on migration and integration issues. Between 2003 and 2008, the Swiss National Fund commissioned a large-scale special research programme on integration, with a total funding amount of CHF 13 million. This was the second major framework programme on migration and integration, following a CHF 8 million research grant by the Fund on migration and intercultural relations which ended in 2000. 
12. Figure 1 provides an overview of the evolution of the employment rates of immigrants in Switzerland since 2003. For immigrant men, one observes a continuous improvement in the employment rates since 2003, both in absolute terms and relative to the native-born population. This is to some degree attributable to a shift in the composition in the immigrant population towards more immigrants from higher-income countries. Indeed, it is surprising to note that the employment rates of the latter are almost perfectly correlated with those of the native-born population over the entire period. For the foreign-born from lower-income countries, there has been a notable improvement in the labour market situation, with the gap in employment rates having almost halved since 2003.

13. For women, there is again an almost perfect correlation between the employment rates of immigrants from high-income OECD countries and the native-born. Significant gaps, however, are observed for immigrant women from lower-income countries. In addition, and in contrast to the situation for men, the gap between the labour market outcomes of native-born women and women from lowerincome countries is now growing again. However, the level remains rather high in international comparison (see Table 1) - at an employment rate of about $60 \%$.

Figure 1: Evolution of the employment rate since 2003 by country of birth, aged 15-64 Men Women
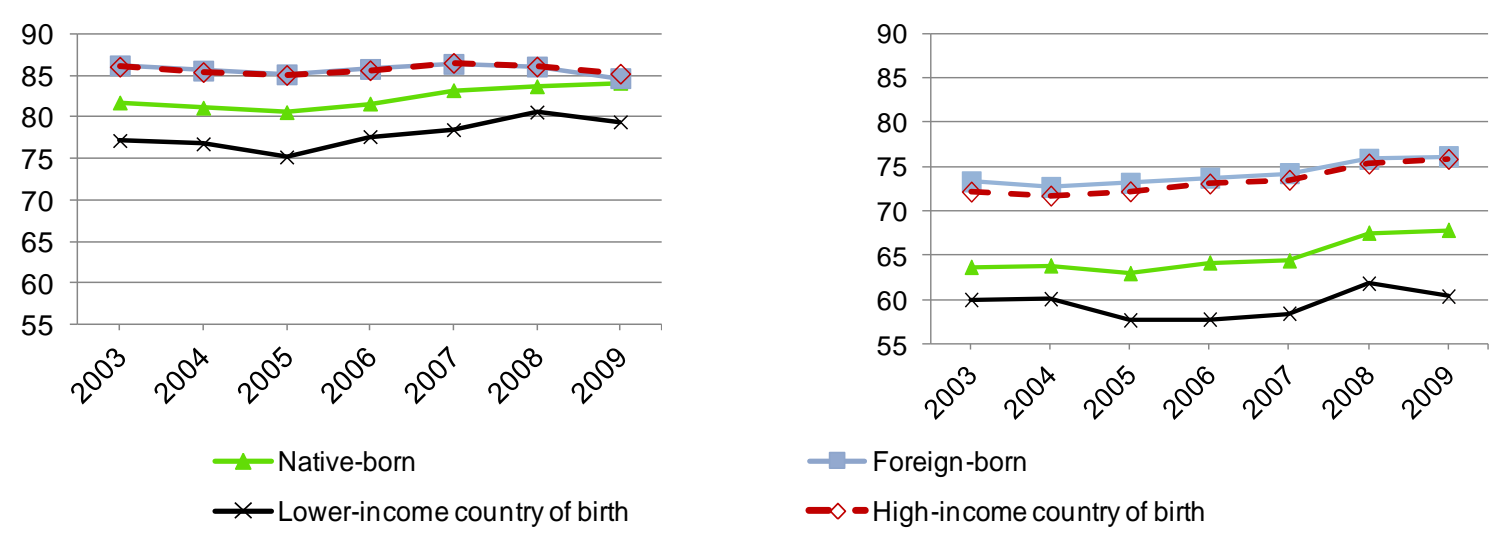

Source: Swiss Labour Force Survey, Swiss Federal Statistical Office.

Figure 2: Evolution of the unemployment rate since 2003 by country of birth, aged 15-64
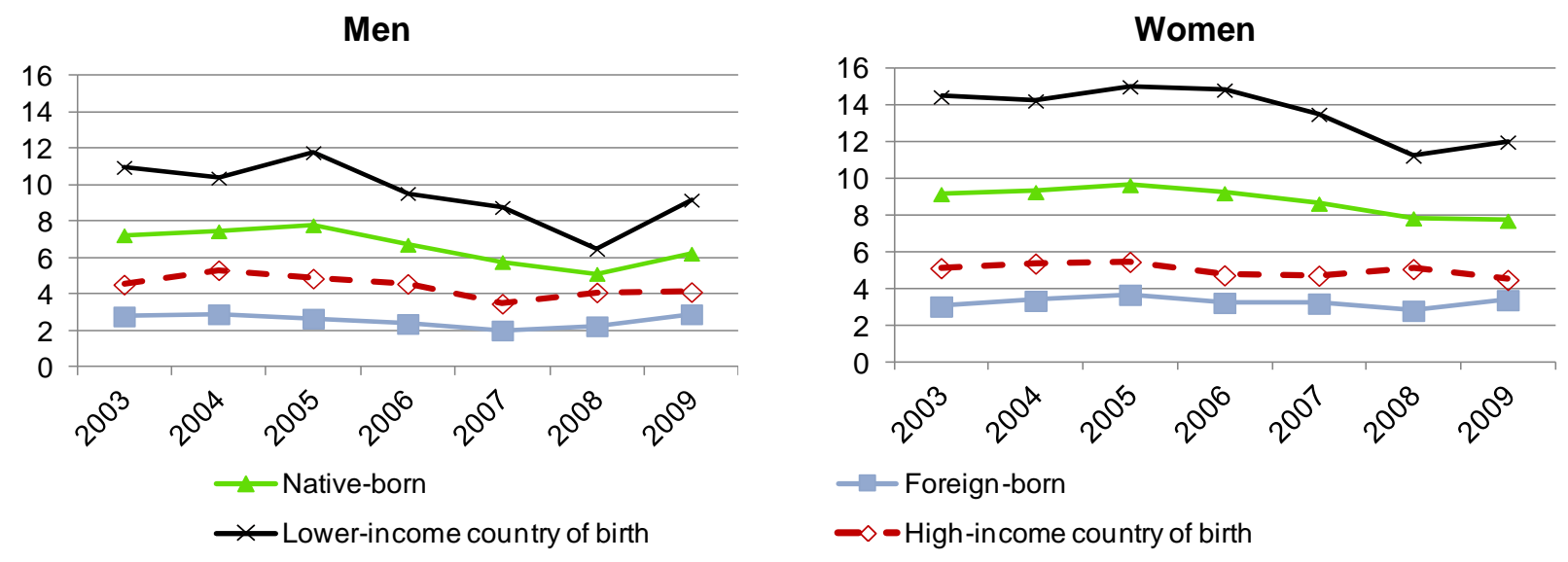

Source: Swiss Labour Force Survey, Swiss Federal Statistical Office. 
14. The evolution of the situation regarding unemployment is shown in Figure 2. Here one observes for all immigrant groups higher unemployment, and the differences are again particularly pronounced for women from lower-income countries. For both genders, immigrants from lower-income countries have nevertheless experienced a significant decline in unemployment between 2005 and 2008. For men, the unemployment rates even declined to a little more than half the 2005 level. However, their unemployment rates increased disproportionately with the crisis.

15. A look at the wages of immigrants shows that when employed, immigrants are clustered among those with a low salary (see Annex Figure 1). There are again rather significant differences between immigrants from high- and lower-income countries, with the latter having much lower salaries. $28 \%$ of immigrants from lower-income countries earn less than two thirds of the hourly median wage for full-time employed, compared with $17 \%$ for immigrants from higher-income countries and $20 \%$ for the native-born. At the same time, immigrants from lower-income countries are underrepresented among the high earners (that is, persons earning more than $166 \%$ of the hourly median wage for the full-time employed).

\section{Children of immigrants}

16. When arriving in their host country, immigrants often face substantial difficulties to enter the labour market, because their human capital differs from that of the native-born. The native-born children of immigrants, however, should not be facing these difficulties as they grew up with the host-country language and have been educated in the host-country's education system. A priori, their labour market outcomes should thus not differ much from those of the children of native-born parents and they are often considered the "benchmark" for integration (Card, 2004).

17. Internationally comparable data on the labour market integration of the children of immigrants is available for the 20-29 year olds. Across almost all OECD countries under comparison, the native-born children of immigrants have a substantially lower employment rate than the children of natives (see Figure 3). Switzerland, in contrast, stands out with an almost negligible difference. Indeed, for women, the employment rates of the native-born children of immigrants are even higher than for the children of natives in Switzerland. For both genders, children of immigrants enjoy the highest employment rates across the OECD.

Figure 3: Employment-population ratios for children of natives and native-born children of immigrants, by gender, aged 20-29 and not in education, around 2008

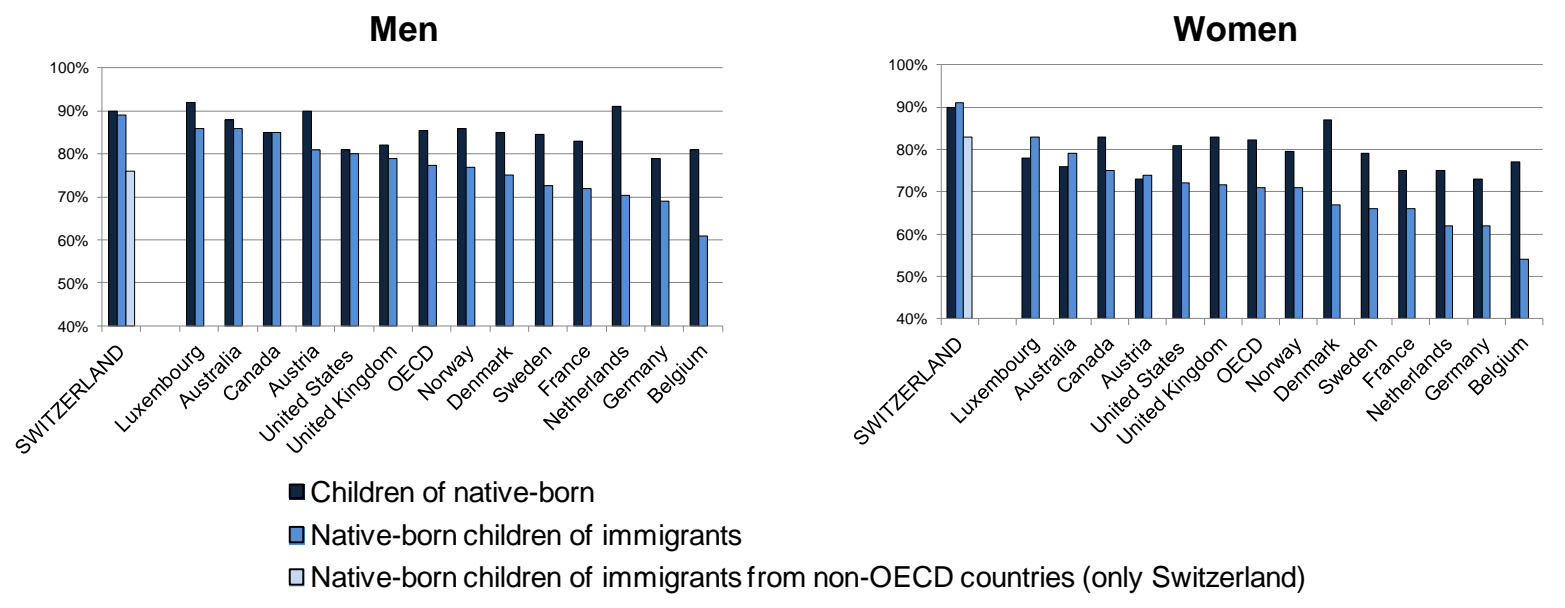

Source: For Switzerland, Swiss Labour Force Survey, Swiss Federal Statistical Office. For the other countries and for the notes, see Liebig and Widmaier (2010). 
18. This favourable picture also holds for a group that is of particular concern for policy, the loweducated youth who are neither in employment nor in education or training (the so-called "NEET"). Here also Switzerland enjoys the smallest share of this "population at risk" among the native-born children of immigrants across the OECD (Figure 4). ${ }^{6}$

19. In all countries, children of parents from lower-income countries tend to have lower employment rates than the offspring of immigrants from high-income countries. While around $90 \%$ of the children of natives and of native-born children of immigrants from high-income countries are in employment, this is the case for less than $80 \%$ of children of immigrants from lower-income countries.

\section{Figure 4: "Population at risk" (the NEET group) among the native-born children of immigrants and the children of native-born, by gender, aged 20-29, around 2007 \\ Men \\ Women}
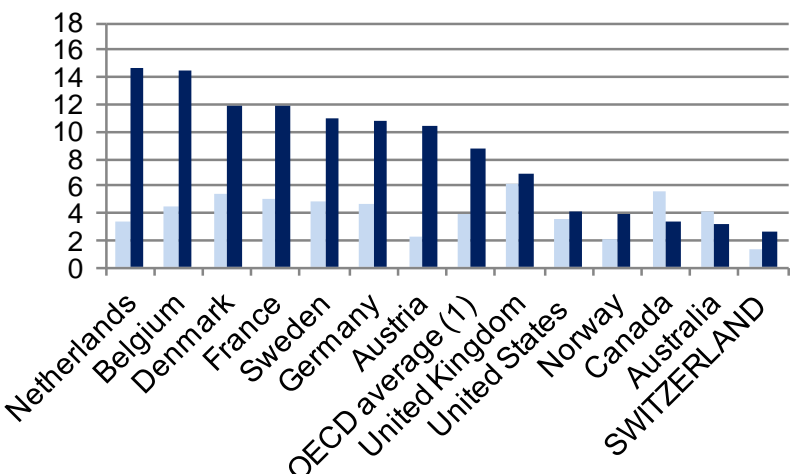

Children of native-born $\quad$ Native-born children of immigrants
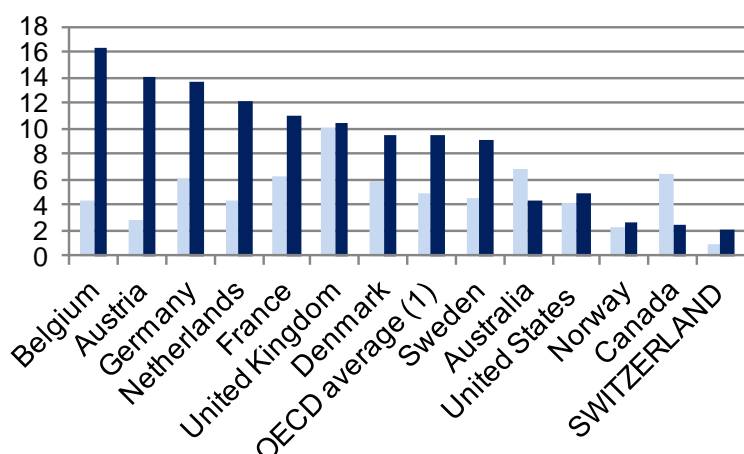

Note: The "population at risk" is defined as being low-educated and not in employment, education or training. 1: The OECD average refers to the unweighted average of the countries included in the figure.

Source: Adapted from OECD (2010a).

20. Indeed, the overall favourable picture of immigrant offspring's labour market integration in this age-group in Switzerland is partly associated with the fact that the share of offspring with parents from high-income countries is bigger in Switzerland than in any other OECD country that has been under review thus far. Almost two-thirds of native-born immigrant offspring aged 20-29 have parents who have come from a high-income country, mostly Italy, Spain and Portugal. These latter three alone account for almost half of the native-born immigrant offspring in this age-group. Only 30\% of the native-born children of immigrants have parents from lower-income countries, compared with an average of $65 \%$ for the 12 OECD countries for which this information is available (see OECD, 2010a). In Switzerland, two thirds of these have parents from the former Yugoslavia or from Turkey.

21. However, the composition of the native-born children of immigrants is changing rather quickly, as Figure 5 shows. Among those now entering the labour market (age 15-19), the majority has parents from lower-income countries, accounting for more than six percent of this age-cohort.

6 Figures regarding NEET in Switzerland for native-born children from lower-income countries are below the publication threshold. 
Figure 5: Size and composition of the native-born children of immigrants, by origin group and age, 2008/2009

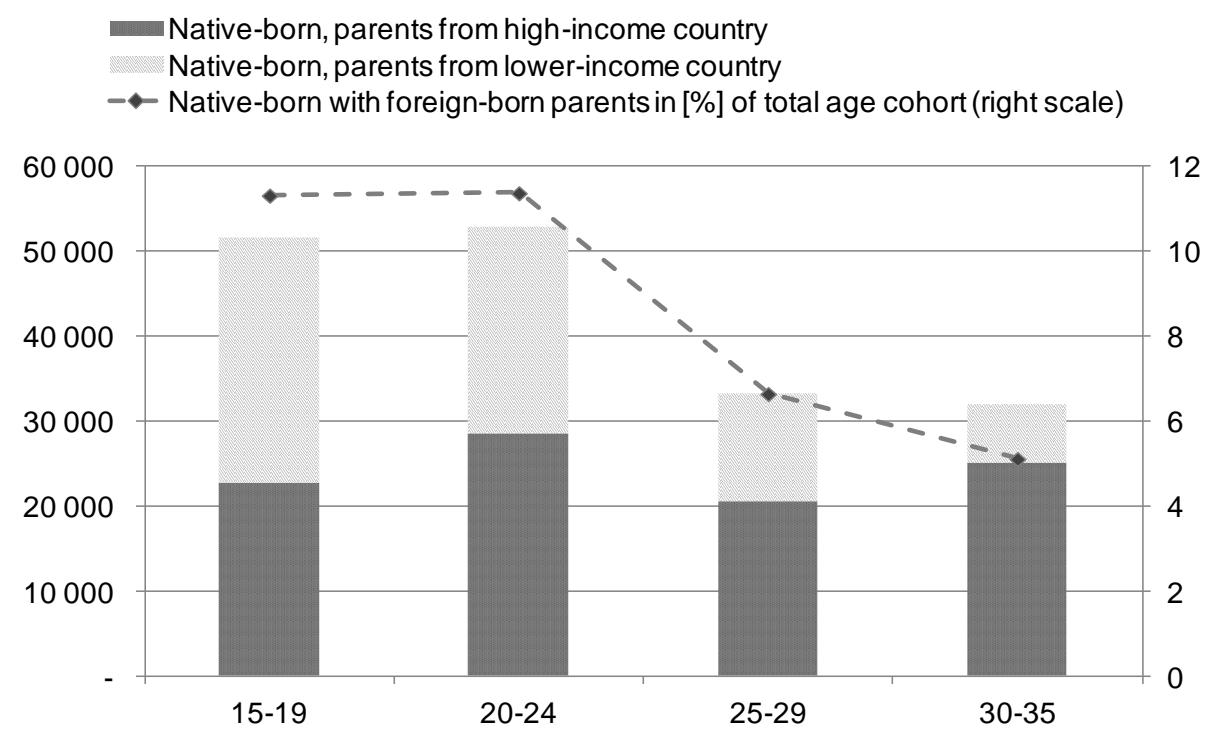

Source: Swiss Labour Force Survey, Swiss Federal Statistical Office.

22. In summary, a first look at the aggregate outcomes reveals that the favourable country-of-origin mix of the foreign-born population is crucial in explaining the overall favourable employment outcomes of immigrants and their offspring in Switzerland. Nevertheless, outcomes appear to be quite favourable even for the relatively small share of immigrants from lower-income countries who tend to have more difficulties in all OECD countries. 


\section{THE FRAMEWORK FOR INTEGRATION}

\section{The evolution of immigration to Switzerland and the main migrant groups}

23. Shortly after World War II, Switzerland experienced an economic boom which led to an increased demand for labour. Switzerland's capital stock had remained largely untouched during the war, and a shortage of labour was felt earlier than in other European countries.

24. In 1948, Switzerland was one of the first European countries to actively recruit foreign workers by signing a recruitment treaty with Italy. As the competition for "guest workers" with countries like Germany intensified, Switzerland had to revise its 1948 recruitment treaty with Italy in 1964, giving more rights to Italians living in Switzerland (for example, facilitated provisions for permanent residency and family reunion).

25. Unlike other Western European countries, Switzerland did not have publicly-provided recruitment agencies for foreign workers. Instead, recruitment was organised by the employers themselves (see Körner, 1990). Even today, the social partners (employers' associations and labour unions) in several sectors maintain recruitment and training facilities abroad. Like other countries, Switzerland thought that the demand for labour and the corresponding immigration would be temporary, which resulted in significant labour migration without major restrictions. However, the rapid increase in the pool of labour was met by rising hostility towards immigrants. In 1963, Switzerland began to gradually control labour immigration by introducing a ceiling on the number of foreigners per establishment.

26. Already in 1970, the share of foreigners among the population in Switzerland was above 16\%, together with Luxemburg the largest in Europe. ${ }^{7}$ At that time, about three quarters of the foreign population were from Switzerland's neighbouring countries. Italians were by far the most important group, accounting for more than half of all foreigners (see Figure 6). The next most important countries were Spain (11\%), Germany (11\%), France (5\%) and Austria (4\%).

27. That same year, the Swiss government placed a global upper limit on the number of immigrants allowed to enter the country. ${ }^{8}$ Switzerland was thus one of the first Western European countries to restrict labour migration. Partly due to this early reaction, Switzerland was able to maintain its labour migration framework even after the first oil crisis and, unlike other European OECD countries such as its neighbours Austria, France and Germany, did not opt for a general stop of the recruitment of foreign labour.

28. At the time of the first oil shock, Switzerland did not have mandatory unemployment insurance and many foreigners who did not enjoy social protection left the country. By doing so, the foreign workers served as a "buffer" on the labour market: despite a reduction of the overall workforce of eight percent the highest fall in the OECD - the unemployment rate never topped one percent (see Sheldon, 2001).

29. With Italy's rapid economic development and integration in the European Economic Area (EEA) and the economic development and democratisation in Spain, immigration to Switzerland has become less attractive for immigrants from these countries. Most of the labour needs in the two decades following the first oil crisis were filled with immigrants from the former Yugoslavia and, to a more limited degree, from

Data on the foreign-born population are only available for recent years. However, for most of the post-war era, there was a large overlap between the foreign- and foreign-born populations in Switzerland.

8 This was a response to a popular initiative ("Schwarzenbach") which sought to restrict the share of foreigners in the total population to ten percent. After an intense campaign and one of the largest voter turnouts in Swiss history, the initiative was rejected by the Swiss people by a relatively close margin of $54 \%$ against $46 \%$. Five further initiatives which aimed at limiting the share of foreigners in the population were voted upon subsequently and were all rejected, most recently in 2000. 
Portugal. These were mainly recruited for low-skilled seasonal jobs in agriculture and hospitality. After four years, however, such seasonal permits could be transformed into a regular residence permit (B-permit which is an annual permit, renewable) which implied that a large share of labour migration entered through low-skilled employment in the seasonal sectors. ${ }^{9}$ Indeed, in the 1980s, the macroeconomic impact of the essentially low-skilled nature of past immigration became a major issue of debate. Empirical evidence suggested that it had hampered structural change and thus economic growth (see e.g. Schwarz, 1988). In parallel, the country-of-origin composition of recent immigrants shifted away from the predominance of Italy to a larger share of immigrants from the former Yugoslavia.

\section{Figure 6: Evolution and composition of the foreign population in Switzerland, absolute numbers and share in the total population, 1950-2009}
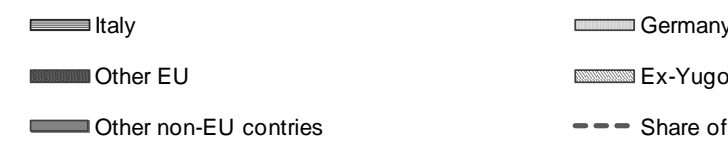

Other non-EU contries

Ex-Yugoslavia

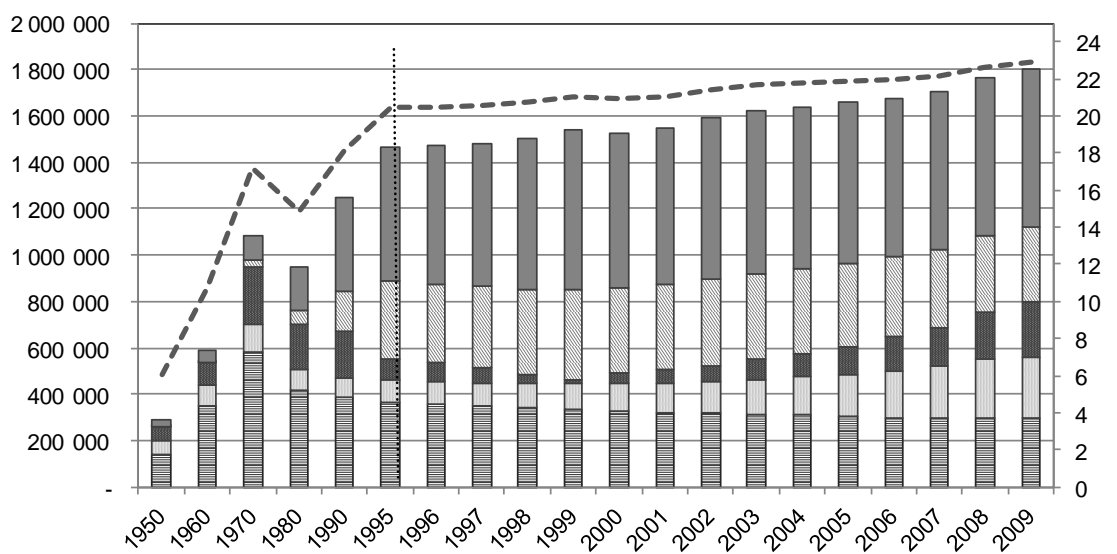

Note: Prior to 1995, data are from the Swiss Census; after that year, data are from population registers.

Source: OECD Secretariat calculations on the basis of data from the Swiss Federal Statistical Office.

30. As a reaction to these developments, the Swiss government introduced the so-called "ThreeCircles Model" in 1991. According to this concept, immigrants from the EEA were granted preferential status (first circle). If labour demand could not be met by immigrants from these countries, people from the USA, Canada, Australia and New Zealand could be recruited (second circle). ${ }^{10}$ All other countries were consigned to the third circle. Along with the change in policy, labour migration from non-EEA countries was gradually restricted to highly-qualified foreigners. Indeed, in contrast to the migrants of the $1980 \mathrm{~s}$, the labour migrants who entered in the 1990s were overrepresented in high-skilled occupations, and there is evidence that this had a positive impact on economic growth in Switzerland (Becker, Liebig and SousaPoza, 2006).

31. With a longstanding humanitarian tradition, Switzerland has also been one of the most important destination countries for asylum seekers. Until the fall of the Iron Curtain in 1989, however, asylum seeking remained relatively modest, but then grew rapidly. Asylum seeking was particularly strong in the

$9 \quad$ For a discussion of the evolution of Swiss labour migration policy, see Liebig (2002).

10 The distinction between the second and the third circle was justified by the better "integratability" of immigrants from the former countries. This was criticised as being discriminatory (see CFR, 1996), and the Three-Circles Model was replaced by the "dual recruitment system" in 1998, which only differentiates between EEA nationals and other immigrants. This model is in essence still in place today. 
1990s, a decade during which Switzerland received, on a per capita basis, more asylum seekers than any other OECD country. The overwhelming majority of the asylum seekers during this period came from the successor countries of the former Yugoslavia. Asylum seeking peaked in 1999 with the war in Kosovo, when more than 46000 persons sought asylum in Switzerland. Mainly as a result of these humanitarian flows and family reunification, almost three-quarters of all immigrants from the former Yugoslavia who are resident in Switzerland today have arrived after 1991, i.e. after the end of most labour recruitment from the former Yugoslavia. These latter migrants have mainly settled in the German-speaking part of the country, in particular in Eastern Switzerland (see Annex Figure 4). Since humanitarian migrants and their families tend to have lower labour market outcomes in all countries, it is not surprising that the employment rates of the migrants who arrived after 1991 are significantly below those of previous arrivals from the former Yugoslavia, for both genders. Likewise, the incidence of unemployment is higher among the post-1991 migrants (Annex Table 3).

32. Today, Switzerland still has one of the largest per-capita inflows of asylum seekers in the OECD, but current numbers are well below the figures seen in the 1990s. In parallel, there has been a shift in the origin countries, with a large part now coming from Africa.

33. Nevertheless, humanitarian migration has generally accounted for a relatively small part of overall migration to Switzerland - its share in total permanent-type migration exceeded $10 \%$ only in the early 1990s (see Figure 7). ${ }^{11}$ Indeed, compared with most other European OECD countries which have participated in the OECD reviews on the labour market integration of immigrants and their children, the share of humanitarian migration in total permanent-based migration has been relatively small over the past six years for which standardised data are available (see OECD, 2011a). In addition, with respect to the flows of asylum seekers, the pattern has been rather procyclical (see Figure 8 ). ${ }^{12}$

\section{Figure 7: Evolution of permanent-type migration to Switzerland, by main category of entry, 1987-2009}

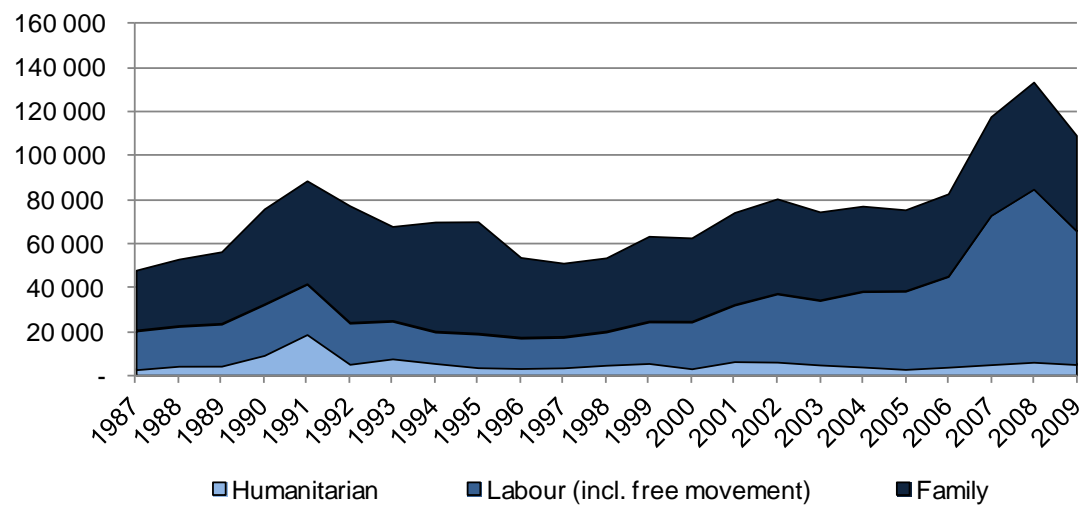

Source: Swiss Federal Statistical Office.

Note: Pensioners and students are excluded. Data are based on national statistics and differ slightly from the standardised statistics published by the OECD (see OECD, 2011a).

34. Since 2002, Switzerland has gradually established freedom of movement with the EEA member countries. This has been associated with a recent boom in free-movement (labour) migration, in particular from Germany. This recent migration has led to a major shift in the composition of the migrant population

11 Note that family migration includes, as in other OECD countries, family formation and family reunification with refugees. 
in several ways. ${ }^{13}$ First, in contrast to the past, the majority of recent labour migrants have been highlyeducated. ${ }^{14}$ Second, whereas the share of immigrants from higher-income countries in the migrant population had been declining since the late 1980s, it increased again since 2002. Third, a majority of recent migrants spoke one of the national languages when they arrived.

Figure 8: Asylum seekers and the labour market situation in Switzerland

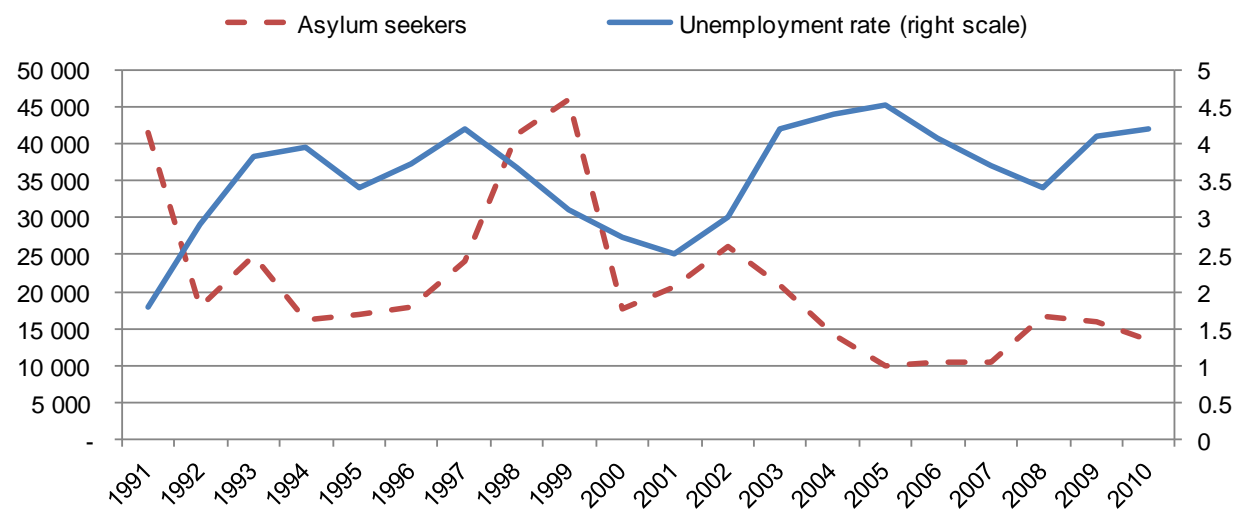

Source: UNHCR, OECD Labour Force Statistics.

35. Figure 9 provides an overview of the current scale and composition of permanent migration inflows to OECD countries. Switzerland stands out in two respects. First, it had the largest share of migration in per-capita terms, at a rate of $1.5 \%$ in 2009 compared with an OECD average of $0.6 \%$. Second, three quarters of all permanent-type migration in 2009 to Switzerland was of the free-movement type, the largest share in the OECD. ${ }^{15}$

Figure 9: Permanent-type migration flows into selected OECD and non-OECD countries by category of entry, 2009 (percentage of the total population)

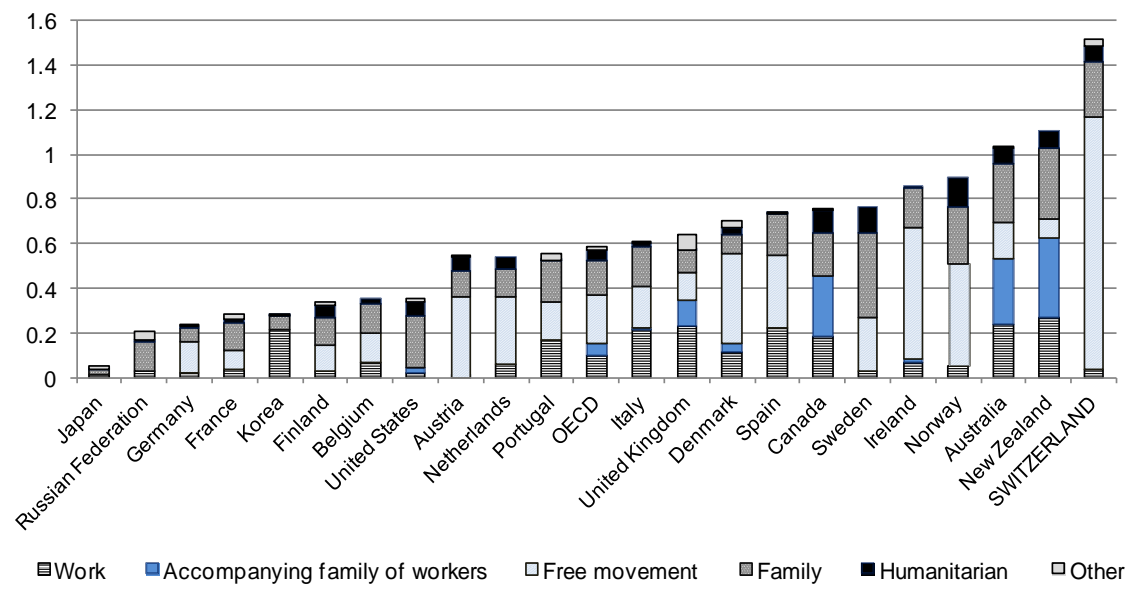

Note: For information on the compilation of the standardised statistics and the definitions, see: www.oecd.org/els/migration/imo Source: OECD International Migration Outlook (2011b).

13 For a comprehensive analysis of this "new" immigration to Switzerland, see Avenir Suisse (ed.) (2008).

14 According to data from the Swiss labour force survey, in 2009, 53\% of immigrants from the EU-15 with less than five years residence in Switzerland had a tertiary degree.

For an in-depth overview of recent trends in migration and migration policy in Switzerland, see de Coulon and Gäumann (2011). 
36. Among the total resident immigrant population in Switzerland, currently more than one out of five in working age have come from one of the successor countries of the former Yugoslavia (see Annex Table 1). The single most important origin country is Germany (13\%), followed by Italy (10\%) and Portugal (9\%). Among the lower-income countries, Turkey ranks second next to the successor countries of the former Yugoslavia, accounting for 5\% of all immigrants. Box 2 provides an overview of the labour market outcomes of immigrants from the former Yugoslavia and Turkey in international comparison.

\section{Box 2. Immigrants from the former Yugoslavia and Turkey and their labour market integration in Switzerland}

Immigrants from the various successor countries of the former Yugoslavia and Turkey together account for $24 \%$ of the immigrant population in working-age in Switzerland, and $54 \%$ of the immigrants from lower-income countries in that age-range.

With the recent update of the OECD database on immigrants and expatriates in OECD countries (DIOC-2005), a comparative overview of the labour market outcomes of immigrants by origin country is possible for those OECD countries where they account for a sizeable population group. The table below provides such an overview for selected OECD countries around 2005. Overall, both groups fare relatively well in the Swiss labour market compared with other countries. This is particularly notable for immigrant women from Turkey who have an employment rate of $59 \%$ compared with an average of $40 \%$ for the selected countries. In contrast, immigrant women from the former Yugoslavia fare only slightly above average, and notably less well than in Austria and Norway. In addition, for both origin groups and both genders, differences in unemployment rates vis-à-vis natives tend to be relatively large in Switzerland. The differences are particularly large for men from Turkey.

Labour force characteristics of immigrants from the former Yugoslavia and Turkey in Switzerland, Austria and in other main European host countries, 15-64 years old, around 2005

\begin{tabular}{|c|c|c|c|c|c|c|c|c|c|c|c|c|}
\hline & \multicolumn{3}{|c|}{ Employment rates (ER) in \% } & \multicolumn{3}{|c|}{$\begin{array}{l}\text { Percentage point difference in the ER } \\
\text { compared with the native-born } \\
\text { (native-born minus other) }\end{array}$} & \multicolumn{3}{|c|}{ Unemployment rates (UR) in \% } & \multicolumn{3}{|c|}{$\begin{array}{l}\text { Percentage point difference in the UR } \\
\text { compared with the native-born } \\
\text { (native-born minus other) }\end{array}$} \\
\hline & Ex-Yugoslavia & Turkey & Foreign-born & Ex-Yugoslavia & Turkey & Foreign-born & Ex-Yugoslavia & Turkey & Foreign-born & Ex-Yugoslavia & Turkey & Foreign-born \\
\hline Australia & 63 & 51 & 70 & 13 & 25 & 5 & 6 & 11 & 6 & -1 & -6 & -1 \\
\hline Austria & 67 & 53 & 63 & 4 & 18 & 8 & 10 & 17 & 10 & -6 & -13 & -6 \\
\hline Belgium & 45 & 36 & 50 & 18 & 27 & 12 & .. & 28 & 17 & & -21 & -10 \\
\hline Canada & 75 & 61 & 72 & 0 & 14 & 3 & 6 & 11 & 7 & 0 & -5 & -1 \\
\hline Denmark & 58 & 61 & 63 & 23 & 20 & 18 & 7 & 12 & 7 & -5 & -10 & -5 \\
\hline France & 52 & 46 & 57 & 13 & 19 & 8 & 23 & 27 & 18 & -13 & -17 & -8 \\
\hline Germany & 59 & 51 & 61 & 11 & 19 & 9 & 15 & 20 & 15 & -6 & -12 & -6 \\
\hline Netherlands & 58 & 54 & 60 & 17 & 21 & 15 & 13 & 11 & 11 & -8 & -7 & -6 \\
\hline Norway & 65 & 52 & 70 & 27 & 41 & 22 & & .. & & .. & & .. \\
\hline Switzerland & 68 & 65 & 74 & 14 & 17 & 8 & 11 & 15 & 8 & -8 & -12 & -5 \\
\hline United States & 74 & 70 & 72 & -2 & 2 & 0 & 7 & 7 & 7 & 0 & 1 & 1 \\
\hline Average $^{1}$ & 62 & 54 & 65 & 13 & 20 & 10 & 11 & 16 & 11 & -5 & -10 & -5 \\
\hline \multicolumn{13}{|l|}{ Men } \\
\hline Australia & 71 & 65 & 80 & 11 & 17 & 2 & 6 & 10 & 6 & -1 & -5 & -1 \\
\hline Austria & 73 & 69 & 73 & 5 & 9 & 5 & 9 & 15 & 10 & -6 & -11 & -6 \\
\hline Belgium & 57 & 54 & 61 & 13 & 15 & 8 & & .. & 16 & .. & & -9 \\
\hline Canada & 81 & 74 & 80 & -2 & 5 & -1 & 5 & $\ddot{g}$ & 6 & $\ddot{1}$ & -3 & 0 \\
\hline Denmark & 64 & 68 & 67 & 21 & 16 & 17 & 6 & 10 & 2 & -4 & -8 & -5 \\
\hline France & 57 & 65 & 65 & 13 & 5 & 5 & 21 & 21 & 15 & -12 & -12 & -6 \\
\hline Germany & 67 & 65 & 69 & 8 & 10 & 6 & 16 & 20 & 9 & -8 & -11 & -7 \\
\hline Netherlands & 65 & 70 & 69 & 18 & 12 & 13 & 13 & 10 & 4 & -9 & -6 & -7 \\
\hline Norway & 66 & 59 & 71 & 26 & 33 & 21 & .. & .. & .. & .. & .. &.. \\
\hline Switzerland & 77 & 70 & 83 & 11 & 18 & 5 & 8 & 16 & 7 & -6 & -13 & -5 \\
\hline United States & 81 & 81 & 82 & -5 & -5 & -7 & 6 & 6 & 6 & 2 & 2 & 2 \\
\hline Average $^{1}$ & 69 & 67 & 73 & 11 & 12 & 7 & 10 & 13 & 8 & -5 & -7 & -4 \\
\hline \multicolumn{13}{|l|}{ Women } \\
\hline Australia & 54 & 36 & 62 & 16 & 34 & 8 & 6 & 13 & 7 & -2 & -8 & -2 \\
\hline Austria & 61 & 34 & 54 & 3 & 30 & 10 & 10 & 20 & 10 & -5 & -16 & -6 \\
\hline Belgium & 31 & 18 & 40 & 25 & 38 & 16 & .. & .. & 18 & .. & .. & -10 \\
\hline Canada & 68 & 46 & 65 & 3 & 25 & 6 & 7 & 15 & 8 & -1 & -8 & -2 \\
\hline Denmark & 52 & 51 & 58 & 24 & 25 & 18 & 7 & 9 & 15 & -4 & -6 & -13 \\
\hline France & 47 & 24 & 49 & 14 & 36 & 12 & 26 & 42 & 21 & -14 & -31 & -10 \\
\hline Germany & 51 & 35 & 52 & 13 & 29 & 13 & 15 & 13 & 22 & -6 & -4 & -13 \\
\hline Netherlands & 51 & 36 & 51 & 17 & 32 & 16 & 11 & 12 & 14 & -6 & -8 & -10 \\
\hline Norway & 63 & 43 & 69 & 29 & 50 & 24 & & . & & . & & . \\
\hline Switzerland & 58 & 59 & 65 & 17 & 16 & 10 & 13 & 13 & $\ddot{g}$ & -10 & -10 & -6 \\
\hline United States & 67 & 57 & 61 & 1 & 11 & 8 & 8 & 8 & 8 & -1 & -1 & -1 \\
\hline Average $^{1}$ & 55 & 40 & 57 & 15 & 30 & 13 & 11 & 16 & 13 & -6 & -10 & -7 \\
\hline
\end{tabular}


37. As in other OECD countries, immigrants are not evenly distributed across Switzerland. Annex Figure 3 provides an overview of the immigrant population by region and its composition. The largest immigrant concentration (almost 40\%) is found in the Italian-speaking canton of Ticino, where, not surprisingly, half of all migrants have come from Italy. In the remainder of the country, the immigrant population is more diverse. Next to Ticino, a particularly large immigrant population is also found in the Lake Geneva region, where immigrants from neighbouring France and from Portugal are the two main origin groups. In Zurich and in North-western Switzerland, immigrants also account for more than 30\% of the population. In these two regions, immigrants from Germany are the main origin group, followed by immigrants from the former Yugoslavia.

38. In summary, one can distinguish four broad waves of different composition of immigration to Switzerland. The first was the early "guestworker" migrants and their families who arrived between 1950 and 1970, mainly from Italy. The second were the late "guestworkers" who arrived between 1970 and 1991, mainly from the former Yugoslavia and Portugal and to a lesser degree from Spain. The third is humanitarian migration, which peaked in the 1990s and is still non-negligible, and here again the former Yugoslavia has been the main origin country in the past, albeit more recently origin countries have diversified, mainly towards Africa but also Asia. The fourth and most recent wave has been free-movement migration from the European Union, in particular from Germany.

\section{The evolution of integration policy}

39. As already mentioned, for most of the post-war period, the permanent settlement of immigrants in Switzerland, and consequently any idea of integration, was not on the policy agenda. On the contrary, the amount of time immigrants could stay was strictly limited under a model of rotating workers without family reunification ("Gastarbeiter"). For example, under the labour recruitment agreement signed with Italy in 1948, workers could be asked to return home at any time and the length of stay required before a permanent residence permit could be obtained was set at ten years. The underlying idea was that immigrants only wanted to stay for a limited time and would thereafter return to their home country. Geographical mobility within the country was limited, as was the right to change employers. These restrictions in the mobility even of permanent-type immigrants remained in place until 2008.

40. The considerable restrictions placed on immigrants in Switzerland were mainly intended to prevent lasting settlement. Although measures targeted at supporting migrant workers were sometimes taken, they consisted of improving the conditions of their stay, but were not aimed at promoting their integration. ${ }^{16}$

41. In the early 1960s, the labour-market-oriented migration policy without concern for integration based on the rotation of workers began to show its limits with the emergence of a xenophobic current and international pressure to improve the status of migrants. Already in 1953, the predecessor of today's OECD, the OEEC, had suggested reducing the time required to obtain a permanent residence permit from ten to five years and Italian diplomacy was taking active steps to assist the 400000 Italian nationals in Switzerland. The Confederation gave ground on these issues, and new directives were adopted to facilitate family reunification. There were also first signs of a growing awareness that immigration was a lasting rather than a merely cyclical phenomenon, and the Federal Council commissioned a working group of scientists and representatives of the administration to prepare an exhaustive report on "the problem of foreign labour". This planning document, published in 1964, charted the course for the decades to come,

16 For example, in 1962, there was a verification of the adequacy of the housing provided by employers. This measure was taken because of the awareness that workers were often inadequately housed in shanties or dilapidated buildings converted into housing. The degree of spatial segregation of migrant workers remained considerable and contact with the local population was limited, without this giving any cause for concern. 
i.e. the rotation model would continue to be applied for the majority of migrants, ${ }^{17}$ but those who were called upon to remain in Switzerland had to take (once they had been allowed to do so) the only pathway that made it possible to "combat an excessive foreign penetration", i.e. assimilation followed by naturalisation (which has been difficult to obtain, see section III for a discussion). The working group also adopted a "universalist" approach and suggested that the equal treatment of Swiss citizens and foreigners should be extended to all forms of social security and vocational training. It also opposed the idea of educating immigrant children in separate classes.

42. A more targeted strategy was also outlined around the concept of "contact points". This suggested creating support centres in major cities to provide services such as language courses for newly arriving immigrants. The idea was to promote mutual knowledge and reduce conflicts between foreigners and natives. However, the implementation of what clearly constituted the first integration programme officially mentioned in Switzerland was left entirely to the good will of individuals, as an appeal to promote integration was implicitly made to landlords, fellow tenants, neighbours, employers, colleagues and subordinates, members of all kinds of groups and organisations, craftsmen, managers of public institutions, doctors, teachers, etc. In line with the tradition of the Swiss social partnership, great hope was placed in the integrating potential of trade unions and it was regretted that there were few foreigners who were union members. In fact, the various concrete measures were being taken in a geographically uneven and uncoordinated manner, and mainly provided some basic language training as well as advice and support to employers, trade unions and also the associations representing the immigrants themselves at the national or regional level.

43. Only following the shock of the xenophobic "Schwarzenbach" initiative of 7 June 1970, which proposed a drastic reduction in the number of foreigners and which was only narrowly defeated, did the federal authorities become more aware of the need for integration and take steps to develop a concrete policy in this field. The fact that mention was made in 1970, for the first time, of the existence of a "second generation" of immigrants during a session of the Federal Council was very symptomatic in this regard (Niederberger, 2005). ${ }^{18}$ A specialised standing commission was established at the national level - the predecessor of today's Federal Migration Commission (see below) ${ }^{19}$ Although the "universalist" approach to policies remained dominant and the Federal Council's programme for the 1971-1975 period was aimed at granting all workers the freedom to change their job, profession or residence, maintaining national priority on the labour market remained key for Swiss policy which in practice continued the nonintegration policy of the 1960s. For example, when the economic situation was severely affected by the oil shock of 1973, the Federal Council announced that Swiss job-seekers were to be given priority over resident foreigners and a circular to this effect was sent to the cantonal authorities (Piguet, 2009). However, the fact that the newly established Federal Commission took the liberty of criticising the federal authorities was a sign that a change was underway.

44. During the period from the mid-1970s to the 1990s, in which immigration began to grow again, federal integration policy remained minimalist and was limited to trying to gradually improve the legal

17 [The status of seasonal worker] "constitutes one of the most effective means of combating Überfremdung [swamping by foreigners] and...should be maintained to the greatest possible extent" (p. 200). immigrants..." - Meeting of the Federal Council, excerpt from protocol, Wednesday 15 July 1970, Federal Archives. city of Zurich had played a pioneering role with its "Commission for Assimilation Issues" (Mahnig (ed.), 2005). The Federal Commission was later called the Commission for Issues relating to Foreign Nationals in 1980 and then the Federal Commission for Foreigners (Commission fédérale des étrangers, CFE) in 1993; its membership consisted of representatives of employers, churches, trade unions, communes and civil society in general. Until 1980, the Federal Council refused to allow foreign representatives to sit in the commission. 
situation of foreigners so that they would enjoy the same civil rights as Swiss citizens. The main obstacle to this policy proved to be the sensitive nature of migration issues among the Swiss population and the willingness of xenophobic movements to make use of the tool of direct democracy. When the measures proposed were universal in scope and only affected foreigners indirectly, as was the case with the general extension of unemployment insurance in 1976, they were accepted. When they were more specific, such as the attempt to reform the Act on Foreign Nationals in 1978 and the two attempts to facilitate the naturalisation of children of immigrants in 1983 and 1994, they failed to pass the popular vote. ${ }^{20}$

45. Another reason why central government did not play a particularly active role is the importance given in Switzerland to the federalist principle of subsidiarity, which has been particularly apparent in the area of integration. Under this principle, responsibility for implementing concrete integration measures lies primarily with the local authorities. As the Confederation did not, until recently, have a legal basis for allocating financial resources to integration, its modest efforts in the domain were limited to trying to promote initiatives by the cantons and municipalities, which are not always convinced of the need for the suggested policies. For example, the Federal Commission initially sought, with limited success, to encourage the establishment of local commissions devoted to integration issues that would act as contact points and centres for disseminating information (Niederberger, 2004). It also encouraged the involvement of foreign delegates on an advisory basis. In 1979, a document was jointly published with the major associations of Swiss communes to provide information and support to municipalities in the field of integration, which stressed the need to enable foreigners to participate more fully in public life (Steiner, 2007). This manual was revised in 1989 ("Foreigners in Our Commune") and demonstrates the predominant role played by the local level in the field of integration until the 1990s.

46. In the 1980s, when Switzerland faced a growing diversification of the immigrant population and an increasing number of immigrant offspring, the Commission became involved in encouraging cantons and cities to establish educational support schemes for children of immigrants, to facilitate their access to social and medical services and to ensure that parents were included in school boards. Among the cantonal measures specifically intended for immigrants, separate classes for new arrivals, which had initially met with criticism, became widespread. Emphasis was also placed on the vocational training of young people with an immigrant background, the number of whom was increasing rapidly.

47. In the 1990s, along with the growing numbers of humanitarian migrants, attention at the federal level shifted to the issue of asylum, to the detriment of interest in integration issues. To this was added the fact that there was significant return migration during the cyclical downturn around 1993, which reinforced the view that immigrants with difficulties to integrate into the labour market would leave the country. In 1991, a major report was published that the Federal Council had commissioned from its administration on the design and priorities of Swiss policy regarding foreigners for the 1990s (OFIAMT/OFE, 1991), but the issue of integration was only addressed marginally. It was at the level of cities and cantons, through the introduction of active integration policies, that a change became perceptible during this period. Many cities and cantons adopted "guidelines" regarding integration and set up specialised administrative services (Sancar, 1999). ${ }^{21}$ This central role played by the local level confirmed the primacy of "ordinary" and "universalist" structures with regard to integration (education, etc.), since these are communal or cantonal responsibilities in Switzerland. It is also possible that the strong decentralisation of integration policy has contributed to the divergence, pointed out by many observers, between the conceptions of integration in French-speaking Switzerland - more focused on participation - and in German-speaking Switzerland, more focused on rights and duties (D'Amato, 2009).

20 A third attempt failed in 2004 (see also Section III below).

21 It was at this time also that cantons ended the exclusion from school of children who did not have a residence permit, first in Geneva in 1991 and then throughout the country, at the time of Switzerland's ratification of the UN Convention on the Rights of the Child in 1997. 
48. By the end of the 1990s, because of many factors - the above-mentioned growing diversity of the origin of immigrants and the reasons why they immigrated, the prospect of permanently relinquishing the "guestworker"-type approach to labour migration associated with the rotation model, the concern over the socio-economic situation of certain groups of settled immigrants and the prospect of complete freedom of movement with the European Union - the issue of integration had come to the forefront of political agendas. In 1999, an article on integration was added to the Foreigners' Act, which provided, for the first time, a legal basis for action by the Confederation to support the integration activities of the cantons. The broad mandate of the revised Act was specified in 2000 when an Order on the Integration of Foreign Nationals issued by the Federal Council came into force. For the first time, it gave the Confederation an explicit mandate, together with a budget of CHF 10 million, to promote the integration of immigrants. Even though the amount was very small, a new era was opened for integration policy.

49. With the new Foreigners' Act which entered into force in 2008, this legal base was enlarged. The new act includes many references to integration and provided the Federal Office for Migration (Office fédéral des migrations, ODM) with the co-ordination role for integration. It also provides for labour market access and full intra-Swiss mobility (that is, the right to change the place of work and the employer) of most permanent-type immigrants in Switzerland. ${ }^{22}$ In addition, the cantons were equipped with the possibility to introduce "integration conventions" which can bind the issuance of residence permits or access to support through social care for migrants from Non-EU/Non-EFTA countries to certain conditions such as the attendance of language classes or other vocational training or employment measures. To date, this tool has only been used in some exceptional circumstances.

50. The new integration policy of the Confederation was elaborated through the "Report Integration Measures" (ODM, 2007), which set the focal points of the federal integration policy for the years 20082011. Within this action frame, measures are undertaken to increase the intercultural competence and language skills of the staff in labour mediation institutions through the offering of courses and specific action recommendations like adding intercultural skills as criteria in the hiring process of new staff. Additionally, the competitiveness of migrants on the labour market is to be increased through imparting basic labour-market-oriented knowledge (e.g. everyday mathematics), as well as basic language training. In addition, cooperation between government agencies, providers of labour-market placement measures and private corporations was to be improved, and the number of foreign job seekers accessing integration allowances to be increased. In addition to these measures that take place within the mainstream services, the Confederation also provides a number of measures targeted at migrants (see below).

51. In 2010, the Federal Council decided in the "Report for the further development of federal integration policy" (Federal Council, 2010; see also de Coulon and Gäumann, 2011) to maintain funding levels and priorities, while continuing to restructure responsibilities. In addition, federal funding will be stepped up from 2014 onwards. The Confederation will be the strategic actor, and the cantons the operative actors within the frame of specific integration policies. Even though parliamentary debates raised the issue of discrimination as a substantial obstacle to the labour market integration of immigrants, the federal council did not see any need to implement additional legislation to prevent discriminatory actions. However, some awareness-raising measures are foreseen from 2014 onwards. In addition, the federal state intends to make welcoming information sessions for recent arrivals obligatory from 2014. Within these meetings, the immigrant's ability to integrate will be evaluated and, depending on the appraisal and the admission status, the authorities will arrange an integration convention with him or her.

Prior to the new law, changing jobs or cantons was subject to permission for persons without a settlement permit, which was generally only obtained after five and ten years of residence in Switzerland for EEA and non-EEA nationals, respectively. 


\section{Key actors}

52. As described above, due to subsidiarity and the structure of the Swiss state, migration and integration policy in Switzerland is relatively decentralised. The decentralised nature of active labour market policy in general creates specific challenges for co-ordination (see Duell et al., 2010 for a comprehensive description).

\section{At the federal level, Switzerland has several actors which develop and influence integration policy}

53. At the federal level, the Federal Office for Migration (ODM) was created in 2005 to handle all migration issues for which the competence is Federal, including immigration and naturalisation. It is in charge of Federal integration policy and co-ordinates the integration activities at the sub-central level. The ODM was the result of a merger between the Federal Office for Refugees and the Federal Office of Immigration, Integration and Emigration. The office has more than 700 employees. In recent years, it has progressively expanded its activities with respect to integration and about CHF 72 million were budgeted for integration measures in 2010. The vast majority of this budget - 59 million - was lump-sum payments to cantons for the integration of humanitarian migrants (that is, refugees and provisionally admitted persons). Only CHF 16 million were available for general integration measures (that is, not targeted at humanitarian migrants), mainly for language training (9 million). The remainder was for "Integration competence centres", which are mainly responsible for welcoming migrants and providing information on integration issues as well as mediating between institutions and people involved in integration processes, for a "mediation centre for intercultural translation" and for the development of innovative integration pilot projects. By 2014, it is planned to merge the lump-sum payments for humanitarian migrants with the regular budget and to top this up by an additional 20 million. This should not only significantly enhance the budget, but also the scale and scope of integration activities at the Federal level which will nevertheless remain more limited than in other OECD countries.

54. The second key player at the federal level is the State Secretariat for Economic Affairs (Secrétariat d'Etat à l'économie, SECO), the Swiss government's "competence centre" for all issues related to economic policy. Within the SECO, the Directorate for Employment is in charge of labour market policy. SECO has also a mandate in public policy analysis which means that it reviews labour market integration policy, and produces periodic reports and recommendations.

55. The Federal Migration Commission (Commission fédérale pour les questions de migration, CFM) was created by the Federal Council in 2008, through merger of the Federal Foreigners Commission (Commission fédérale des étrangers, CFE) and the Federal Refugee Commission (Commission fédérale pour les questions des réfugiés). The CFM is meant to serve as a bridge between civil society and the federal administration. It is an extra-parliamentary commission, with 30 elected members serving a threeyear term, and a full-time staff of 4 . The predecessor to the Commission managed special federal integration funds from 2001-2007, of 10 million per year. Since 2008, the CFM provides grants of about CHF 2 million annually, through tenders. Projects may cover language, integration services, or "innovative projects" in which the CFM is directly involved. Given its limited funds, the CFM concentrates on experimentation, to stimulate local authorities to implement good practices. In addition to funding projects, it publishes reports and recommendations and advises the government. In 2010-2011, it published recommendations on several issues (migrant women, integration contracts, naturalisation, and undocumented migrants). However, the focus of the activities is not on the actual labour market integration of immigrants.

56. Finally, at the Federal level, there is an "Anti-racism Commission" (Commission fédérale contre le racisme, CFR) with a rather modest budget of CHF 155000 (in 2008). The commission essentially runs information campaigns related to discrimination and racism and issues policy statements in these domains. 


\section{But “operation" means expenditures and this is at cantonal/communal level}

57. While most responsibility for policies and expenditures related to integration is at the sub-federal level, it is divided between different levels and different branches. The cantons, for example, are the main level of government responsible for active labour market policies for the unemployed. The cantonal labour offices, which are part of the cantonal economic departments, run the local employment offices ("offices régionaux de placement", ORP / "regionale Arbeitsvermittlungszentren", RAV). The cantons also handle unemployment insurance, although benefit administration is generally not coordinated with job-placement activities. In addition, while invalidity insurance is regulated by federal law, the offices are run at the cantonal level (see Duell et al., 2010 for details).

58. Beyond the mainstream services provided by the public employment and social assistance services and the invalidity-insurance offices, most cantons have established cantonal integration services which deal with projects and stakeholders. They also decide how to disburse the lump-sum integration payment provided for the integration of humanitarian migrants. In addition, all cantons now have integration delegates who co-ordinate integration activities at the cantonal level. The scale and scope of their activities differ widely, partly reflecting differences in the size and composition of the immigrant population (see Annex Figure 3). It is not uncommon even in some of the larger cantons that the integration activities are more or less exclusively confined to recently-arrived humanitarian migrants for whom there are, as already mentioned, some targeted funds available.

59. The municipalities are generally responsible for social assistance and health support, subject to cantonal rules. Smaller municipalities may pool or outsource their social benefit administration to the canton, allowing for more comprehensive cantonal intervention. Active labour market policy for those receiving social benefits is generally co-funded by the canton. The public employment services, which are organised to place the unemployed and benchmarked accordingly, do not normally provide active labour market policy services for those receiving social benefits. The larger cities also have established their own integration services.

60. The tripartite agglomeration conference, founded in 2001, serves as a co-ordination platform for policy across the three levels of government. One of its key tasks is the development of recommendations regarding integration policy and in 2009, it authored a key policy document on the future of integration (Tripartite Agglomeration Conference 2009), which provided an important impetus for the further development of integration policy (see Federal Council, 2010).

\section{The operational model for labour market integration is through contract fee-for-service provision and short-term tenders to private social and non-social enterprises}

61. The public employment services are key actors in placement, but private actors do most of the formal job placement: in 2008, there were about 4000 private placement agencies and temporary-work agencies, placing $70-80 \%$ of all jobseekers passing through institutional placement support.

62. Most funds for active labour market policy (ALMP) are outsourced by cantons. Cantonal budgets vary according to the caseload. The contracted organisations generally do training and preparation. ALMP service providers can be funded by different cantons, and may propose interventions to different funders for beneficiaries with different benefits. Training institutes - often with close links to employers' associations - are another key actor in the Swiss system, with courses subsidised according to the case file of the beneficiary.

63. The wide variety of actors conducting labour market integration policy for immigrants seems both a strength and a weakness. On the one hand, actors are able to experiment different approaches. On 
the other hand, differences in philosophy and approach may make successful initiatives difficult to imitate, and a fully-fledged evaluation is rarely done. Finally, the provision of ALMPs - when they are outsourced - is determined by the parameters of evaluation in the tender, so that initiatives may be designed not around the individual needs of beneficiaries, but to meet performance targets on which projects are reapproved. This may be a particular issue for migrants, whose needs differ and who are often quite far from the labour market. This may notably lead to so-called "creaming" effects, i.e. immigrants benefiting less from ALMP, although there is little evidence that this has been an issue in Switzerland thus far (see Section III below).

\section{Non-governmental organisations play a more limited role than elsewhere}

64. In contrast to other OECD countries such as Belgium, Germany or the Nordic countries, there is no formal representation of immigrants at the federal level, although migrant representatives have half of the seats in the Federal Commission for Migration (Commission fédérale pour les questions de migration, $C F M$ ). More generally, non-governmental organisations (NGOs) appear to play less of a role than elsewhere. The largest NGO with respect to integration is the Swiss Refugee Aid which runs a number of integration-related projects for humanitarian migrants and asylum seekers. ${ }^{23}$ In 2010, it had a budget of about CHF 6.8 million.

65. Business and employers' associations have not played a major role with respect to labour market integration of immigrants thus far. Labour unions, in contrast, have a long tradition of having a strong migrant representation in their membership - particularly the blue-collar unions. More than $50 \%$ of the members of Switzerland's largest union, UNIA, are immigrants (leading it to declare itself "Switzerland's largest migrant association"). UNIA provides language training and mentorship programmes. These, however, are mainly for persons already in employment. Further, migrant membership appears due largely to its sectoral concentration (construction accounts for more than a quarter of the members in employment) and comprises mostly the labour migrants (Italian, Spanish and Portuguese) who have arrived several decades ago and many of whom are approaching pension age, rather than young immigrants from the other countries or humanitarian migrants.

23 Until 2008, the Swiss Refugee Aid was the main actor in charge of the integration of humanitarian migrants. 


\section{KEY ISSUES IN THE LABOUR MARKET INTEGRATION OF IMMIGRANTS}

\section{Migrants' qualifications and labour market outcomes}

66. The qualification structure of the Swiss workforce aged 25-54 is largely dominated by uppersecondary and tertiary qualifications (see Table 2). As in the United States, Austria and Germany, the medium-educated represent more than half of the native-born population and in addition, the highlyeducated have a rather high share of $38 \%$. The low-educated population, on the other hand, is smaller in Switzerland than in any other country in the comparison group. The share of low-educated amounts to only $5 \%$ among the native-born, compared with $15 \%$ on average in the comparison group.

Table 2: Distribution (in \%) of the native and foreign-born populations, aged 25-54, by educational level, selected high-income countries, 2008/2009

\begin{tabular}{|c|c|c|c|c|}
\hline & & ISCED 0-2 & ISCED 3/4 & ISCED 5/6 \\
\hline \multirow{3}{*}{ Austria } & Native-born & 13 & 68 & 19 \\
\hline & Foreign-born & 30 & 51 & 19 \\
\hline & Foreign-born, lower-income & 44 & 43 & 14 \\
\hline \multirow{3}{*}{ Belgium } & Native-born & 23 & 41 & 37 \\
\hline & Foreign-born & 39 & 30 & 31 \\
\hline & Foreign-born, lower-income & 46 & 28 & 26 \\
\hline \multirow{3}{*}{ Denmark } & Native-born & 20 & 43 & 37 \\
\hline & Foreign-born & 29 & 39 & 32 \\
\hline & Foreign-born, lower-income & 42 & 36 & 22 \\
\hline \multirow{3}{*}{ France } & Native-born & 23 & 45 & 32 \\
\hline & Foreign-born & 41 & 31 & 28 \\
\hline & Foreign-born, lower-income & 43 & 30 & 27 \\
\hline \multirow{3}{*}{ Germany } & Native-born & 9 & 64 & 28 \\
\hline & Foreign-born & 35 & 45 & 20 \\
\hline & Foreign-born, lower-income & $\ldots$ & $\ldots$ & $\ldots$ \\
\hline \multirow{3}{*}{ Netherlands } & Native-born & 22 & 44 & 35 \\
\hline & Foreign-born & 39 & 33 & 28 \\
\hline & Foreign-born, lower-income & 45 & 32 & 22 \\
\hline \multirow{3}{*}{ Norway } & Native-born & 18 & 44 & 38 \\
\hline & Foreign-born & 26 & 35 & 38 \\
\hline & Foreign-born, lower-income & 36 & 33 & 31 \\
\hline \multirow{3}{*}{ Sweden } & Native-born & 11 & 55 & 34 \\
\hline & Foreign-born & 25 & 40 & 35 \\
\hline & Foreign-born, lower-income & 29 & 37 & 33 \\
\hline \multirow{3}{*}{ United Kingdom } & Native-born & 20 & 35 & 46 \\
\hline & Foreign-born & 19 & 24 & 57 \\
\hline & Foreign-born, lower-income & 23 & 22 & 55 \\
\hline \multirow{3}{*}{ United States } & Native-born & 7 & 61 & 32 \\
\hline & Foreign-born & 28 & 42 & 30 \\
\hline & Foreign-born, lower-income & 31 & 41 & 28 \\
\hline \multirow{3}{*}{ Switzerland } & Native-born & 5 & 58 & 36 \\
\hline & Foreign-born & 27 & 38 & 36 \\
\hline & Foreign-born, lower-income & 31 & 40 & 29 \\
\hline
\end{tabular}

Source: European Community Labour Force Survey 2009 and Current Population Survey March Supplement 2009 for the United States.

67. Among immigrants, qualifications below upper-secondary level are more widespread than among the native-born - more than one quarter of the foreign-born are low-educated. The share of highlyeducated, on the other hand, is as high as among the natives. Among the group of immigrants from lowerincome countries, there are almost even shares of low- and highly-educated, roughly $30 \%$ each.

68. In terms of labour market outcomes, and in contrast to all other European OECD countries in the comparison group, low-educated immigrants fare better in the Swiss labour market than their native peers 
(see Figure 10). ${ }^{24}$ However, the medium- and highly-educated face rather large differences in their employment rates compared with their respective native peers.

69. $69 \%$ of the highly-educated immigrants work in jobs that match their skill level, which is the highest share in international comparison (see Annex Table 2). This is, however, again driven by the large share of immigrants from high-income countries in the foreign-born population. Indeed, this group is even less concerned by over-qualification than the native-born. The picture is quite different for immigrants from lower-income countries. Only 53\% of the highly-educated are in jobs that match their skill level. Although this share is still quite high in international comparison, it is much lower than for the natives and immigrants from higher-income countries who have shares of $72 \%$ and $76 \%$, respectively. It thus appears that the highly-educated immigrants from lower-income countries face obstacles to having their qualifications and work experience valued in the Swiss labour market, although these are not necessarily larger than elsewhere.

\section{Figure 10: Percentage-point differences in employment rates of foreign- and native-born, by} educational level, aged 15-64 and not in education, 2008/2009 average

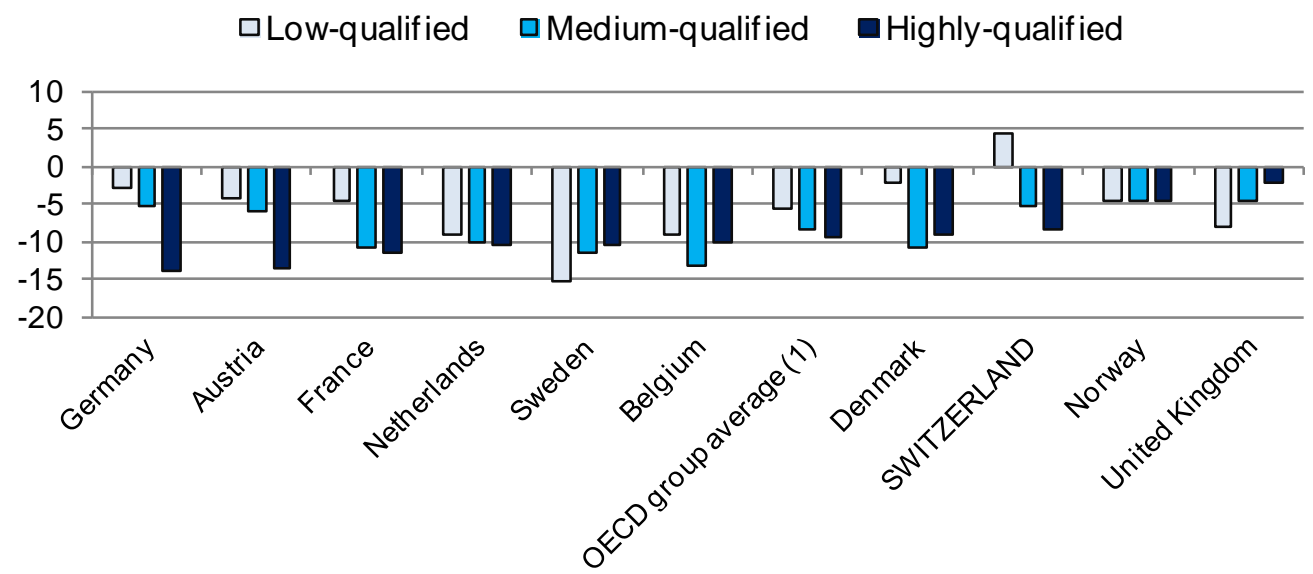

Note: 1 . The OECD group average refers to the unweighted average of the countries included in the figure.

Source: European Community Labour Force Survey.

70. There are several possible reasons for this observation. First, immigrants may have obtained their qualifications and work experience abroad and employers may have difficulties in assessing such qualifications and work experience, particularly when they have been obtained in education systems and workplaces which differ substantially from the Swiss ones. It is also conceivable that qualifications obtained in non-OECD countries may actually be of less use in the Swiss labour market and indeed, there is some evidence that this explains part of the discount of foreign qualifications in the labour markets of OECD countries (see OECD, 2008b). However, empirical analysis (Table 3) suggests that highly-educated immigrants from lower-income countries are disadvantaged even when they have obtained Swiss qualifications. This disadvantage also remains significant when differences in work experience in the Swiss labour market are taken into account. This suggests that this group of immigrants faces additional obstacles not related to the origin of their qualifications or work experience.

71. Among these obstacles may be lack of access to networks and lack of knowledge about labour market functioning, both of which particularly concern immigrants. Although there is no evidence of the importance of these obstacles for the Swiss case, there is little reason to believe that the situation differs

24 In the United States, the favourable outcomes for immigrants with low educational attainment have to be seen in the context of the fact that many immigrants in this group are labour migrants, many of whom are irregular. 
much from the one observed in other OECD countries such as Norway, Sweden, Germany or Austria where a large part - if not the majority - of jobs involve informal contacts with employers. Immigrants have fewer of these and a number of OECD countries have implemented mentorship programmes to provide immigrants with such contacts. Although some cantons have implemented them in Switzerland, the scale and scope of such programmes is rather limited, and they are often not targeted at immigrants. ${ }^{25}$ Discrimination in the labour market remains as a third possibility and indeed, its incidence seems to be high in Switzerland (see below).

72. A particularly strong discount of foreign qualifications is observed by immigrants who have obtained their highest diplomas in lower-income countries. Weins (2010), in an analysis of data from the International Adult Literacy Survey, shows that the devaluation of foreign credentials on the Swiss labour market holds even after accounting for an objective measure of literacy. With respect to the returns from education, immigrants with a foreign vocational or university diploma benefit significantly less from having invested in vocational or higher education than their peers with Swiss qualifications. The former (except for holders of tertiary vocational diplomas) do not seem to yield a significant increase in their salary levels, compared with persons who did not obtain any upper-secondary diploma, whereas this is the case for Swiss diplomas.

73. Information on qualifications recognition from the Swiss Labour Force Survey suggests that immigrants who obtained a formal recognition of their foreign diploma appear to be no longer significantly disadvantaged in the Swiss labour market in terms of employment opportunities (see Table 3 ). ${ }^{26}$

Table 3: Percentage points differences in the probability of being in high-skilled employment for highly-educated persons aged 15-64 in Switzerland, foreign-born compared to native-born, 2008

\begin{tabular}{|c|c|c|c|c|}
\hline Variables & Model 1 & Model 2 & Model 3 & Model 4 \\
\hline $\begin{array}{l}\text { Foreign-born } \\
\text { Highest education obtained in Switzerland } \\
\qquad \text { Born in high-income country } \\
\text { Born in lower-income country } \\
\text { Highest education obtained in high-income country } \\
\text { Highest education obtained in lower-income country } \\
\text { Highest education recognised } \\
\text { Highest education not recognised } \\
\text { Did not file a request for recognition } \\
\text { Request for recognition was rejected }\end{array}$ & $-6.5^{\star \star *}$ & 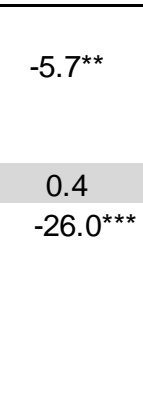 & \begin{tabular}{l}
\multicolumn{1}{c}{0} \\
$-15.4^{\star \star *}$ \\
0.4 \\
-7.5 \\
$-29.9^{\star \star *}$
\end{tabular} & $\begin{array}{c}0 \\
-15.4^{\star \star \star} \\
0.4 \\
-7.5\end{array}$ \\
\hline \multicolumn{5}{|l|}{ Controls } \\
\hline $\begin{array}{l}\text { Workexperience } \\
\text { Workexperience }{ }^{2} \\
\text { Gender }\end{array}$ & $\begin{array}{l}0.5^{\star \star \star} \\
-0.02 \\
-6.0^{\star \star \star \star}\end{array}$ & $\begin{array}{l}0.6^{\star \star \star} \\
-0.03^{\star \star \star} \\
-5.6^{\star \star \star}\end{array}$ & $\begin{array}{l}0.6^{\star \star \star} \\
-0.03^{\star \star \star} \\
-5.7^{\star \star \star}\end{array}$ & $\begin{array}{l}0.6^{\star \star \star} \\
-0.03^{\star \star \star} \\
-5.7^{\star \star \star}\end{array}$ \\
\hline
\end{tabular}

Note: The figures show the differences between immigrants and the native-born. They correspond to marginal effects in a logistic regression, calculated at the sample means of the respective variables. The reference group is the native-born. ${ }^{*}$, ${ }^{\star *}$, ${ }^{* \star *}$ denote significance at the $1 \%, 5 \%$ and $10 \%$ level, respectively. All regressions contain controls for gender and a proxy for years of work experience in Switzerland. Managers of small enterprises (up to 5 employees) were excluded from the sample.

Source: Swiss Labour Force Survey, Swiss Federal Statistical Office.

25 Among the larger ones is the mentoring project run by the Canton of St. Gallen to facilitate labour market entry for youth ("Tandem"). Since 2006, it has had 150 participants.

26 Indeed, they appear to have better outcomes than migrants from the same group of countries who obtained their qualifications in Switzerland. However, this may be partly due to different origin countries, since many migrants within this group who have Swiss qualifications have come from Asia, Africa and Latin America, whereas migrants who have a recognised foreign education have more often come from Central and Eastern Europe. 
74. More generally, in the Swiss context, the recognition of a foreign diploma could be expected to play a particularly important role, as formal credentials have a high importance in the labour market and send strong signals to employers during the hiring process (see Weins, 2010). This is partly related to the relatively high stratification of the Swiss education system. Like Austria, Denmark and Germany, Switzerland maintains quite specialised tracks of vocational and professional training leading to rather specific professional profiles that are certified through formal credentials (for a more detailed discussion of vocational education and training in Switzerland, see Section IV).

\section{Recognition of foreign qualifications}

\section{Foreign qualifications on the Swiss labour market and the value of recognition}

75. Given the disadvantages facing highly-educated immigrants from lower-income countries in the Swiss labour market and the apparent benefits of having a foreign qualification formally recognised, one could expect a rather high demand for recognition in Switzerland, especially as over $80 \%$ of the highlyeducated immigrants have obtained their highest degree abroad (see Table 4). They would thus be potentially concerned by a devaluation of foreign higher degrees in the Swiss labour market.

76. Therefore, it is surprising to find that the vast majority of immigrants with tertiary degrees do not seek recognition. Among immigrants from lower-income countries, only about one quarter report that they have applied for recognition, while the majority deemed recognition "not necessary" (see Table 4). ${ }^{27}$ For those who apply, the actual chances to obtain recognition appear to be quite good, as two out of three requests filed by immigrants from lower-income countries until 2008 were approved. These findings leave one with a puzzle - recognition seems highly valuable in the Swiss labour market, but few immigrants seek it. This could be due either to a lack of awareness about the possibilities for recognition and the value which it provides or to other factors intrinsic to the Swiss system for the recognition of foreign qualifications which might discourage them from applying. To shed some light on this question, it is important to first take a closer look at the system.

Table 4: Origin of qualifications and participation in recognition, highly-qualified foreign-born aged 15-64, 2008

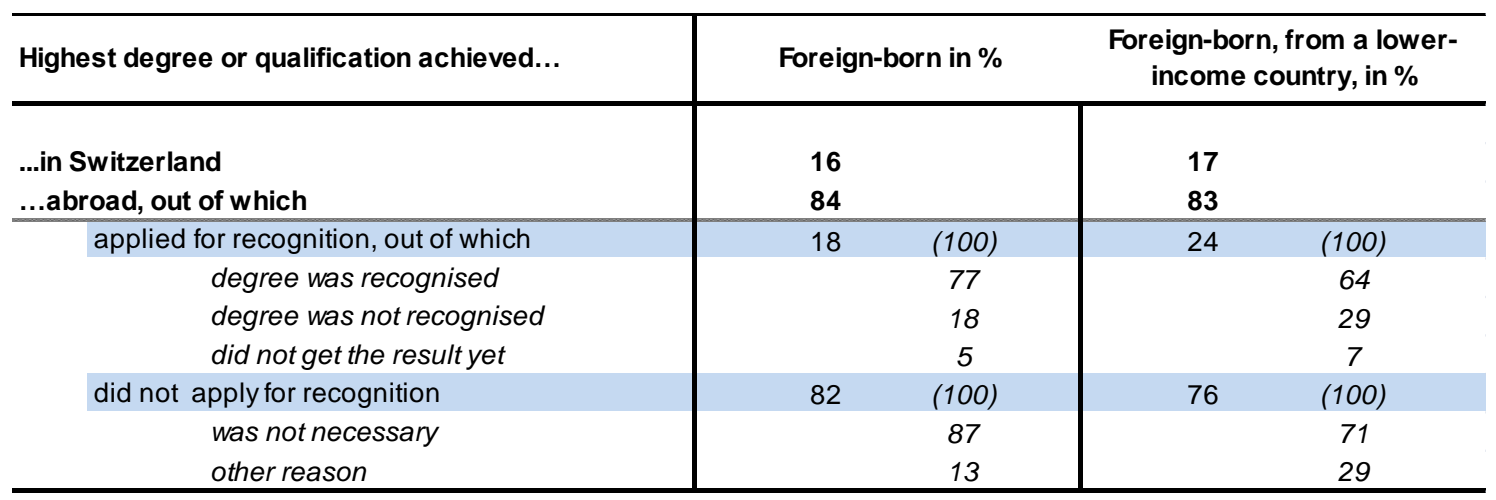

Note: How to read the table: $84 \%$ of the highly-skilled immigrants got their highest qualification abroad. $18 \%$ applied for its recognition.

Source: Swiss Labour Force Survey, Swiss Federal Statistical Office.

27 It remains unclear, however, whether immigrants choose this response category because they simply did not need the assessment to find a job that matched their skill level, or because they had their qualification recognised automatically, i.e. through bilateral agreements. The corresponding variable in the Swiss Labour Force Survey does not provide for a detailed distinction of motives and the response category "not necessary" might thus be chosen for different reasons. 


\section{The Swiss system for the recognition of foreign qualifications}

77. As in other OECD countries, there are no formal recognition requirements for non-regulated occupations in Switzerland: it is up to the employer to decide whether or not to accept the job applicant's claim to have the necessary skills. For regulated professions, formal recognition is generally required, although the same profession may be regulated or non-regulated depending on Cantonal legislation. Compared with other OECD countries, Switzerland regulates relatively few professions, but for these, the system of recognition is complex.

78. There is no national framework or comprehensive law governing the recognition of foreign qualifications, and responsibilities are shared among a multitude of different actors. These include different federal ministries and offices, as well as the Cantons and organisations such as the Rectors' Conference of Swiss Universities (Conférence des Recteurs des Universités Suisses, CRUS) or the Swiss Red Cross. This fragmentation stems from Swiss federalism, as well as from the stratified nature of the training system (universities, universities of applied sciences and vocational programmes fall under different ministerial and cantonal responsibility) and the exclusion of certain professions (such as medical professions) from general regulations.

79. The most comprehensive structure for recognition is maintained by the Federal Office for Professional Education and Technology (Office fédéral de la formation professionnelle et de la technologie, OFFT) that is in charge of assessing professional qualifications gained through vocational education and training (VET), professional education and training (PET) and at universities of applied sciences (UAS). In a sort of one-stop-shop procedure, the OFFT accepts "preliminary applications" for recognition and subjects them to a first evaluation aiming to sort out diplomas that fall under the responsibility of a different body. ${ }^{28}$ The applicant is then informed about further action to take and, if necessary, referred to the third body in charge.

80. Regarding applications in its own domain of competence, the OFFT proceeds to the proper assessment after having received certified copies of the necessary documents. On average, the overall recognition procedure takes between two and four months. In the case of an application being successful, recognition can be granted in two different forms. For credentials in regulated professions, the OFFT usually issues a recognition certificate ("reconnaissance"/"Anerkennung") that costs CHF 550 and is legally binding in the sense that it grants the permission to exercise a regulated profession. Where doubts remain about the full equality of a diploma to a Swiss one, the OFFT can recommend adjustment measures, but these are not linked with bridging offers. For credentials in non-regulated professions that do not actually require formal recognition, the OFFT offers a so-called level certificate ("attestation de niveau"/"Niveaubestätigung") for which it charges CHF 150. This assessment aims to classify the foreign diploma with respect to the Swiss system in order to help employers assess its value.

81. In 2009, the OFFT received about 4000 "preliminary applications". Only one third concerned regulated professions, while the majority were filed by immigrants with qualifications in non-regulated professions. $60 \%$ of the applicants were EU citizens. ${ }^{29}$ Around 900 applications were referred to third bodies - for example to the CRUS in the case of higher-education diplomas - while roughly 1200 were

Certified copies of diplomas are not required at this step in the procedure. The evaluation is based on documents (in any Swiss language or English, or free translation), describing the level, duration, content and on-the-job component of the training programme. bilateral agreement on free movement that Switzerland has signed with the EU and its member countries in 1999. The agreement applies to a specified list of regulated professions that is quite extensive and covers tertiary as well as vocational qualifications. 
assessed and processed by the OFFT itself. Only between 1 and 3\% of the processed applications were eventually rejected.

82. Immigrants who cannot provide proof of a VET diploma (e.g. because they lack the required documents) or have never obtained a formal upper-secondary qualification cannot be considered for formal recognition by the OFFT. However, Switzerland is currently in the process of developing a national framework for the accreditation of prior learning (APL) that is usually referred to as validation d'acquis. Within this framework, professionals without an upper-secondary diploma will have the possibility to obtain a basic Swiss VET diploma to have the non-formal and informal skills that they gained from their work experience valued on the labour market. ${ }^{30}$

83. The Cantons are charged with the implementation of the validation d'acquis, while the OFFT sets the guidelines at the federal level. To enhance the harmonisation of the validation procedures, the OFFT published a set of guidelines in 2010, jointly with the Cantons, the social partners and employers' associations (see OFFT, 2010a). In these guidelines, the relevant actors develop a concept for a step-bystep assessment of an individual qualification profile that is only accorded a formal diploma if applicants can demonstrate the skills usually required from participants in the corresponding formal VET course. Although not all cantons have come forward with a concept for a validation procedure, the process is underway.

84. While the recognition of vocational qualifications appears to be administered quite effectively at the federal level, university diplomas (with the exception of universities of applied sciences) are not subject to federal regulations. They fall under the responsibility of the CRUS that can issue non-binding "recommendations" for foreign university diplomas under the condition that a similar university course or diploma is offered by a Swiss university. "Recommendations" aim to facilitate access to non-regulated professions and are meant for holders of foreign qualifications who would like to enter the Swiss labour market.

85. In cases where recognition is a pre-requisite for the pursuit of further higher education, however, universities conduct their own assessment of previous diplomas autonomously. This is also the case for secondary school-leaving certificates and it appears that Swiss universities tend to be quite demanding with respect to the pre-requisites for admission. According to CRUS - which holds bi-monthly meetings with admissions officers from the different Swiss universities to harmonise the approach to recognition universities are particularly sceptical of degrees from lower-income countries. However, there is no common concept for structured bridging courses in order to make up for deficits in previous education. Instead, guidance counsellors tend to orient applicants away from the university system, which is often justified by the view that Switzerland offers highly-skilled jobs that do not require a university diploma.

86. Problems may further arise where non-EU university degrees correspond to a VET qualification in the Swiss system (e.g. in the case of social work). For such degrees, the CRUS cannot issue any "recommendation" and equivalence would have to be assessed by the OFFT. The OFFT, in turn, does not take university degrees into consideration (with the exception of degrees from universities of applied sciences), even in cases where their only Swiss equivalent would be a VET degree. By consequence, immigrants with such degrees have neither access to a non-binding "recommendation" nor to a formal

30 The legal basis for this measure has been laid by amendments to the Federal Law on Vocational Education and Training that were introduced in 2002 and 2003.

31 This recommendation is done in the framework of the Council of Europe's ENIC (European Network of National Information Centres on Academic Recognition and Mobility). The Swiss ENIC has been delegated to the CRUS. The CRUS uses the correspondence information developed and shared by ENIC and treats non-EU degrees according to the same framework. 
recognition in Switzerland. For this group, a validation d'acquis would appear to be particularly useful, in order to have their skills better valued on the labour market and to obtain a recognised Swiss qualification. This also applies to those immigrants who are unable to document their studies - which is, for instance, the case for many refugees.

87. There are certain professions that require an official license and are thus subject to exceptional recognition procedures in Switzerland. These are healthcare professions, teaching professions, certain technical professions, lawyers and notaries. In these cases, recognition is covered by the responsible licensing bodies at the federal or cantonal level. If responsibility lies with the cantons, the recognition procedures may vary according to cantonal legislation. Architect, for instance, is a regulated profession requiring official recognition in some cantons, while it is non-regulated in others. ${ }^{32}$ As a consequence, immigrants can be disadvantaged just from living in a specific canton, which is questionable with respect to principles of equal treatment, especially if their resident status does not permit them to change Cantons without obstacles.

88. Immigrants from outside the European Union, moreover, face considerable obstacles if they have degrees in medical professions. Recognition of the latter is only possible under the bilateral agreement asserting the mutual recognition of foreign qualifications between Switzerland and the EU-25/EFTA. ${ }^{33}$ As a consequence, third-country nationals, as well as Romanian and Bulgarian citizens with foreign degrees, are excluded from formal recognition, unless they have already obtained recognition elsewhere in the EU and fulfil a range of additional pre-requisites. ${ }^{34}$ Nevertheless, some cantons authorise medical staff trained outside of the EU/EFTA to practice, under certain conditions, even without recognition.

89. In sum, recognition procedures for foreign qualifications vary substantially in Switzerland, depending on the type and level of the qualification, the relevant profession and licensing body and cantonal legislation. This tends to make the overall system rather complex and is associated with inequalities in the access to recognition procedures and the opportunities to practice certain professions and generates obstacles to the labour market integration of immigrants with qualifications from non-EU countries. Since the fees involved are not high, the complexity of the system and a lack of knowledge about its functioning and benefits on the part of immigrants appear to be the main obstacles to their making more extensive use of it.

\section{The labour market integration of recent arrivals}

\section{Overview}

90. In recent years, Switzerland has experienced exceptionally large inflows of immigrants. It has received the highest number of permanent-type immigrants in the OECD since the collection of comparable statistics by the OECD in 2003. As a result, about one out of five resident immigrants has arrived over the past five years, accounting for $5 \%$ of the total resident population. Given these figures, the labour market integration of these new arrivals is an issue of particular importance in Switzerland.

\footnotetext{
32 Such problems of intercantonal mobility used to be an issue even for persons with Swiss degrees, but for this group the 1995 law on the Swiss internal market removed previously existing obstacles.

The agreement refers to both tertiary medical professions (doctor, dentist, veterinarian and pharmacist) and to secondary qualifications in human and dental medicine. While the recognition of medical professions falls under the responsibility of the Federal Ministry of Health, the Swiss Red Cross is in charge of secondary healthcare professions. 
91. The convergence concept of integration suggests that gradually, over time, as migrants acquire host-country specific human capital such as language skills, their labour market outcomes should approach those of the native-born. Evidence from other OECD countries (see OECD, 2007; 2008b) suggests that early labour market entry is a crucial determinant of integration outcomes in the long-run.

92. Figure 11a shows the employment-population ratios of immigrants in Switzerland by years of residence and migrant group, for 2003/04 and 2008/09. As can be seen, for men the labour market outcomes of recent arrivals are quite favourable in Switzerland. The outcomes are particularly good for immigrants from higher-income countries who have accounted for the bulk of new arrivals in Switzerland. The favourable picture also holds in international comparison and when looking only at immigrants from lower-income countries (Figure 11b). However, for women from lower-income countries, the picture is less favourable and there is some evidence that the outcomes of recent arrivals are lower now than what they used to be.

Figure 11a: Differences in the employment rates of immigrants vis-à-vis native-born by years-ofresidence, origin group and gender, aged 15-64, 2003/2004 and 2008/2009

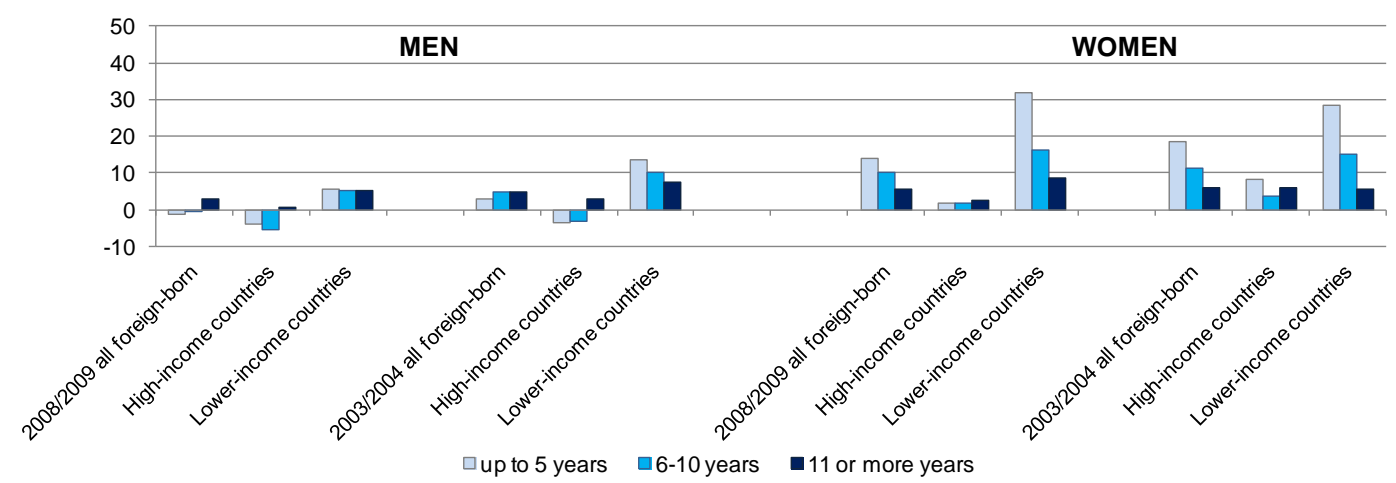

Source: Switzerland: Swiss Labour Force Survey, Swiss Federal Statistical Office.

Figure 11b: Differences in the employment rates of immigrants from lower-income countries vis-àvis the native-born by years-of-residence and gender, aged 15-64, selected OECD countries, 2008/2009

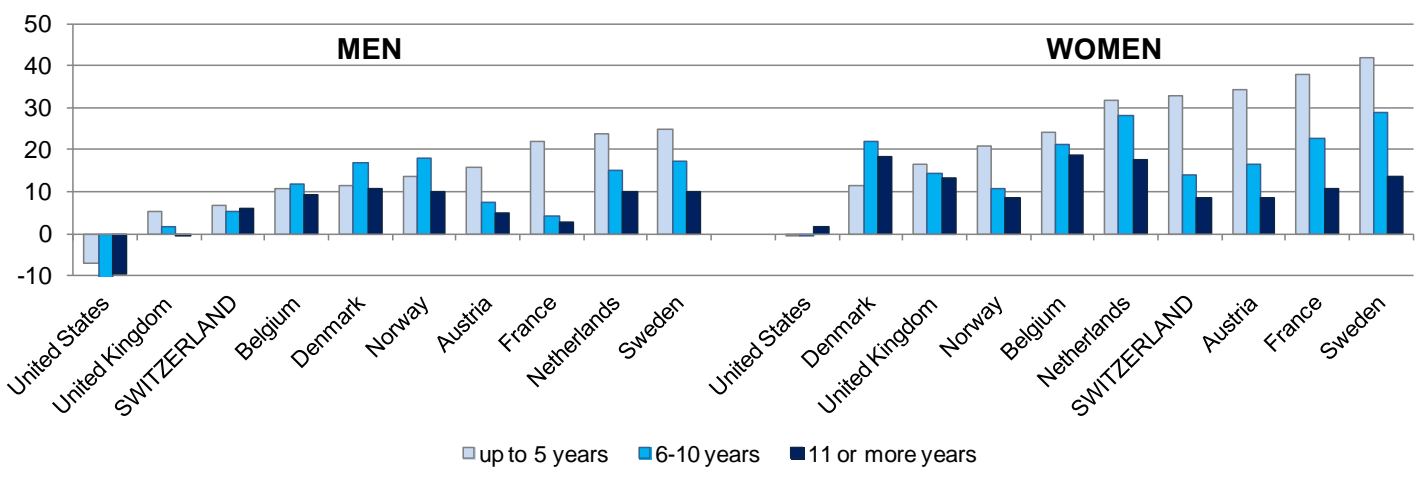

Source: European Community Labour Force Survey.

Note: The definition of "lower-income countries" in the European Community Labour Force Survey differs slightly from the Swiss Labour Force Survey. The differences in the employment rates are calculated as employment rate of the native-born minus employment rate of the foreign-born. 
93. Note that Figures 11a and $\mathrm{b}$ are not based on longitudinal data, that is, persons are not followed over time. By using the information on year-of-arrival from the Swiss Labour Force Survey, a pseudocohort analysis is possible for immigrants who arrived around 2003. The results of this are depicted in Figure 12. Of particular interest are again immigrants from lower-income countries since most of these are non-labour migrants - in contrast to immigrants from higher-income countries, in particular those from the EU (see below). On average, the former start from a low level of employment but enjoy a rather quick convergence over the first three years: $60 \%$ were in employment after three years. This is higher than what is observed for all migrants with that duration in countries which also have favourable labour market conditions, such as Denmark (around 55\% for the 2004 cohort), Norway (51\% for the 2002 cohort), Austria (50\% for those who arrived around 2004) or the Netherlands (40\% for the 2000 cohort). However, after about three years, the progress appears to slow down significantly.

Figure 12: Estimated evolution of the employment rate of immigrants who arrived around 2003, aged 15-64

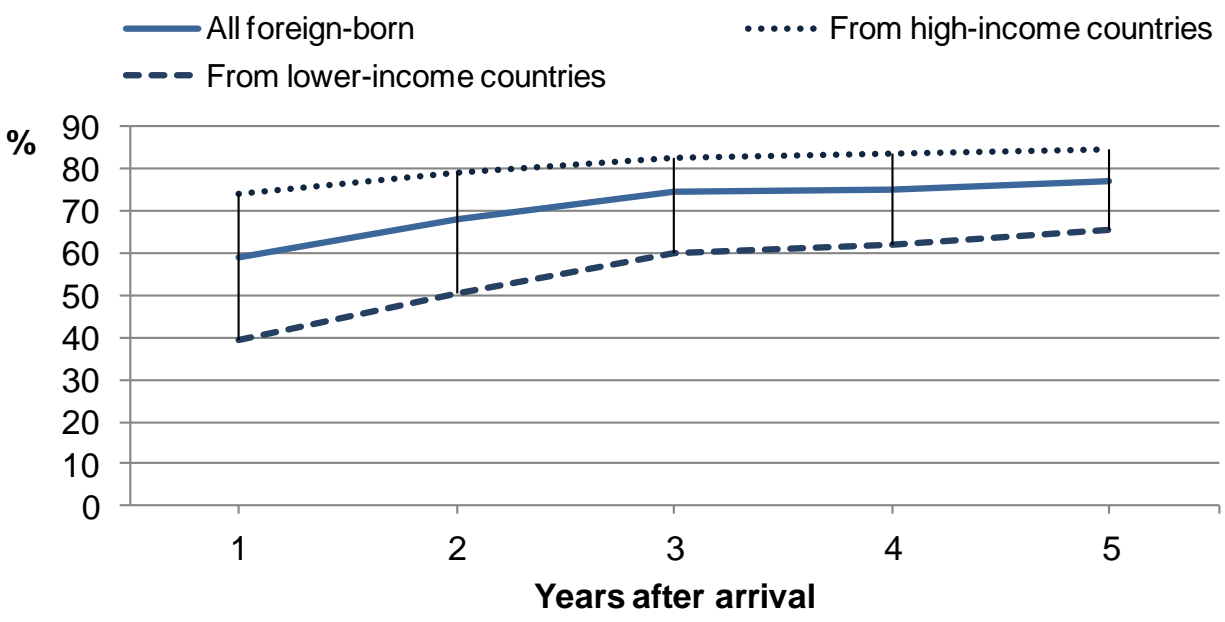

Note: The figure has been constructed through a pseudo-cohort analysis using cross-sectional data and information on years-ofresidence. To obtain reliable results, three consecutive years of labour force survey data have been pooled.

Source: Swiss Labour Force Survey, Swiss Federal Statistical Office.

\section{The integration of new arrivals from the $\mathrm{EU}-27$}

94. The overwhelming majority $-64 \%$ - of recent arrivals (i.e., with less than five years of residence) are from the EU-27, following Switzerland's gradual establishment of freedom of movement with the EU and its member countries on the basis of bilateral agreements. Recent arrivals account for more than five percent of the resident population at working age and their significant number has been an issue of much public debate in Switzerland. However, labour market integration of these new arrivals has been less of an issue than their macroeconomic impacts on growth, wages, housing prices and on the infrastructure. ${ }^{35}$

95. Since most of these recent migrants came for employment, it is not surprising to see that they have an employment rate of more than $84 \%$. The high educational attainment of this group $-58 \%$ of those in prime working age (25-54) have a university degrees, compared with $37 \%$ of the native-born population - has also contributed to their good overall labour market integration.

35 The available evidence suggests that there has been little impact on wages (see e.g. Cueni and Sheldon, 2011). In contrast, there seems to have been a positive impact on growth - both on an aggregate level and on a per-capita basis. To which degree immigration has put pressure on the infrastructure and the housing market remains unclear, since these are mainly driven by other factors not linked with immigration (see OECD, forthcoming). 
96. Table 5 provides an overview of the labour market outcomes and the education levels of recent arrivals from the EU-27 in comparison with the total migrant population and the native-born. The first and salient observation is the large diversity even within the recent migrants from the enlarged EU. Recent migrants from Portugal are predominantly low-educated and employed in medium and low-skilled occupations. They also face rather high unemployment. In contrast, migrants from Germany and from EEA countries other than Germany, Portugal and Italy are mainly highly-educated and find themselves overrepresented in highly-skilled occupations. ${ }^{36}$ Their unemployment rate is similar to that of the nativeborn. Recent immigrants from Italy find themselves between the Germans and the Portuguese in terms of educational attainment and labour market outcomes.

Table 5: Labour market outcomes and educational profile of recent arrivals in Switzerland, by origin, aged 15-64, 2008/2009 average

\begin{tabular}{|c|c|c|c|c|c|c|c|c|}
\hline & \multicolumn{6}{|c|}{ Recent arrivals from... } & \multirow{2}{*}{$\begin{array}{c}\text { All } \\
\text { resident } \\
\text { migrants }\end{array}$} & \multirow[b]{2}{*}{ Native-born } \\
\hline & Germany & Portugal & Italy & Other EU-27 & All EU-27 & $\begin{array}{c}\text { All recent } \\
\text { arrivals }\end{array}$ & & \\
\hline$\%$ of all resident migrants & 5 & 2 & 1 & 4 & 12 & 20 & 100 & - \\
\hline$\%$ of all recent arrivals & 26 & 11 & 5 & 22 & 64 & 100 & - & - \\
\hline \multicolumn{9}{|l|}{ Education level (in \%) } \\
\hline Low-educated & 3 & 73 & 20 & 6 & 17 & 19 & 29 & 15 \\
\hline Medium-educated & 36 & 19 & 34 & 29 & 31 & 32 & 39 & 57 \\
\hline Highly-educated & 61 & [8] & 45 & 65 & 52 & 50 & 31 & 28 \\
\hline \multicolumn{9}{|l|}{ Occupational profile (in \%) } \\
\hline Managers & 5 & $\ldots$ & $\ldots$ & 7 & 5 & 5 & 3 & 4 \\
\hline Professionals and Technicians & 65 & [9] & 52 & 65 & 41 & 50 & 37 & 45 \\
\hline Service, sales, craft and related trad $\epsilon$ & 19 & 57 & 27 & 18 & 28 & 27 & 33 & 27 \\
\hline Other medium-skilled professions & 9 & 16 & 12 & 8 & 13 & 11 & 17 & 21 \\
\hline Elementary occupations (ISCO 9) & [2] & 16 & $\ldots$ & [3] & 13 & 7 & 10 & 4 \\
\hline \multicolumn{9}{|l|}{ Labour market outcomes (in \%) } \\
\hline Employment rate & 89 & 81 & 83 & 78 & 83 & 75 & 76 & 81 \\
\hline Unemployment rate & 3 & 11 & $\ldots$ & 5 & 5 & 8 & 7 & 3 \\
\hline $\begin{array}{l}\text { Over-qualification rate among highly- } \\
\& \text { medium-educated }\end{array}$ & 9 & $\ldots$ & 8 & 11 & 11 & 13 & 13 & 11 \\
\hline Median gross hourly wage (in CHF) & 41 & 26 & 32 & 45 & 38 & 36 & 35 & 40 \\
\hline
\end{tabular}

Note: Numbers in brackets are based on sample sizes below 50. “...” refers to less than five observations.

Source: Swiss Labour Force Survey, Swiss Federal Statistical Office.

97. The overall favourable picture also holds when looking at other indicators such as wages (see Annex Table 2). As a group, recent arrivals from the EEA have lower over-qualification rates than the native-born. In addition, in a standard wage regression they enjoy slightly higher wages than the Swiss with otherwise similar observable characteristics.

98. A comprehensive analysis of the links between the recent migration from the EU and the Swiss labour market is provided in Cueni and Sheldon (2011). They also find that these migrants enjoy on average higher employment and higher wages than native Swiss. The authors estimate that the vast majority (more than three quarters) of the difference is attributable to the more favourable observable characteristics of the recent migrants including a higher education level, longer working time and an overrepresentation in regions with high wages. In contrast, the year-to-year risk of exiting from employment into unemployment is almost $70 \%$ higher for EU migrants than for natives, and only a little more than one third of this disadvantage can be explained by differences in observable characteristics, including seniority. They also find no evidence of a negative impact on the wages of natives.

36 The migrants from these other EEA countries are mainly from France, the United Kingdom and Austria. 


\section{Immigrants' participation in active labour market policy measures}

99. As already mentioned, Switzerland has opted for a mainstream approach to integration, and there are only a few measures specifically targeted at immigrants. However, there is strong indirect targeting as immigrants and their children account for the majority of those receiving unemployment aid or social assistance. ${ }^{37}$ In April 2011, a reform of the federal unemployment insurance law lowered the possibilities for cantonal employment services to offer certain programmes to persons not fulfilling the contribution period for unemployment insurance, unless social assistance steps in. This lowers access to labour market measures for many recent arrivals and family migrants. However, there remains a possibility to participate in some ALMPs if the cantons contribute $50 \%$ of the cost.

100. Although immigrants are strongly overrepresented in the groups targeted by active labour market policy, there is no evaluation study available that focuses explicitly on their actual participation or the specific effects of active labour market policy on the group of immigrants. ${ }^{38}$ Indeed, in contrast to the overall rather well-developed evaluation culture in Switzerland, programme evaluation regarding immigrants is scarce. However, a number of evaluations use nationality and/or permit status as control variables. Overall, foreigners are represented in ALMPs to roughly the same degree as they are represented among the unemployed (see Duell et al., 2010), a result which has also been observed in earlier studies (see Gerfin and Lechner, 2002; and Spycher et al., 2007).

101. Gerfin and Lechner (2002), in their microeconometric evaluation of Swiss active labour market policy, find positive effects of wage subsidies for foreigners, and this effect is stronger than for comparable Swiss nationals. They find, however, that, given their characteristics, foreigners are underrepresented in temporary wage subsidy programmes. ${ }^{39}$ Similar results are obtained by Lalive et al. (2002) who find, using information on permits, that this programme provides strong benefits only for foreigners with a B-permit (i.e. an annual permit, renewable), but the latter are also quite significantly underrepresented in this measure. These results are in line with empirical evidence from the Nordic countries (see Nekby, 2008).

\section{Language training}

102. There is also little information available on the available language training for migrants. The Federal Office for Migration finances some basic alphabetisation courses with CHF 9 million, but this accounts only for a small part of overall language training. Most training is provided by the cantons, and there is great diversity in the available offers, not only between but also within cantons, as language training can be financed either through the social assistance services or through the public employment services, or through the invalidity services.

103. The limited available evidence suggests that this diversity of actors has been associated with under- rather than with overprovision of language training. In their overview of labour market integration measures for immigrants, Spycher et al. (2007) conclude that all branches of social security provide too little language training, and that the overall quality often leaves much to be desired.

\footnotetext{
37 Immigrants and their children also account for $35 \%$ of those receiving invalidity benefits, which is the third pillar of social protection. For a comprehensive overview of the Swiss social protection system and activation policy, see Duell et al. (2010).

38 However, Spycher et al. (2007) provide an in-depth discussion of the links between the Swiss social security setting and the labour market integration of foreigners. Likewise, BASS (2006), in a study commissioned by the Swiss State Secretariat for Economic Affairs, looks at the risk of unemployment for foreigners and discusses possible policy responses.

They attribute this to the fact that only "easy-to-integrate" foreigners are admitted to these programmes.
} 
104. Some basic (self-reported) information on participation in language training is available from the 2008 module of the Swiss Labour Force Survey. This suggests that less than one out of four immigrants from lower-income countries have obtained language training in the first two years after arrival. Even among humanitarian migrants who are the main target group of integration policy at the federal level (see below), less than half claim to have obtained language training.

105. Although there has been no in-depth evaluation of language training in Switzerland thus far, some basic information on the impact of language training financed by the public employment service is available from the general evaluation studies. These generally find no impact on participants' labour market prospects compared with non-participants. Gerfin and Lechner (2002) even find negative effects; however, this may be due to negative selection of participants (i.e., immigrants with few difficulties do not participate) and does not necessarily imply that these courses have actually a negative impact. In any case, less than a third of participants are in employment one year after programme participation.

106. In summary, there is a great diversity of language training across Switzerland. It nevertheless seems that only a minority of immigrants from countries with a language different from the Swiss national languages benefit from language training, and the available offers do not seem to yield good results in terms of labour market integration.

\section{The labour market integration of humanitarian migrants}

\section{Labour market access}

107. Within the group of humanitarian migrants, there are two main groups of roughly equal size. The first are refugees under the UN convention, about 25300 . These receive a regular residence permit (Bpermit) and enjoy full labour market access. The second are provisionally admitted persons, about 23500 , who need to apply for a work permit which is nevertheless granted without a labour market test (such a test applied until 2007) if they find an employer willing to hire them. ${ }^{40}$ They also need to apply for permission to change residence between cantons. In recent years, the number of new provisionally admitted persons has largely surpassed the number of newly admitted refugees.

108. Asylum seekers do not have access to the labour market during the first three months. After that, they may obtain employment subject to a labour market test. It seems, however, that the test is generally waived for a range of lesser-skilled occupations where there are perceived labour shortages, notably in the hotel and restaurant sector.

\section{Labour market outcomes in international comparison}

109. In all OECD countries, humanitarian migrants face particular difficulties in integrating into the labour market. They have generally arrived without any attachment or link with the host-country labour market and often suffer from psychological stress or disabilities. In addition, their qualifications and work experience have been acquired under conditions that generally differ greatly from those of the host-county education system and labour market, and they may be unable to document them.

110. Compared with other OECD countries, humanitarian migrants constitute only a relatively small fraction of the foreign-born in Switzerland. ${ }^{41}$ According to the Swiss labour force survey, which in 2008

\footnotetext{
40 Although these migrants are formally admitted only on a provisional basis, most of them can be expected to remain in Switzerland. However, their pathway to a secure residence status is long. They may obtain a regular residence permit (Bpermit) after five years which can then be transformed into a settlement permit after an additional ten years.

41 The following analysis of humanitarian migrants is based on the self-reporting by the foreign-born in the ESPA 2008 (migration motive $=$ asylum seeking). For migrants who have arrived over the last 15 years, there is also administrative
} 
included a question on the reason for migration, humanitarian migrants account for about $3.4 \%$ of the foreign-born population in Switzerland and about $10 \%$ of immigrants from lower-income countries. In contrast, in Sweden, almost 23\% of the foreign-born have arrived on humanitarian grounds. Among the new inflows in 2009, according to the standardised statistics of the OECD, less than 5\% of new permanenttype migrants to Switzerland were humanitarian migrants, compared with around 10\% in Austria and 15\% in Canada, Norway and Sweden.

111. Based on the information from the labour force survey, Table 6 provides an overview of the labour market outcomes of humanitarian migrants compared with non-humanitarian migrants and with the native-born. Humanitarian migrants tend to have lower educational attainment levels than other migrant groups. Nevertheless, they have relatively high labour market participation, particularly those who are loweducated. The main issues related to their integration seem to be their high incidence of long-term unemployment and the fact that they often find themselves in occupations for which they are formally over-educated. About one in two employed highly-educated humanitarian migrant in Switzerland works in a job that is below his or her educational level. The high employment rate is thus associated with a high level of formal over-qualification. Indeed, for this group the issue of the transferability and recognition of qualifications obtained abroad is a crucial one (see above on these issues).

\section{Table 6: Labour market outcomes and education level of humanitarian migrants in Switzerland, aged 15-64, 2008}

\begin{tabular}{|c|c|c|c|c|c|}
\hline & \multirow[b]{3}{*}{ Native-born (in \%) } & \multicolumn{4}{|c|}{ Percentage-point difference to the native-born } \\
\hline & & \multirow[b]{2}{*}{\begin{tabular}{|c} 
Foreign-born \\
from high- \\
income \\
country
\end{tabular}} & \multicolumn{2}{|c|}{ Born in lower-income country } & \multirow[b]{2}{*}{$\begin{array}{l}\text { All foreign- } \\
\text { born (in\%) }\end{array}$} \\
\hline & & & $\begin{array}{l}\text { Non- } \\
\text { humanitarian } \\
\text { migrants } \\
\text { (in\%) }\end{array}$ & $\begin{array}{l}\text { Humanitarian } \\
\text { migrants (in \%) }\end{array}$ & \\
\hline Percentage of all immigrants & & 54.3 & 42.2 & 3.4 & 100 \\
\hline Employment rate & 81 & -1 & -11 & -4 & -5 \\
\hline of low-educated & 56 & 16 & 3 & 20 & 10 \\
\hline of highly-educated & 93 & -7 & -15 & -16 & -10 \\
\hline Unemployment rate & 2 & 2 & 6 & 8 & 4 \\
\hline Median duration of unemployment (months) & $4 \|$ & 2 & 5 & 11 & 4 \\
\hline Overqualified (2) & $21 \|$ & -8 & 8 & 28 & -2 \\
\hline $\begin{array}{l}\text { Percentage of full-time employed among all } \\
\text { employed }\end{array}$ & 65 & 7 & 10 & 16 & 9 \\
\hline $\begin{array}{l}\text { Total median gross hourly wages in the last } \\
12 \text { months of low-educated full-time } \\
\text { employees (CHF) (3) }\end{array}$ & 8 & 23 & 19 & 22 & 27 \\
\hline $\begin{array}{l}\text { Total median gross hourly wages in the last } \\
12 \text { months of highly-educated full-time } \\
\text { employees (CHF) (3) }\end{array}$ & 53 & 0 & -8 & -20 & -2 \\
\hline ISCED $1-2$ & 15 & 10 & 21 & 24 & 15 \\
\hline ISCED 3-4 & 58 & -20 & -15 & -16 & -18 \\
\hline ISCED 5-6 & 28 & 10 & -6 & -8 & 3 \\
\hline
\end{tabular}

Note: 1. Humanitarian migrants are migrants who state to have arrived in Switzerland with the intention to apply for asylum. 2. Only highly-educated (ISCED5-6). 3. The hourly wage has been derived from the total gross salary of the respondents of the last 12 months using the average working hours per year in Switzerland (1926h following the Swiss Federal Statistical Office). Only people who stated that they have been employed without "longer interruption" during this period are included. "..." means not significant for publication.

Source: Swiss Labour Force Survey, Swiss Federal Statistical Office.

data available (the so-called SYMIC). A comparison of the migration motives of the migrants who are included in both datasets reveals that of those who specified humanitarian reasons as their motive for entering Switzerland in the ESPA 2008 , $48 \%$ were registered in the SYMIC as humanitarian migrants and $45 \%$ as migrants who came for family migration which includes family migration linked to humanitarian migrants. 
112. Note that the labour force survey data above refer to the first permit under which the person entered Switzerland which may differ from the current permit, in particular for those who have been in Switzerland for more than ten years. $80 \%$ of the humanitarian migrants in the labour force survey have been in Switzerland for more than ten years, and $94 \%$ for more than five years.

113. To look into the labour market integration of more recent cohorts of refugees in particular, the Federal Office for Migration conducted in 2006 a comprehensive survey among refugees who had just received their permit, as well as surveying two additional cohorts of refugees one and three years after the decision. The employment rates were $22 \%, 17 \%$ and $32 \%$, respectively. These figures are lower than those observed for example, in Norway, where about $27 \%$ and $43 \%$ of humanitarian migrants are in employment one and three years, respectively, after arrival.

114. The overall picture regarding the employment of immigrants is thus rather ambiguous. The outcomes of recent arrivals appear to be low in international comparison, whereas those of longer-standing immigrants are rather favourable. In the absence of both longitudinal data and different years for comparison, it is difficult to ascertain whether or not this reflects a process of belated, but significant convergence or whether these differences in outcomes mainly reflect cohort effects - that is, more recent humanitarian migrants have more difficulties in integrating into the Swiss labour market. An indication that the latter explanation is the more likely one is given by the fact that recent humanitarian migrants mainly come from Africa, whereas past humanitarian migrants often came from Europe, and the latter tend to have better labour market outcomes in most OECD countries.

\section{Programmes for humanitarian migrants}

115. Humanitarian migrants are the main focus group of integration policy in Switzerland, at least as far as the federal level is concerned. Since 2008, the federal state provides the cantons with a lump sum of CHF 6000 per recognised refugee and provisionally admitted person, earmarked for "occupational integration measures and the acquisition of a national language". $80 \%$ of the payment is given as an upfront lump sum, the remainder is paid after "successful integration". The corresponding ordinance stipulates that the main indicator to measure integration is employment "under consideration of the overall labour market situation in the canton". In practice, however, in virtually all cases the full lump sum is paid out with no attention being paid to this "indicator". The cantons use these funds on the one hand to generally support measures and programmes and on the other hand to finance participation costs for specific individuals. The federal spending in this field amounted to CHF 31 million in 2009 and CHF 56 million in 2010.

116. In addition, the Federation reimburses the cantons for social assistance benefits (which are paid at the sub-federal level) during the first five years after entry into Switzerland and for provisionally admitted persons during the first seven years. However, for provisionally admitted persons, the social assistance payments are much lower than the regular assistance. In practice, it appears that this lower level has often been associated with a lower effort by cantons to integrate these particular migrants into the labour market. Two cantons, Luzern and Basel City, have decided to provide provisionally admitted persons with access to full regular social assistance, accompanied by intensive integration support. An evaluation of the effects of this measure is currently under way.

117. The current structure thus means in essence that cantons and municipalities have little incentive to integrate refugees and provisionally admitted persons into the labour market during the first five to seven years. This is a crucial period, since it is an important predictor of long-term labour market integration outcomes (see OECD, 2007). The degree to which cantons and municipalities offer structured integration services varies widely. Since humanitarian migrants are dispersed throughout Switzerland, such 
a wide dispersion in the inter-cantonal provision on integration services raises questions regarding equal treatment. ${ }^{42}$

118. Nevertheless, there are a number of projects in the cantons and municipalities in place to facilitate the labour market integration of humanitarian migrants. In addition, there have also been pilot projects financed by the Federal Office for Migration. The projects in place mainly focus on lesser-skilled employment in the hotel and restaurant sector, trade/industry, construction and cleaning (see KEK-CDC, 2008). Most programmes are open to all humanitarian migrants and not targeted at recent arrivals. It is not clear to which degree they may have contributed to the current picture of relatively high employment, in parallel with a high incidence of overqualification for those humanitarian migrants who have tertiary education.

119. In contrast to other OECD countries that have been under review by the OECD thus far, notably the Nordic countries, most cantons in Switzerland do not have a structured integration programme. ${ }^{43}$ The available evidence on these programmes - e.g. from Denmark and Norway - suggests that, when properly designed, they can contribute to increasing the labour market integration of immigrants (see OECD, 2007; and Liebig, 2009). Given the low labour market outcomes of recently arrived humanitarian migrants, a structured and tailor-made integration programme for all newly-arrived humanitarian migrants and their families could thus entail significant benefits for Switzerland.

\section{The employment of immigrant women}

120. Switzerland has one of the highest employment rates of women of all OECD countries and this holds also for immigrant women, with an overall employment rate of more than $66 \%$ (see Table 7). A specific issue in the employment of women in Switzerland is the large incidence of part-time employment. As a result, the full-time equivalent employment of women is average in international comparison. More than half of employed women work part-time in Switzerland, compared with only one quarter of women on average in the OECD (see OECD, 2006b). Immigrant women participate less in part-time employment than their native-born peers. According to 2009 data from the Swiss Labour Force Survey, the share of full-time employed women among all women in the working-age group is $31 \%$ for native-born and $32 \%$ for foreign-born from lower-income countries, whereas the share of part-time employed is $44 \%$ and $27 \%$, respectively. Thus, on the aggregate, the difference in employment rates between native-born and foreignborn women from lower-income countries is attributable to the higher share of part-time employment among the former.

121. One key factor which determines the labour market participation of women is the availability of childcare, and here Switzerland lags behind other OECD countries (see OECD, 2009; and Section IV below). Early childhood education and care (ECEC) is mainly the responsibility of the cantons. Although ECEC increased significantly over the past two decades, the increase in coverage was particularly pronounced in those cantons which already had a relatively high coverage (see Swiss Federal Statistical Office, 2008), namely the urban cantons Geneva, Zurich and Basel. In 2005, an extensive study on ECEC estimated that overall only $40 \%$ of all potential demand for ECEC was met by the existing offers (Swiss National Fund, 2005). The study provided also some indications that families from the former Yugoslavia

\footnotetext{
42 Of course, different levels of cantonal service provision are an issue that also affects the native-born. However, for humanitarian migrants - in particular for the provisionally admitted - the situation is different since they do not enjoy full mobility within Switzerland and cannot freely choose their canton of residence. 
participate more often in ECEC than native families with otherwise similar observable characteristics. Such a pattern was not observed, however, for other migrant groups. ${ }^{44}$

122. Table 7 takes a closer look at the determinants of the employment of immigrant women in Switzerland. It reveals a number of interesting patterns. First, there are large differences in the employment rates between immigrant groups, with women from Turkey having the lowest employment rates. Second, about half of the disadvantage for women from Turkey and from the former Yugoslavia is due to their less favourable age and education structure compared with the native-born. Third, having a child below the age of six has a particularly negative effect on the employment rate of foreign-born women from Turkey and from lower-income countries other than the former Yugoslavia. Part of the explanation for the fact that childbearing seems to have less of a detrimental impact on women from the former Yugoslavia could be linked to the high participation of their children in ECEC.

123. Table 7 also shows the results regarding the association between the presence of children in the household and the employment of immigrant women in comparison with native-born women, separately for full-time and part-time employment. The gaps are most pronounced regarding part-time employment. However, as the positive interaction terms for immigrant women from lower-income countries in model $4 \mathrm{a}$ suggest, having children is associated with a much stronger decline in the probability to be in full-time employment for native-born women than for immigrant women from lower-income countries.

Table 7: Determinants of the employment of immigrant women in Switzerland, aged 15-64, 2009

\begin{tabular}{|c|c|c|c|c|c|c|c|c|}
\hline Variables & (1) & (2) & (3) & $\begin{array}{l}\text { (3a) full-time } \\
\text { employment } \\
\text { vs. not in } \\
\text { employment }\end{array}$ & $\begin{array}{c}\text { (3b) part-time } \\
\text { employment } v s \text {. } \\
\text { not in employment }\end{array}$ & (4) & $\begin{array}{l}\text { (4a) full-time } \\
\text { employment } v s \text {. } \\
\text { not in } \\
\text { employment }\end{array}$ & $\begin{array}{c}\text { (4b) part-time } \\
\text { employment vs. } \\
\text { not in } \\
\text { employment }\end{array}$ \\
\hline Turkey & $-24^{* * *}$ & $-12^{\star * \star}$ & $-10^{\star \star *}$ & -1 & $-14^{\star * \star}$ & $-11^{* \star}$ & $-9^{*}$ & $-14^{\star * *}$ \\
\hline Ex-Yugoslavia & $-14^{\star \star *}$ & $-6^{\star \star \star}$ & $-5^{\star * \star}$ & $6^{\star \star *}$ & $-12^{\star \star *}$ & $-8^{\star \star \star}$ & -2 & $-16^{\star \star *}$ \\
\hline Other lower-income countries & $-16^{\star * *}$ & $-16^{\star * *}$ & $-15^{\star \star *}$ & $-8^{\star * *}$ & $-22^{* \star *}$ & $-15^{\star \star \star}$ & $-16^{\star \star *}$ & $-22^{\star \star *}$ \\
\hline High-income countries & $-2^{*}$ & -1 & 0 & $6^{* * *}$ & $-5^{\star * \star}$ & 0 & $3^{*}$ & $-5^{\star * *}$ \\
\hline Having at least one child below age 6 & & & $-11^{* * *}$ & $-35^{\star * \star}$ & 0 & $-9^{* * *}$ & $-40^{* * *}$ & 2 \\
\hline Having at least one child between $6-17$ & & & 0 & $-13^{\star * *}$ & $10^{* * *}$ & 0 & $-18^{\star \star *}$ & $9^{* \star *}$ \\
\hline Child below $6 *$ Born in Turkey & & & & & & $-17^{\star *}$ & 5 & $-17^{\star *}$ \\
\hline Child 6-17*Born in Turkey & & & & & & $11^{*}$ & $19^{\star \star *}$ & 9 \\
\hline Child below $6^{*}$ Born in Ex-Yugoslavia & & & & & & -5 & $9^{* *}$ & 0 \\
\hline Child 6-17*Born in Ex-Yugoslavia & & & & & & $8^{* * *}$ & $18^{\star * *}$ & $7^{*}$ \\
\hline $\begin{array}{l}\text { Child below } 6^{*} \text { Born in other lower-income } \\
\text { countries }\end{array}$ & & & & & & $-9^{* *}$ & $13^{* \star *}$ & $-10^{* *}$ \\
\hline $\begin{array}{l}\text { Child } 6-17^{*} \text { Born in other lower-income } \\
\text { countries }\end{array}$ & & & & & & $6^{\star *}$ & $18^{* * *}$ & 6 \\
\hline Child below $6^{\star}$ Born in high-income countries & & & & & & -2 & $10^{* * *}$ & -3 \\
\hline Child $6-17^{\star}$ Born in high-income countries & & & & & & 0 & $9^{* \star *}$ & 0 \\
\hline Number of observations & 19616 & 19578 & 19578 & 12026 & 13266 & 19578 & 12026 & 13266 \\
\hline
\end{tabular}

Note: The dependent variable is the dichotomous variable "employed". The coefficients of the independent variables are based on an OLS regression on the employment rate of women between the ages of 15 and 64 years. All models include a constant. Models $2-6$ also include control variables for age and educational attainment. ${ }^{*},{ }^{* *},{ }^{* * *}$ denote significance at the $1 \%, 5 \%$ and $10 \%$ level. "Born in" refers to the respective country of birth of the women. Reference group are the native-born women. In columns $3 a / b$ and $4 a / b$, a positive coefficient is associated with a higher probability to be in fulltime/part-time employment, the reference group being not in employment.

Source: Swiss Labour Force Survey, Swiss Federal Statistical Office.

124. There are few integration measures for immigrant women. Evidence of this is that according to data from the Swiss labour force survey, only $15 \%$ of immigrant women from non-neighbouring countries (i.e. countries with which Switzerland does not share a common language) have participated in language training.

44 Unfortunately, the study only covered immigrant families from the former Yugoslavia, Portugal and Italy. 
125. Indeed, for many immigrant women, access to mainstream services is limited. The measures provided by the cantonal public employment services are mainly available to the beneficiaries of unemployment insurance, which implies that the person has been previously employed in Switzerland. Until 2011, cantonal employment services had the possibility to extend their services to other groups, but this option has been curtailed under the recent revision of the unemployment insurance law.

\section{Discrimination in the labour market}

126. The issue of discrimination against immigrants has received little attention in Switzerland thus far. There is no specific legislation covering discrimination against immigrants and no institution is in charge of bringing discrimination cases to a court (see OECD, 2008c). ${ }^{45}$ The overall framework for antidiscrimination is thus less developed than in other European OECD countries. ${ }^{46}$

127. At the federal level, the Federal Commission against Racism (Commission fédérale contre le racisme, CFR) provides advice for victims of discrimination, but may not bring cases to court or levy sanctions on employers. There are "advisory offices" at the sub-federal level which provide advice regarding discrimination by private persons. Seven of these (including the Federal Commission against Racism) have joined forces through a network. In 2010, the network treated only 23 cases of discrimination in the labour market. The low number of cases may be linked with the fact that the issue of sanctions regarding discrimination in hiring is unclear in the current legal setting. ${ }^{47}$

128. Regarding discrimination by the authorities or public institutions, there is an "Office for the fight against racism" within the Federal Department of the Interior. In contrast to the Federal Commission against Racism, the Office has a small budget - about CHF 1 million - for financing projects to combat discrimination within the Federal administration. In addition, at the cantonal and municipal level, there are about a dozen ombudsmen offices providing advice on discrimination.

129. The lack of a strong institutional framework against discrimination holds in particular with regard to the labour market, where contractual freedom prevails and nothing prevents a priori employers from making their choices on the basis of criteria such as origin. ${ }^{48}$ This state of affairs, added to the fact that historically immigrants have only had moderate difficulties in entering the labour market in Switzerland, has meant that the issue of discrimination has attracted little public debate and media coverage. Even today, the existence of systematic discrimination on the labour market is doubted by many actors in Swiss society, and there are few policies aimed at combating labour market discrimination. ${ }^{49}$

45 However, there are some legal provisions that in principle allow workers to bring a discrimination case before the courts In addition, the Federal Commission against Racism and the Service for Combating Racism may offer guidance and counseling to victims of discrimination. In addition, in some cantons, there are institutions which may provide support as well. Finally, since 2002, EU nationals are protected against discrimination in the labour market through provisions in the agreement on the freedom of movement between Switzerland and the EU.

The OECD countries which are member of the European Union all have a basic framework against ethnic discrimination on the basis of the EU anti-discrimination directive; for Norway, see Liebig (2009). For an overview of anti-discrimination legislation in general, see OECD (2008c).

47 For a comprehensive critical discussion of the current framework, see CFR (2009).

48 Provided that they do not express their preferences, which could be deemed public discrimination under Art. 261bis of the Criminal Code. Discrimination on grounds of gender is punishable under a specific law (Act on Equality), see Fibbi (2005).

49 The grounds of a judgement by the Federal Court in 2002 may be symptomatic of this situation. Following the request by two girls - living with their Swiss mother divorced from their Albanian father - to be allowed to take their mother's name, the court refused unanimously and contested the fact that an Albanian name might be detrimental to their future professional careers. The Court did not exclude the possibility that the Balkan-sounding name might sometimes be 
130. As seen above, immigrants from lower-income countries are disadvantaged in the Swiss labour market, even after accounting for a range of socio-demographic characteristics and an objective measure of skills. Differences in labour market outcomes after controlling for such characteristics are often interpreted as indirect measure of discrimination (de Coulon and Flückiger, 2000; Fibbi, Lerch and Wanner, 2006). However, there is always the possibility that other factors which have not been explicitly taken into account or which are not observed directly could explain such differences.

131. The shortcomings in demonstrating the existence of discrimination are overcome in large-scale experimental tests of hiring procedures carried out in a number of OECD countries in recent years. These suggest the existence of significant discriminatory behaviour on the part of employers (see Simeone, 2005). The tests consist of the submission of applications for the same job from two (fictitious) candidates differing essentially only in name. Since the qualifications need to be approximately the same for both candidates, the testing concerns persons who received their highest level of attainment in the host country and thus apply essentially to offspring of immigrants. A sufficient number of applications are sent to exclude the effect of chance and, if the applicants of one origin group are rejected more often than others, it can be concluded that there is discrimination. Such studies have demonstrated the prevalence of significant discrimination in hiring in six of the nine countries under review thus far (Belgium, Denmark, France, Germany, the Netherlands and Sweden).

132. A study of this type was conducted in Switzerland in 2002 funded by the Swiss National Science Foundation (Fibbi et al., 2004) using fictitious applications by young men with credentials from Swiss educational institutions, all looking for their first permanent job. Four groups of immigrants were under study - immigrants from Portugal in the French-speaking part of the country, immigrants from Turkey in the German-speaking part, and immigrants from the former Yugoslavia in both parts. ${ }^{50}$ In the design of the study, candidates who were invited to a job interview sent a refusal letter; often, the immigrant candidate was only invited after the native candidate had refused the invitation. It is somewhat ambiguous whether or not these cases of differential treatment should be treated as discrimination or not, since a causal link between the time-lag between the sending of the invitation letters to the two candidates and the refusal of the offer by the first candidate cannot be established. Table 8 summarises the results. It shows that discrimination against immigrants in the hiring process appears to be quite wide-spread in Switzerland. Immigrants from Turkey have to write three times as many applications as an otherwise equivalent native Swiss to get invited to a job interview, and immigrants from the former Yugoslavia up to five times as many. ${ }^{51}$ The significant difference in the two alternative measurements suggests that Switzerland's tight labour market may limit discrimination.

133. More generally, it seems that discrimination against the largest group - i.e. immigrants from the former Yugoslavia - is most pronounced. Discrimination seems to be more pronounced in the Germanspeaking part of the country. The study also showed that the degree of discrimination does not seem to vary with the size of the company nor the sector of activity, but there is a slightly greater tendency towards discrimination when the job involves direct contact with customers.

disadvantageous for job applicants, but stated that "in the vast majority of cases, this influence has neither been proven nor suspected" (Judgement 5C.163/2002 of 1.10.02).

50 The place of birth in the fictitious application was Kosovo, and Albanian was stated as "mother tongue".

51 The actual incidence of discrimination may be even higher, since the study excluded job offers which required Swiss nationality or "Swiss-German mother tongue". 
Table 8: Estimated number of applications to be sent by different immigrant groups in order to receive an invitation to a job interview, relative to an otherwise equivalent native Swiss candidate

\begin{tabular}{lcc}
\hline & Upper limit & Lower limit \\
\hline Portuguese in French-speaking part & 2.1 & no difference \\
Ex-Yugoslavian in French-speaking part & 2.9 & 1.3 \\
Turkish in German-speaking part & 3.3 & 1.4 \\
Ex-Yugoslavian in German-speaking part & 4.8 & 2.5 \\
\hline
\end{tabular}

Source: OECD Secretariat calculations on the basis of the data in Fibbi, Kaya and Piguet (2003).

134. More generally, it can be assumed that there is much confusion in the minds of the public and employers regarding the preference - enshrined in the law - given to the resident Swiss and foreign population in the field of immigration policy (a person can only be admitted in the country for work if there are no Swiss, EU, or settled applicants available), and the attitude to be adopted towards foreign job-seekers who are already legally residing in Switzerland and legally have equal access to the labour market. A periodic national opinion survey included a question on "do you think that priority on the labour market should be given to Swiss citizens?" in $2001 .^{52}$ It showed that a majority of Swiss supported the idea of national preference in hiring (33\% entirely and $27 \%$ partially) and that only $12 \%$ were strongly opposed (Raymann, 2003).

135. Indeed, it is not uncommon in job offers in private enterprises that "Swiss nationality" is required. ${ }^{53}$ In contrast to other OECD countries (see, for example, OECD, 2008b; and OECD, 2008c), this type of discrimination is at present generally not illegal in Switzerland. ${ }^{54}$

136. In sum, there seems to be a good prima facie case for strengthening the anti-discrimination framework in Switzerland. However, one should not expect too much from mere legal measures, even when they involve strong enforcement and penalties. Even in OECD countries with a strong and established anti-discrimination framework, such measures generally cover only the tip of the iceberg. To overcome discrimination in hiring, it is important to bring the issue into the limelight. Other OECD countries have also gone beyond formal antidiscrimination legislation to implement so-called "diversity policies" (Box 3).

\section{Box 3. Policies to promote diversity}

In contrast to most other OECD countries, Switzerland has no comprehensive anti-discrimination legislation to address the problem of discrimination in hiring. Even in countries where the anti-discrimination is strong, it has proved difficult to detect or to demonstrate discrimination. In all countries, the number of complaints related to hiring discrimination is small compared with the level of discriminatory behaviour that is revealed by testing studies in numerous OECD countries, including Switzerland. The perceived lack of effectiveness of anti-discrimination legislation and the persistence of other structural obstacles to the employment of immigrants and their children have prompted governments to take more pro-active measures. A new policy line that has become prominent in many OECD countries in recent years is known as diversity policy. Belgium, in particular, has become a frontrunner in this, inspired by earlier Dutch policies of the 1990s. Diversity policies aim at achieving equal opportunities for disadvantaged groups in the labour market (including immigrants and their children) by incentives and measures with strong indirect targeting.

\footnotetext{
$52 \quad$ This survey has not been repeated since then.

53 In the German-speaking part of the country, "mother-tongue Swiss German" is also at times required.

54 However, EU nationals are somewhat protected against this type of discrimination since they may evoke the treaty on the freedom of movement.
} 


\section{Box 3. Policies to promote diversity (cont.)}

Practices in Belgium (notably in Flanders) include, for example, the exclusive opening of certain job vacancies to disadvantaged groups in the labour market for a limited period, and financial and administrative support for companies who try to diversify their staff both in the hiring and promotion process. First results of an evaluation of this policy indicate that it appears to have contributed to the recent improvements in labour market integration, in particular for the children of immigrants (see Van der Voorde and de Bruijn, 2010).

Efforts in other OECD countries have been less far-reaching, but are also on the rise (see OECD, 2008b). In France, for example, companies have the possibility to pass an audit as to whether or not hiring and promotion practices are inherently discriminatory. If they pass the test and have demonstrably implemented additional actions to promote diversity, they can obtain a diversity label (label diversité) from the authorities in charge of integration. In order to receive the seal of approval, enterprises need to satisfy six criteria: a formal commitment by the enterprise to diversity; an active role of the social partners within the enterprise; equitable human resource procedures; communication by the enterprise on the question of diversity; concrete public measures in favour of diversity; and procedures to evaluate actual practices. France, like a growing number of other OECD countries including Belgium, the Netherlands and Germany, has also been promoting a "diversity charter" in which signatories commit themselves to favour diversity through recruitment and career management, as a strategy for greater efficiency and progress and to enhance their social relations. Without a precise follow-up of hirings and of career progress in signatory enterprises, it is difficult to have a precise idea of how effective this sort of measure is. There is undoubtedly a self-selection of already committed enterprises as signatories, although a formalisation of the process may have its usefulness in disseminating norms throughout the enterprise. Another measure that has been tested in a number of OECD countries, including France, Germany and Norway, are anonymous CVs, although the evidence regarding its effectiveness has been rather mixed.

In Belgium, Norway and the Netherlands, there has been a strong effort to enhance diversity in the public sector. The policies in place tackle the different points in the recruitment process where immigrants and their offspring are at a structural disadvantage. This has included the broad-based introduction of anonymous CVs, the targeted promotion of apprenticeship for young people with a migration background, internship opportunities to give them a first step into the labour market, and special training to help them pass the recruitment tests.

In Switzerland, apart from a few small-scale projects at the cantonal level and some voluntary measures by employers (see Schönenberger and Piguet, 2010), no such diversity policy tools have been implemented thus far.

137. Overall, the area of discrimination seems to be one where there is ample scope and need for improvement, both with respect to the legislative and institutional framework and regarding active measures to raise awareness about the issue and to combat discrimination on the labour market.

\section{Naturalisation and its impact}

138. Access to the host-country nationality is an important instrument of integration policy. OECD (2011a) has shown that naturalisation tends to have a positive impact on immigrants' labour market outcomes through a number of channels. Among these are the removal of institutional barriers in the labour market, notably regarding the public sector and higher-skilled employment. In addition, naturalisation seems to function as a signalling device for the employer of better "integration potential", which in turn may be associated with higher productivity (for example, because of better language mastery or higher motivation). For example, testing studies have shown that immigrants who have naturalised get more frequently invited to a job interview than otherwise equivalent immigrant candidates who have not. The degree to which naturalisation can exert a signalling function depends in part on whether or not it is common to mention one's nationality in the application process (if it is not required for the job itself, which is rarely the case). In Switzerland, it is common to state one's nationality in job applications which suggests that this latter channel may be of considerable importance.

139. The criteria for access to citizenship vary considerably across OECD countries and by many standards, Switzerland has one of the most restrictive naturalisation frameworks in the OECD, reflecting the view that it is a certification of successfully completed integration. For example, minimum residence 
requirements for ordinary naturalisation are twelve years in Switzerland, the longest in the OECD. Another key specificity of the Swiss naturalisation system is the three-tiered nature of citizenship (see Box 4). As a result, only slightly more than one third of all immigrants with more than ten years of residence in Switzerland have Swiss citizenship, compared with the OECD average of more than $60 \%$. Only Luxembourg has a lower percentage of long-term residents who have not naturalised.

140. As a result of the stringent naturalisation policy and longstanding immigration, more than $6 \%$ of the native-born population do not have a Swiss passport. Indeed, among the OECD countries for which comparable data on the nationality of the native-born offspring of immigrants are available, Switzerland has the lowest percentage of those who have naturalised (see Figure 13). ${ }^{55}$

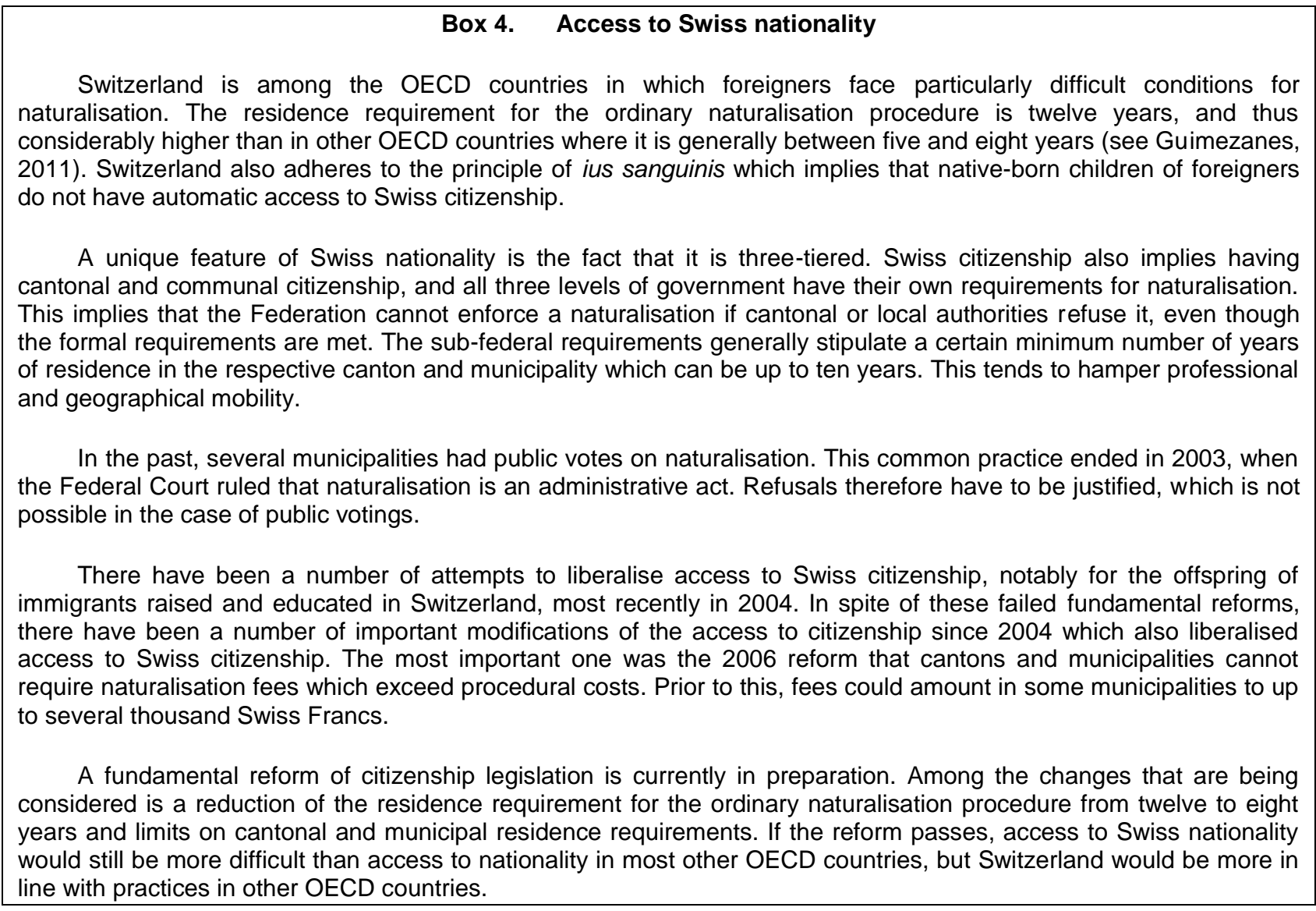

55 However, there are the same facilitations for children of immigrants. In particular, for the calculation of duration of residence requirements, years of residence in Switzerland between the age of 10 and 20 are counted twice. 
Figure 13: Percentage of native-born children of immigrants from lower-income countries who have host-country nationality, aged 20-29 and not in education, around 2007

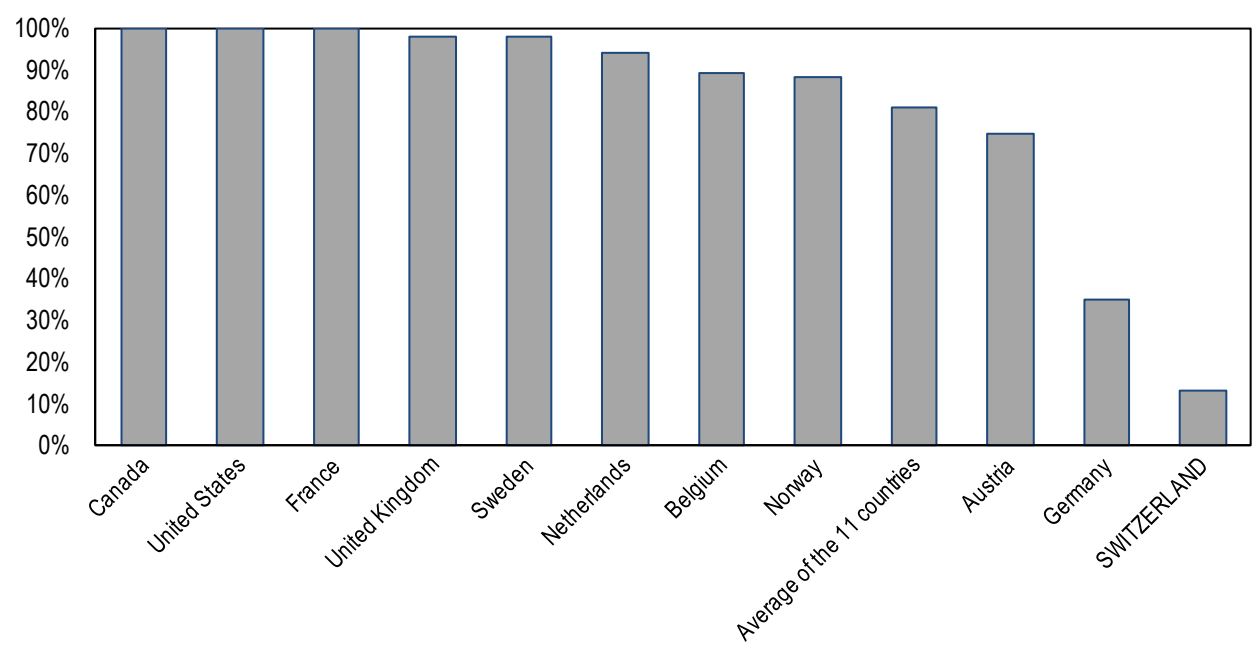

Source: See Liebig and Von Haaren (2011).

141. In any analysis, it is important to keep in mind that naturalised and non-naturalised immigrants differ in many ways, because naturalisation is a selective process. Immigrants have to apply for naturalisation, and they have to meet a number of criteria before they become naturalised. To study the impact of naturalisation, longitudinal data are needed which compare the outcomes of immigrants over time. There has been no such longitudinal study in Switzerland thus far. ${ }^{56}$ Steinhardt et al. (2010) use cross-sectional data from the Swiss labour force survey to compare the labour market outcomes of immigrants who have naturalised with those of immigrants who remained foreigners. Even after controlling for a broad range of socio-demographic characteristics, the authors find that naturalised immigrants have higher employment rates and wages than their non-naturalised peers, although they still have less favourable labour market outcomes than the native Swiss.

142. Liebig and Von Haaren (2011), again with cross-sectional data, compare the labour market outcomes of naturalised and non-naturalised immigrants in 14 OECD countries. Naturalised immigrant men in Switzerland have an almost ten percentage points higher probability to be in a high-skilled occupation than their non-naturalised counterparts with otherwise similar observable characteristics (see Table 9). The difference was particularly strong for immigrant men. Access to higher-skilled jobs is associated to a larger degree with naturalisation in Switzerland than elsewhere, which may at least be partly attributable to the fact that the naturalisation requirements hamper geographical mobility in Switzerland for foreigners (see also Box 4.). to improve labour market outcomes, in particular for the most disadvantaged immigrants. However, the extent to which this is actually the case varies considerably across countries and migrant groups (see OECD, 2011a for a comprehensive analysis of this issue). 
Table 9: Estimated higher probability associated with naturalisation of employment in a highskilled occupation, aged 15-64, around 2007

\begin{tabular}{|c|c|c|c|c|c|c|}
\hline & \multicolumn{2}{|c|}{ All immigrants } & \multicolumn{2}{|c|}{$\begin{array}{l}\text { Immigrants from high- } \\
\text { income countries }\end{array}$} & \multicolumn{2}{|c|}{$\begin{array}{l}\text { Immigrants from lower- } \\
\text { income countries }\end{array}$} \\
\hline & Men & Women & Men & Women & Men & Women \\
\hline Austria & $5^{\star \star \star}$ & $(-1)$ & $9^{\star \star *}$ & $-11^{\star * *}$ & $5^{\star \star \star}$ & $4^{\star *}$ \\
\hline Belgium & $(-4)$ & $(-1)$ & $(-4)$ & $(-2)$ & (1) & $8^{* *}$ \\
\hline Canada & $1^{* \star *}$ & $2^{\star \star \star}$ & & & & \\
\hline Switzerland & $9^{\star \star \star}$ & $5^{\star \star}$ & $8^{\star \star}$ & $(2)$ & $10^{\star \star \star}$ & $7^{\star \star}$ \\
\hline Germany & $-2^{\star \star \star}$ & $3^{\star \star}$ & $-8^{* * *}$ & $4^{\star \star}$ & $3^{* * *}$ & $4^{\star * \star}$ \\
\hline Denmark & $12^{\star \star \star}$ & $8^{\star \star}$ & $13^{\star \star}$ & $(0)$ & $12^{\star \star \star}$ & $12^{\star \star \star}$ \\
\hline Spain & $6^{*}$ & $(0)$ & $(2)$ & $(-5)$ & $11^{* \star *}$ & (4) \\
\hline France & $7^{\star \star \star}$ & $3^{\star \star}$ & $10^{\star \star \star}$ & (3) & $5^{\star \star \star}$ & (3) \\
\hline Luxembourg & (1) & $(-4)$ & $(0)$ & $(-6)$ & (7) & (1) \\
\hline Netherlands & (0) & $(-2)$ & $(-2)$ & $(-2)$ & $5^{\star \star}$ & (1) \\
\hline Norway & (5) & $-12^{\star \star \star}$ & (4) & $(-8)$ & $17^{\star *}$ & $-19^{\star *}$ \\
\hline Sweden & $(-1)$ & (1) & (2) & (5) & $11^{\star \star \star}$ & $(-1)$ \\
\hline United Kingdom & $(2)$ & $(2)$ & (3) & (2) & $5^{\star \star}$ & (2) \\
\hline United States & (2) & $5^{* \star *}$ & (1) & (4) & $2^{*}$ & $5^{* \star *}$ \\
\hline $\begin{array}{l}\text { United States } \\
\text { (excl. irreg.) }\end{array}$ & (1) & $4^{\star *}$ & (1) & (4) & -1 & $4^{\star *}$ \\
\hline
\end{tabular}

Note: The sample is restricted to employed individuals. The table shows the naturalisation coefficients in percentage points. The dependent variable is the dichotomous variable "employed in a high-skilled occupation". The regression includes control variables for origin country, age and education.

Source and further Notes: see Liebig and Von Haaren (2011).

143. Compared with their peers who remained foreigners, naturalised immigrants in Switzerland also have a much higher probability to participate in on-the-job-training and to be employed in the public sector. ${ }^{57}$ However, immigrants from lower-income countries remain largely underrepresented in the public sector in Switzerland, even when they have naturalised (Liebig and Von Haaren, 2011).

57 In general, immigrants in Switzerland are largely underrepresented in the public sector (that is, the public administration and the education system). While this is also the case in other OECD countries, the difference in the relative importance of this sector among immigrants' total employment compared with natives' total employment is particularly large in Switzerland (see Annex Figure 5). This is unfortunate since, by employing immigrants, the public sector acts as a role model for the private sector. If in fact immigrants find employment in the public sector, this can also increase the visibility of immigrants in daily life. Finally, employment of immigrants in the public sector can contribute to enhancing the understanding the needs of immigrants and their children by public institutions. When immigrants are employed in certain key occupations such as teaching, they can also serve as role models for others, notably offspring of immigrants. 


\section{THE LABOUR MARKET INTEGRATION OF IMMIGRANTS' OFFSPRING}

\section{Educational outcomes of the children of immigrants in Switzerland}

144. As seen in Section I, the overall picture of immigrant offspring's labour market integration in Switzerland is favourable both in international comparison and compared with the children of natives. However, as has been pointed out already, this partly stems from the fact that two-thirds of the native-born immigrant offspring aged 20-29 have parents from high-income countries of origin and these seem to face no apparent difficulty integrating into the Swiss labour market. This is not the case for the native-born children of parents from lower-income countries who, on average, have more difficulties. To identify starting points for policy measures that aim to foster the labour market integration of this disadvantaged group, it is worthwhile to take a step back and to examine their integration into the Swiss education system, which in principle prepares them for labour market entry.

145. In general, one would expect the labour market outcomes of immigrant offspring to be better in countries where their educational outcomes are good. Taking differences in the reading performance of 15year olds as an indicator for the degree of integration, results from the 2009 OECD Programme for International Student Assessment (PISA) show that immigrant offspring in Switzerland face larger gaps in education outcomes vis-à-vis children of natives than in other OECD countries (see Table 10). Children of immigrant parents have considerably lower reading scores than the children of natives, especially if they have not been born in Switzerland, but migrated there as children. Particularly striking are the large gaps between the young immigrants and the children of natives, which are almost twice as large as the OECD average - in spite of the fact that the difference in parental schooling between young immigrants and offspring of natives is not larger than the OECD average.

146. Given these substantial differences in school performance, as measured by PISA, the rather low overall differences in labour market outcomes of immigrant offspring come as a surprise. With longitudinal data on the school-to-work transition process, the educational career and subsequent outcomes of immigrant offspring can be examined more thoroughly, in comparison to that of the children of natives. Such data are available for Switzerland in the form of the PISA/TREE panel survey which is the main data source on which the following analysis is based. The PISA/TREE panel follows the participants of the 2000 PISA survey in Switzerland during the process of their school-to-work transition, with the last wave having been conducted in 2010. Box 5 gives more detailed information on this unique dataset. 
Table 10: PISA point differences in reading scores for the children of immigrants compared with the children of natives, 2009

\begin{tabular}{|c|c|c|c|c|c|c|}
\hline & \multicolumn{2}{|c|}{ Unadjusted } & \multicolumn{2}{|c|}{ Adjusted } & \multicolumn{2}{|c|}{$\begin{array}{c}\text { Differences in the number of years } \\
\text { of highest parental schooling } \\
\text { compared with the children of } \\
\text { natives }\end{array}$} \\
\hline & $\begin{array}{l}\text { Native-born } \\
\text { children of } \\
\text { immigrants }\end{array}$ & $\begin{array}{c}\text { Young } \\
\text { immigrants }\end{array}$ & $\begin{array}{l}\text { Native-born } \\
\text { children of } \\
\text { immigrants }\end{array}$ & $\begin{array}{c}\text { Young } \\
\text { immigrants }\end{array}$ & $\begin{array}{l}\text { Native-born } \\
\text { children of } \\
\text { immigrants }\end{array}$ & $\begin{array}{c}\text { Young } \\
\text { immigrants }\end{array}$ \\
\hline Australia & -16 & -3 & -19 & -3 & 0.0 & 0.5 \\
\hline Austria & 55 & 98 & 30 & 69 & -1.2 & -1.9 \\
\hline Belgium & 65 & 71 & 37 & 42 & -1.5 & -1.1 \\
\hline Canada & 5 & 8 & -4 & 7 & -0.4 & 0.6 \\
\hline Denmark & 56 & 79 & 32 & 55 & -1.8 & -0.8 \\
\hline France & 55 & 77 & 24 & 51 & -1.8 & -1.4 \\
\hline Germany & 54 & 61 & 31 & 42 & -2.0 & -0.7 \\
\hline Greece & 33 & 69 & 20 & 36 & 0.2 & -0.6 \\
\hline Ireland & -6 & 36 & 4 & 39 & -0.2 & 0.9 \\
\hline Italy & 45 & 81 & 23 & 54 & -0.2 & 0.0 \\
\hline Luxembourg & 56 & 47 & 22 & 24 & -3.4 & -2.0 \\
\hline Netherlands & 46 & 44 & 21 & 7 & -2.4 & -2.3 \\
\hline New Zealand & 28 & 6 & 10 & 15 & 0.1 & 0.8 \\
\hline Norway & 45 & 60 & 31 & 37 & -0.7 & -0.9 \\
\hline Portugal & 16 & 36 & 9 & 29 & 1.1 & 2.2 \\
\hline Spain & 26 & 62 & 20 & 44 & -0.1 & 0.0 \\
\hline Sweden & 53 & 91 & 31 & 61 & -0.7 & -1.8 \\
\hline SWITZERLAND & 42 & 58 & 21 & 42 & -1.7 & -0.9 \\
\hline United Kingdom & 7 & 41 & 11 & 29 & -0.3 & -0.3 \\
\hline United States & 22 & 21 & 0 & -5 & -2.1 & -1.9 \\
\hline OECD & 25 & 33 & 7 & 14 & -1.5 & -0.9 \\
\hline
\end{tabular}

Note: The figures show the points differences in the PISA 2009 scores for reading literacy between children of natives on the one hand and (native- and foreign-born) children of immigrants on the other. "Young immigrants" are students who are foreign-born and whose parents were also born in another country. "Native-born children of immigrants" refers to native-born students whose parents were both born outside of Switzerland. "Unadjusted" refers to the points' differences in the raw scores, "adjusted" to the differences after controlling for the socio-economic background of students. The socio-economic background index was created on the basis of the following variables: the International Socio-Economic Index of Occupational Status (ISEI), the highest level of education of the student's parents, the index of family wealth, the index of home educational resources and the index of possessions related to "classical culture" in the family home. OECD is the average of all countries for which full data are available. Negative values mean that children of immigrants have better results than children of natives. Differences which are not statistically different from zero are in italics.

Source: OECD, PISA database 2009. 


\section{Box 5. The PISA/TREE Panel Survey}

The PISA/TREE panel surveys the cohort which participated in the PISA 2000 study and finished compulsory education in the same year. Those students in this cohort who accepted to participate were then sent a yearly survey to follow their educational career as well as their labour market integration. The cohort is representative for Switzerland and its language regions. The resulting dataset is rather rich and allows for a broad variety of analyses.

\begin{tabular}{|c|c|c|c|c|c|c|c|c|}
\hline Survey year & 2000 & 2001 & 2002 & 2003 & 2004 & 2005 & 2006 & 2007 \\
\hline Gross sample & 11710 & 6343 & 5944 & 5609 & 5345 & 5060 & 4852 & 4659 \\
\hline Responses & 6343 & 5528 & 5206 & 4877 & 4679 & 4506 & 4133 & 3979 \\
\hline \multicolumn{9}{|l|}{ out of which } \\
\hline Children of natives & $77 \%$ & $78 \%$ & $79 \%$ & $79 \%$ & $79 \%$ & $79 \%$ & $79 \%$ & $80 \%$ \\
\hline $\begin{array}{l}\text { Native-born children of immigrants, } \\
\text { high-income country }\end{array}$ & $10 \%$ & $9 \%$ & $9 \%$ & $9 \%$ & $9 \%$ & $9 \%$ & $9 \%$ & $9 \%$ \\
\hline $\begin{array}{l}\text { Native-born children of immigrants, } \\
\text { lower-income country }\end{array}$ & $6 \%$ & $6 \%$ & $6 \%$ & $6 \%$ & $6 \%$ & $6 \%$ & $6 \%$ & $5 \%$ \\
\hline $\begin{array}{l}\text { Young immigrants, high-income } \\
\text { country }\end{array}$ & $1 \%$ & $1 \%$ & $1 \%$ & $1 \%$ & $1 \%$ & $1 \%$ & $1 \%$ & $1 \%$ \\
\hline $\begin{array}{l}\text { Young immigrants lower-income } \\
\text { country }\end{array}$ & $3 \%$ & $3 \%$ & $3 \%$ & $3 \%$ & $3 \%$ & $3 \%$ & $3 \%$ & $3 \%$ \\
\hline$\%$ responses of yearly gross sample & $54 \%$ & $87 \%$ & $88 \%$ & $87 \%$ & $88 \%$ & $89 \%$ & $85 \%$ & $85 \%$ \\
\hline$\%$ responses of 2001 gross sample & & & $82 \%$ & $77 \%$ & $74 \%$ & $71 \%$ & $65 \%$ & $63 \%$ \\
\hline
\end{tabular}

Source: TREE.

The response rates until 2007 - the most recent year for which the data have been released - do allow for distinct analysis of different groups of offspring of immigrants, but they, nevertheless, limit the extent to which detailed analysis can be done in later years with respect to specific questions. Over the years, the content of the questionnaire varied. While it mainly focused on upper secondary education over the first three waves, emphasis shifted to the transition into the labour market or tertiary education over the last three years of available data.

The sample of 2000 is composed of individuals of different ages. The median as well as the average age was 15 , but the actual ages ranged from 13 to 18 .

147. Already in 2000, the PISA study detected a considerable performance gap for students with immigrant parents at the end of lower-secondary schooling in Switzerland. ${ }^{58}$ The children of immigrants from lower-income countries faced the largest disadvantages. In addition, outcomes varied greatly across different groups of origin: while PISA reading scores were not significantly different from those of the children of natives, among the children of immigrants (either foreign- or native-born) from Germany, France, Austria and Belgium, young immigrants from the successor countries of the former Yugoslavia had lower outcomes by almost 170 points. ${ }^{59}$

148. Part of these differences in educational performance can be explained by differences in the parental socio-economic background. Figure 14 displays the correlation between average PISA reading scores and the average ISEI index of parental socio-economic status for different groups of immigrant offspring, with the area of the bubbles indicating their relative group size (with the exception of the nativeborn). ${ }^{60}$

\footnotetext{
$58 \quad$ For more on the PISA 2000 survey see, for example, OECD (2001).

59 Note, however, that many of these had spent only few years in the Swiss education system.

60 The ISEI refers to the maximum of the father's and the mother's ISEI score.
} 


\section{Figure 14: Parental socio-economic background and PISA reading scores in 2000, by migration background and country of origin}

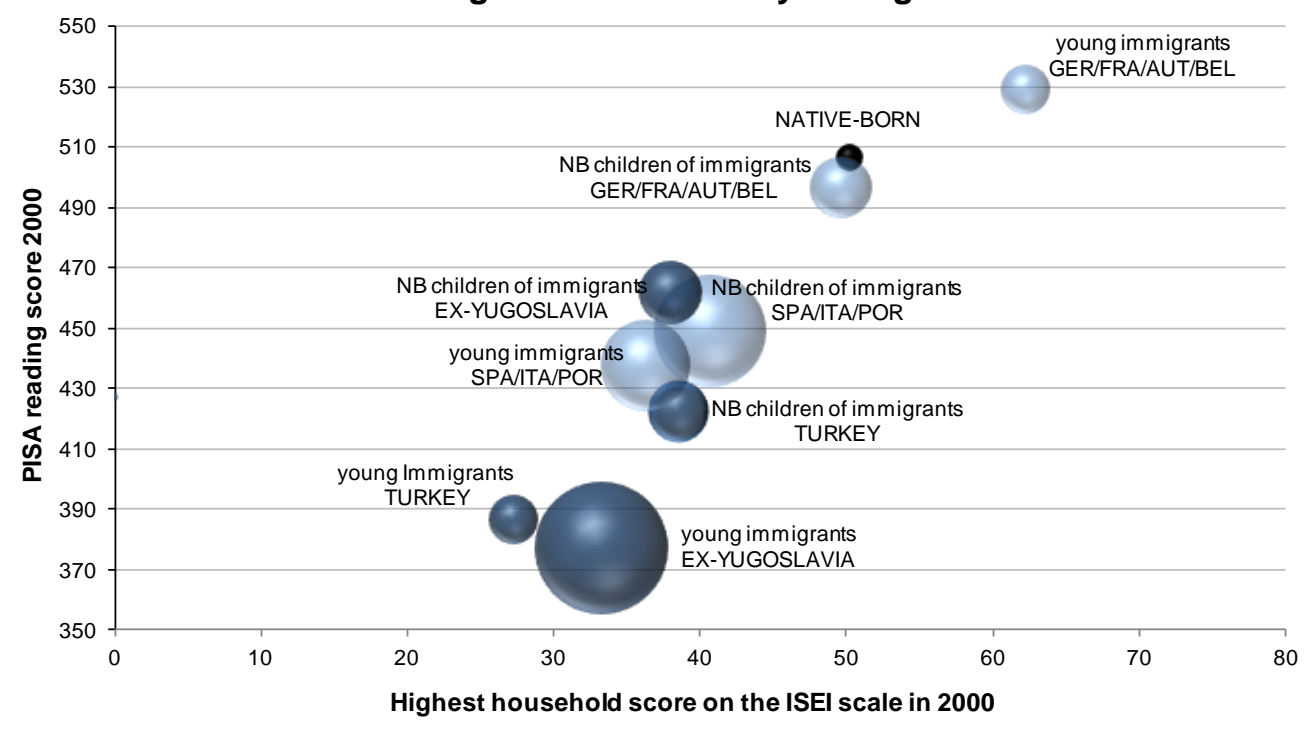

Note: "NB children of immigrants" stands for "native-born children of immigrants". The bubble for the "native-born" is the only one that was not drawn at its correct relative size, since this group is so large that the respective bubble would dominate the whole picture. The bubble can thus only be interpreted in terms of its position, but not its size.

Source: TREE.

149. As Figure 14 illustrates, immigrant offspring from different origin countries tend to differ significantly with respect to their parents' social status. Offspring with parents from high-income countries such as Germany, France, Austria and Belgium have an average socio-economic background that is comparable to that of the children of natives - or, in the case of young immigrants, even more favourable. Offspring with parents from Turkey and the successor countries of the former Yugoslavia, as well as from the high-income countries Spain, Italy and Portugal, on the other hand, tend to come from families with a lower socio-economic status. Although almost all immigrant offspring have, on average, lower education outcomes in the PISA study, even when differences in socio-economic status are taken into account, children of parents with a lower socio-economic status are at a greater disadvantage. For policy making, it is of particular interest to understand how these differences, in correlation with migration background, translate into educational and finally employment outcomes.

\section{Early childhood education}

150. A quite effective way to tackle disadvantages stemming from an unfavourable socio-economic background appears to be the enrolment of children in Early Childhood Education and Care Programmes (ECEC). ${ }^{61}$ Measures targeting children around the age of three to four appear to be particularly successful in this respect and they seem to be even more beneficial to the children of immigrants than for the children of natives. A recent study from Germany found that participation in ECEC measures increased the chances to attend the most challenging type of secondary education (École de maturité) by over 55\% for the children of immigrants, compared with $38 \%$ on average overall (Fritschie and Oesch, 2008). Likewise, a French study has shown that participation in ECEC at the age of three has a positive effect on the education outcomes of immigrant offspring (Caille, 2001). ${ }^{62}$

Throughout this section, pre-school education will be used synonymously with early childhood education and care
(ECEC).

62 For a more thorough overview of ECEC programs, institutions and their effects, see, for example, OECD (2006a). 
151. In Switzerland, participation in ECEC measures has been low, especially for children younger than four. Among the three-year olds, less than 10\% participated in pre-school programmes, which is due to the fact that most cantons offer ECEC only starting from the age of four, with the exception of Ticino. Regarding the enrolment rate of four-year-olds, Switzerland also ranks lowest among all countries in the comparison group. In 2008, only $40 \%$ of the four-year-olds participated in a formal ECEC facility (see Figure 15). On average, children in Switzerland spend only 1.4 years in pre-school programmes, compared with 2.3 years on average for the OECD. ${ }^{63}$ There are no separate figures available on the enrolment rates of children with a migration background. Although there is no evidence that they are particularly disadvantaged in this respect (see above), the percentages are unlikely to be higher than those of the children of natives.

\section{Figure 15: Participation rates in formal care and pre-school for children aged 3 and 4 years, selected OECD countries, 2008}

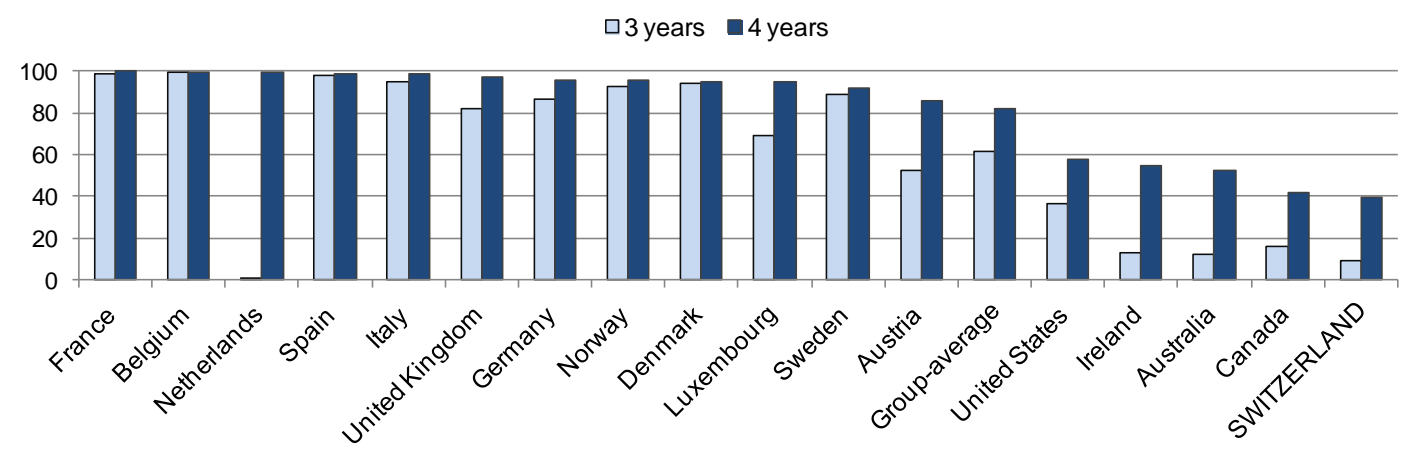

Source: OECD Education Database.

152. Although researchers largely agree on the beneficial impact of Early Childhood Education and Care (ECEC) programmes on the cognitive development of children from disadvantaged backgrounds, this has only recently emerged as a topic of public interest and policy attention in Switzerland. ${ }^{64}$ Caring for young children at home has a long tradition in Switzerland and is still given priority over establishing a comprehensive institutional approach in the public opinion. ${ }^{65}$ Indeed, language support projects ("Step:wise") for disadvantaged children aged 0-3 years in some German-speaking cantons provide language training and assistance to mothers at home, thereby perpetuating the current system rather than enhancing the structures for institutionalised ECEC.

153. A recent choice experiment that has been initiated and financed by the Swiss National Fund revealed that the demand for pre-school programmes targeting children below the age of four is actually much higher than the current supply in Switzerland. Over the course of this experiment, 600 families, 150 of which had a head of household with a foreign nationality, were presented with a set of different fictional offers for ECEC facilities at different prices (derived from actual market prices) and were asked to

63 Figures are derived from data in the OECD Education database and Eurostat (2008).

64 UNICEF published a report in 2008 that provides an overview of ECEC frameworks in 25 OECD countries. In a benchmark ranking that includes ten standards of good practice in the field of ECEC, Switzerland is classified in the bottom group, meeting only three out of ten benchmarks. At the time of the report in 2008, Switzerland provided regulated and subsidised childcare facilities for less than $25 \%$ of the under-3-year old, had not established a national plan highlighting the needs of disadvantaged children and did not meet the expenditure benchmark of $1 \%$ of GDP on childcare services per year. In 2003, only two OECD countries under comparison, Ireland and Korea, spent fewer resources on early childhood education and care (UNICEF, 2008).

For a more detailed discussion, see Schulte-Haller (2009). 
hypothetically choose their preferred means of child-care. Whereas $84 \%$ of the participants took care of their small children at home in real life, only $44 \%$ opted to do so in the fictional thought experiment. Moreover, the share of participants considering sending their child to a nursery school (30\%) was three times higher than the share of those who actually did so. Most notably, the study revealed that the supply of nursery schools could only meet $40 \%$ of the demand at the time and suggested that this demand was quite elastic with respect to prices and income levels (Swiss National Fund, 2005). This pattern of demand was similar for families with and without a migration background.

154. While an initiative has been launched to harmonise pre-schooling across cantons by making participation obligatory starting from the age of four (as stipulated in the so-called "HarmoS Konkordat"), there has been no comparable initiative for children aged three years, which is generally considered a critical age for integration. Existing programmes for this age-group vary even more substantially across cantons and even cities. There is a multitude of low-threshold programmes at the municipal and cantonal level in Switzerland, especially in large cities such as Bern, Basel, Zürich and St. Gallen. Since 2001, for instance, the federal government has provided funding for so-called "playgroups" (Spielgruppen) that integrate elements of language training into their range of activities ${ }^{66}$ Nevertheless, these measures lack a common curriculum and co-ordinated effort and are barely institutionalised. Although many of these local initiatives focus particularly on supporting migrant families and their children, the number of families benefiting from them remains limited (see Schulte-Haller, 2009). In reaction to this fragmentation, the Federal Commission for Migration called for a national action plan in 2009 in order to develop common terms and goals of ECEC for children below the age of four and to incite the harmonisation of the diverse offers across Switzerland. To date, no such plan has been implemented.

\section{Upper secondary education}

155. Children usually enter primary school at the age of six or seven in Switzerland. They are in comprehensive schooling until the end of obligatory education after nine years. After completion of the $9^{\text {th }}$ grade, they are sorted into different tracks of upper-secondary education which is a decisive step in the educational career. The type of upper-secondary schooling that is chosen at this point determines the subsequent educational career. The so-called Écoles de maturitélMaturitätsschulen represent the most prestigious track. Admission is selective and they provide a general education preparing for tertiary education and lead to a university-entrance diploma at ISCED 3A level (Maturité/Matura). The second option is vocational education and training (VET) that generally combines part-time schooling with company-based apprenticeship training. Finally, students can opt for continued full-time schooling in vocation-specific schools, which qualifies them for further schooling or entry into traineeships. This option is, however, rarely used.

156. Students who finish the selective track of an École de maturité tend to achieve rather positive subsequent educational and employment outcomes. Of those participants in the TREE panel who obtained the Maturite (or an equivalent qualification at the ISCED 3A level)-within seven years after the end of obligatory schooling, two out of three also attended tertiary education afterwards. Only 4\% were NEET (neither in employment nor in education or training).

157. A more detailed analysis shows that the offspring of parents from lower-income countries are much less likely to finish this track successfully compared with the children of natives (Table 11), while native-born offspring of immigrants from high-income countries face no significant disadvantage. Parental socio-economic background is a major driving factor accounting for differences in completion rates. When accounting for both PISA scores, the differences disappear. When accounting in addition for parental

66 From 2001 to 2007, resources were provided by the Federal Commission for Foreigners. Since 2008, these measures have been funded by the Federal Office for Migration. 
background, native-born children of immigrants from high-income countries, as well as young immigrants from lower-income countries, are even more likely to obtain the Maturité than the offspring of natives. This mainly concerns young women.

\section{Table 11: Differences in probability in percentage points of successfully completing upper- secondary education that qualifies for university attendance, by gender (PISA 2000 cohort)}

\begin{tabular}{|c|c|c|c|c|c|c|c|c|c|}
\hline & \multicolumn{3}{|c|}{ Model 1} & \multicolumn{3}{|c|}{ Model 2} & \multicolumn{3}{|c|}{ Model 3} \\
\hline & All & Men & Women & All & Men & Women & All & Men & Women \\
\hline \multicolumn{10}{|l|}{ By own migration background } \\
\hline $\begin{array}{l}\text { Native-born children of immigrants, } \\
\text { high-income country }\end{array}$ & -4 & -8 & -2 & $14^{\star}$ & 13 & 15 & $18^{*}$ & 14 & $24^{\star}$ \\
\hline $\begin{array}{l}\text { Native-born children of immigrants, } \\
\text { lower-income country }\end{array}$ & $-24^{\star \star \star}$ & $-25^{\star \star \star}$ & -11 & -8 & -14 & 6 & 2 & -7 & 20 \\
\hline $\begin{array}{l}\text { Young immigrants, high-income } \\
\text { country }\end{array}$ & $-18^{\star \star}$ & -16 & $-20^{\star \star \star}$ & -5 & -7 & -3 & -4 & -8 & 4 \\
\hline $\begin{array}{l}\text { Young immigrants, lower-income } \\
\text { country }\end{array}$ & $-25^{\star \star \star}$ & $-24^{\star \star \star}$ & $-28^{\star \star \star}$ & 11 & 5 & 22 & $21^{*}$ & 11 & 35 \\
\hline \multicolumn{10}{|l|}{ All immigrant offspring } \\
\hline Parents from high-income country & -6 & -11 & -1 & 7 & 1 & 13 & 9 & -2 & $22^{\star}$ \\
\hline Parents from lower-income country & $-21^{\star \star \star}$ & $-27^{\star \star \star}$ & -10 & 3 & -11 & 25 & 12 & -8 & $38^{*}$ \\
\hline \multicolumn{10}{|l|}{ Controls } \\
\hline $\begin{array}{l}\text { PISA } 2000 \text { reading score } \\
\text { Socio-economic background } \\
\text { Mother's education }\end{array}$ & & & & $x$ & $x$ & $x$ & $\begin{array}{l}x \\
x \\
x\end{array}$ & $\begin{array}{l}x \\
x \\
x\end{array}$ & $\begin{array}{l}x \\
x \\
x\end{array}$ \\
\hline
\end{tabular}

Note: The figures show the differences between the children of immigrants and the children of natives. They correspond to marginal effects after a Probit estimation, calculated at the sample means of the respective variables. The reference group is the native-born. *, ${ }^{* *},{ }^{* * *}$ denote significance at the $1 \%, 5 \%$ and $10 \%$ level, respectively. In the top four rows, respondents are grouped by their own migration status as well as their parents' countries of origin. The following two rows report the result for an analysis where respondents are grouped by their parents' countries of origin only.

Source: TREE.

158. Given the overall under-representation of immigrant offspring in the more prestigious track of upper-secondary education, particular attention must be paid to vocational education and training (VET) because it is the pathway that is used by the majority of immigrant offspring in Switzerland. Indeed, offspring with a foreign nationality account for $36 \%$ of students in VET programmes leading to qualifications at the ISCED $3 \mathrm{C}$ level - which is almost twice as much as their share in the age group overall (19\%). The most prominent VET programme is apprenticeship, and having completed an apprenticeship appears to be over-proportionally beneficial for the school-to-work transition of immigrant offspring, especially if the parents have come from lower-income countries (see Table 12). It significantly reduces their risk to be in NEET, both in absolute terms and relative to the native-born. This observation is in line with similar findings from other OECD countries that employ dual VET systems, such as Austria, Germany and the Netherlands (see OECD, 2007; OECD, 2008a; Krause and Liebig, 2011).

159. Although immigrant offspring are already quite well represented in starting apprenticeship training, their general probability to complete it remains below that of the children of natives (see Table 12). It is not entirely clear what explains the apparent higher drop-out of children of immigrants from apprenticeship training. 
Table 12: Difference in the probability of having completed an apprenticeship, children of immigrants relative to children of Swiss-born parents by migration background, 2007 (PISA 2000 cohort)

\begin{tabular}{|c|c|c|c|c|c|c|c|c|c|c|c|c|}
\hline \multirow[b]{2}{*}{ Migration Background } & \multicolumn{3}{|c|}{ Model 1} & \multicolumn{3}{|c|}{ Model 2} & \multicolumn{3}{|c|}{ Model 3} & \multicolumn{3}{|c|}{ Model 4} \\
\hline & All & Men & Women & All & Men & Women & All & Men & Women & All & Men & Women \\
\hline $\begin{array}{l}\text { Native-born children of immigrants from.. } \\
\text { high-income country }\end{array}$ & 2 & -3 & 7 & 1 & -3 & 4 & -4 & -11 & 3 & -5 & -10 & 2 \\
\hline lower-income country & -4 & -7 & 5 & -5 & $-9^{*}$ & 3 & $-17^{\star \star \star}$ & $-20^{* \star *}$ & 1 & $-18^{* \star *}$ & $-21^{\star * *}$ & 0 \\
\hline $\begin{array}{l}\text { Young immigrants from... } \\
\text { high-income country }\end{array}$ & -3 & $-13^{*}$ & $26^{\star \star \star}$ & -3 & $-13^{* *}$ & $27^{\star \star \star}$ & $-11^{*}$ & $-19^{\star \star \star}$ & $20^{*}$ & $-10^{*}$ & $-18^{\star \star \star}$ & $20^{*}$ \\
\hline lower-income country & -1 & $-9^{* *}$ & $16^{\star * *}$ & -3 & $-18^{\star \star \star}$ & $17^{\star \star \star}$ & $-21^{\star \star *}$ & $-25^{\star \star \star}$ & $-14^{\star *}$ & $-23^{\star \star \star}$ & $-30^{\star * *}$ & $-13^{\star \star}$ \\
\hline $\begin{array}{l}\text { Parents from high-income countries of } \\
\text { origin }\end{array}$ & & $-8^{*}$ & $11^{\star *}$ & & $-8^{*}$ & 9 & & $-14^{* * *}$ & 6 & & $-14^{\star \star \star}$ & 5 \\
\hline $\begin{array}{l}\text { Parents from lower-income countries of } \\
\text { origin }\end{array}$ & & $-8^{\star \star}$ & $14^{\star *}$ & & $-14^{\star *}$ & $14^{\star \star \star}$ & & $-21^{\star \star \star}$ & $-11^{*}$ & & $-25^{\star \star \star}$ & $-10^{*}$ \\
\hline Controls & & & & & & & & & & & & \\
\hline Region & $x$ & $x$ & $x$ & $\mathrm{x}$ & $x$ & $x$ & $\mathrm{x}$ & $x$ & $\mathrm{x}$ & $x$ & $x$ & $\mathrm{x}$ \\
\hline Socio-economic Status of parents & & & & $\mathrm{x}$ & $\mathrm{x}$ & $\mathrm{x}$ & & & & $\mathrm{x}$ & $\mathrm{x}$ & $\mathrm{x}$ \\
\hline PISA reading score & & & & & & & $\mathrm{x}$ & $\mathrm{x}$ & $\mathrm{x}$ & $\mathrm{x}$ & $\mathrm{x}$ & $x$ \\
\hline Gender & $x$ & & & $\mathrm{x}$ & & & $\mathrm{x}$ & & & $\mathrm{x}$ & & \\
\hline
\end{tabular}

Note: The figures show the differences between the children of immigrants and the children of natives. They correspond to marginal effects after a Probit estimation, calculated at the sample means of the respective variables. The reference group is the native-born. * ${ }^{* *},{ }^{* * *}$ denote significance at the $1 \%, 5 \%$ and $10 \%$ level, respectively.

Source: TREE.

160. In general, immigrant offspring have a higher tendency than the children of natives to leave the school system without any sort of upper-secondary qualification (see Figure 16). Around 25\% of offspring with parents from lower-income countries who participated in the 2000 PISA study did not obtain any upper-secondary degree within seven years after the end of obligatory schooling, whereas this applied to only $10 \%$ of the children of natives. The share among the children of parents from high-income countries amounted to about $15 \%$ for the native-born and $25 \%$ for young immigrants and was thus, likewise, considerably higher than among the children of natives.

Figure 16: Share of persons without upper-secondary education, seven years after the end of obligatory schooling (PISA 2000 cohort)

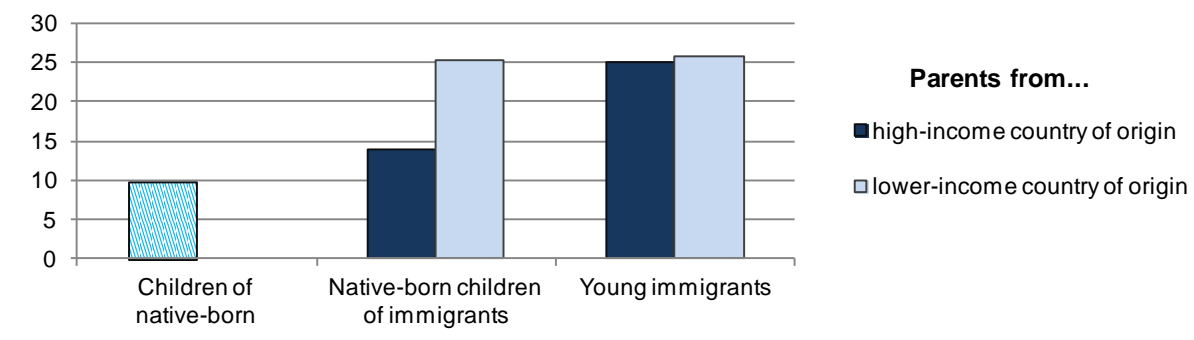

Source: TREE.

161. These differences can be analysed accounting for previous school performance and parental social background. In a regression analysis, the differences tend to become insignificant when both factors are taken into account. ${ }^{67}$ This partly explains the surprisingly unfavourable outcomes of offspring with parents from high-income countries, since the parents from the major origin countries Spain, Portugal and Italy have rather low socio-economic status on average (see Figure 14 above).

67 The results of the respective regression analysis are not reported here but are available from the Secretariat upon request. 
162. A particularly important group for policy are children who find themselves neither in employment nor in education or training (the so-called "NEET" group). Children of immigrants from lower-income countries, even after accounting for their lower PISA results and attainment level, have a much higher probability than children of natives to be in the NEET group seven years after the end of obligatory schooling (Table 13). The differences are particularly strong for men and indeed, their lower PISA results do not account for much of the disadvantage.

Table 13: Difference in the probability to be neither in education nor in employment (NEET), seven years after the end of obligatory schooling (PISA 2000 cohort)

\begin{tabular}{|c|c|c|c|c|c|c|c|c|c|c|c|c|}
\hline & \multicolumn{3}{|c|}{ Model 1} & \multicolumn{3}{|c|}{ Model 2} & \multicolumn{3}{|c|}{ Model 3} & \multicolumn{3}{|c|}{ Model 4} \\
\hline & All & Men & Women & All & Men & Women & All & Men & Women & All & Men & Women \\
\hline $\begin{array}{l}\text { Immigrant offspring with } \\
\text { parents from... }\end{array}$ & & & & & & & & & & & & \\
\hline high-income country & 2 & $14^{* * *}$ & 1 & 1 & $13^{* * *}$ & 0 & 1 & 5 & $-3^{*}$ & 1 & 4 & $-3^{*}$ \\
\hline lower-income country & $17^{* * *}$ & $13^{* * *}$ & $20^{* * *}$ & $13^{* * *}$ & $12^{* * *}$ & $8^{* *}$ & $13^{* * *}$ & $18^{* * *}$ & $9^{* *}$ & $27^{* * *}$ & $36^{* * *}$ & $-7^{* \star *}$ \\
\hline $\begin{array}{l}\text { apprenticeship } \\
\text { Interaction apprenticeship } \\
\text { * lower-income country } \\
\text { Controls } \\
\end{array}$ & & & & & & & 1 & $-5^{\star * *}$ & $6^{\star \star *}$ & $\begin{array}{c}2^{*} \\
-5^{\star \star *}\end{array}$ & $\begin{array}{c}-3 \\
-5^{\star \star \star}\end{array}$ & $\begin{array}{l}5^{\star \star *} \\
-2^{\star \star *}\end{array}$ \\
\hline PISA reading score & & & & $x$ & $x$ & $x$ & $x$ & $\mathrm{x}$ & $\mathrm{x}$ & $x$ & $x$ & $x$ \\
\hline Language region & $x$ & $x$ & $x$ & $\mathrm{x}$ & $\mathrm{x}$ & $x$ & $x$ & $x$ & $x$ & $\mathrm{x}$ & $\mathrm{x}$ & $x$ \\
\hline Gender & $x$ & & & $x$ & & & $x$ & & & $x$ & & \\
\hline
\end{tabular}

Note: The figures show the differences between the children of immigrants and the children of natives. They correspond to marginal effects after Probit estimation, calculated at the sample means of the respective variables. The reference group is the native-born. *, **,*** denote significance at the $1 \%, 5 \%$ and $10 \%$ level, respectively. "Apprenticeship" refers to having completed apprenticeship training. The sample is restricted to children who obtained at least ISCED 3 level.

Source: TREE.

163. Whereas only about $5 \%$ of children with native-born parents were neither in employment nor in education seven years after the end of obligatory schooling, this applied to almost $20 \%$ of youth with parents from lower-income countries, even for those who managed to obtain an upper-secondary qualification (see Figure 17). 
Figure 17: Share of youth in NEET seven years after the end of obligatory schooling, by parental origin and educational attainment

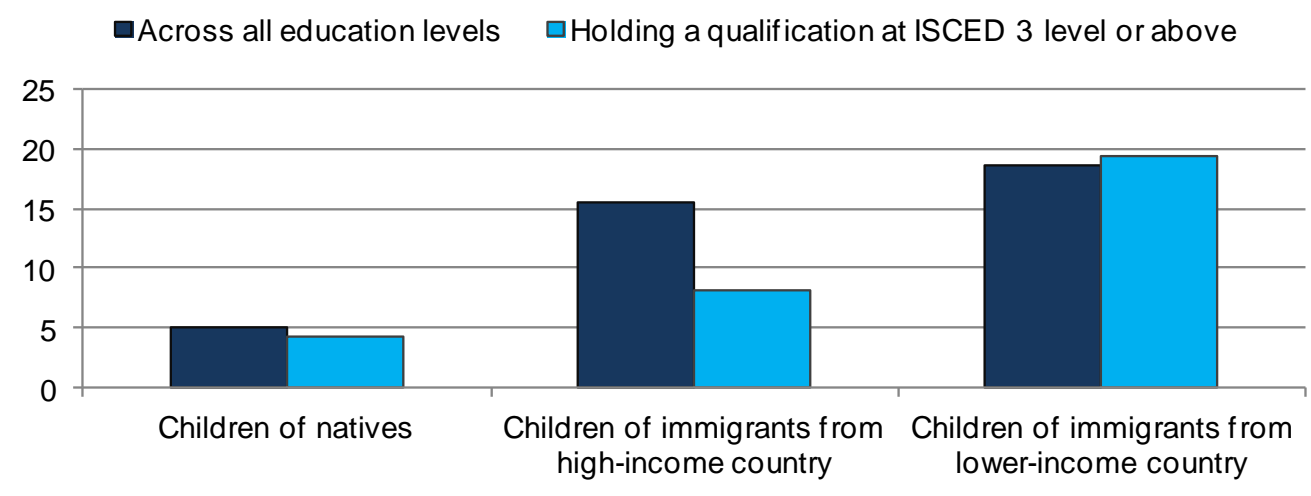

Source: TREE.

164. In summary, poorer school performance at the end of obligatory schooling and an unfavourable socio-economic background lead to a perpetuation of disadvantages throughout upper-secondary education for the children of immigrants from lower-income countries, which results in an over representation among youth without an upper-secondary diploma and among NEET. Finding ways to better integrate the children of immigrants during pre-schooling and the early years of compulsory education, and decreasing performance differences such as those found by PISA before the end of obligatory schooling seems to be a crucial element in preventing immigrant offspring from falling behind in their educational careers. ${ }^{68}$

\section{School-to-work transition process and labour market outcomes}

165. During the school-to-work transition process, it is not only previous school performance that matters, but also the transition process as such, that is, the duration of job search and the channels used to find a first employment.

166. Data from the TREE panel show that the native-born children of immigrants from high-income countries pursue a transition process broadly similar to that of the children of Swiss-born parents (see Figure 18). On average, they spend around the same number of years in the education system and have a similar share of youth in employment seven years after the end of obligatory schooling (between 40 and $50 \%$ ). Children of immigrants from lower-income countries, in turn, tend to leave the education system and to take up employment - earlier. incite early immigration by imposing that children above the age of twelve have to migrate to Switzerland within one year. It is currently under discussion to further lower this age. 


\section{Figure 18: Transition from education into employment, children of natives and native-born children} of immigrants (PISA 2000 cohort)

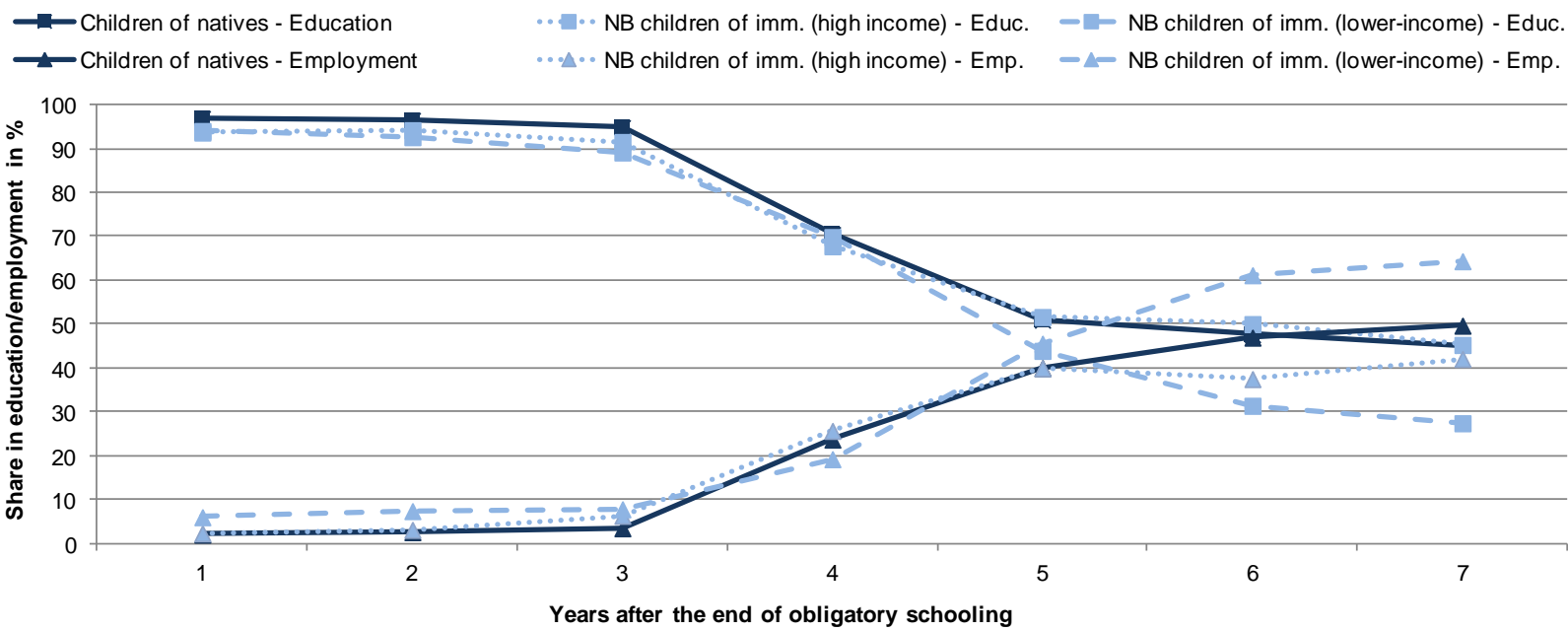

Note: "NB" = native-born.

Source: TREE.

167. When looking only at the individual employment situation of participants in the TREE panel two years after the highest degree was obtained, there does not seem to be any difference in outcomes vis-à-vis children of natives, not even for children of immigrants from lower-income countries. ${ }^{69}$ The majority of those who had completed a degree two years earlier and were not in full-time education anymore had participated in vocational training. Equipped with company-based apprenticeship training, they managed the transition process rather well, which highlights the success of this pathway in ensuring employment for children of immigrants. In this respect, personal networks as providers of such channels are one factor that shapes school-to-work transition, beyond the mere quantity and quality of education. ${ }^{70}$

168. Analysis based on data from the 2009 Swiss Labour force Survey (Enquête suisse sur la population active, ESPA) which contains a special module on the school-to-work transition suggests that formal channels of job search play a much greater role for native-born children of immigrants from lowerincome ocuntries than for any other group. The differences are even more pronounced among participants in the TREE panel (see Figure 19). Here, immigrant offspring from lower-income countries appear considerably less likely to have found their first job through an informal channel. Differences observed in both the ESPA and the TREE survey data become, however, insignificant, once previous education is accounted for. ${ }^{71}$ Thus, although the Labour Force Survey and the TREE panel suggest that there are differences in the ways the children of immigrants from lower-income countries find their first jobs, these differences appear to stem primarily from differences in education.

Students in the panel differ in their educational careers; they are going back and forth between education and employment. Due to the sample size, it is impossible to control for all of these factors by using more complex statistical models. Instead the analysis focuses on the employment situation for each respondent in the second year after the highest reported educational degree in order to achieve a solid level of comparability. At this time, students who chose to continue with tertiary education have, for the most part, entered the respective institutions and those who chose to enter the labour market have had some time to adjust.

The reliability of survey responses regarding the degrees obtained and the dates of graduation are questionable and it is therefore difficult to assess the overall representativeness of the result.

71 The corresponding regression tables can be made available on request. These results are to be taken with caution as sample sizes are rather small. 
Figure 19: Channels through which 20-29 year olds found their first jobs, by migration background (PISA 2000 cohort)

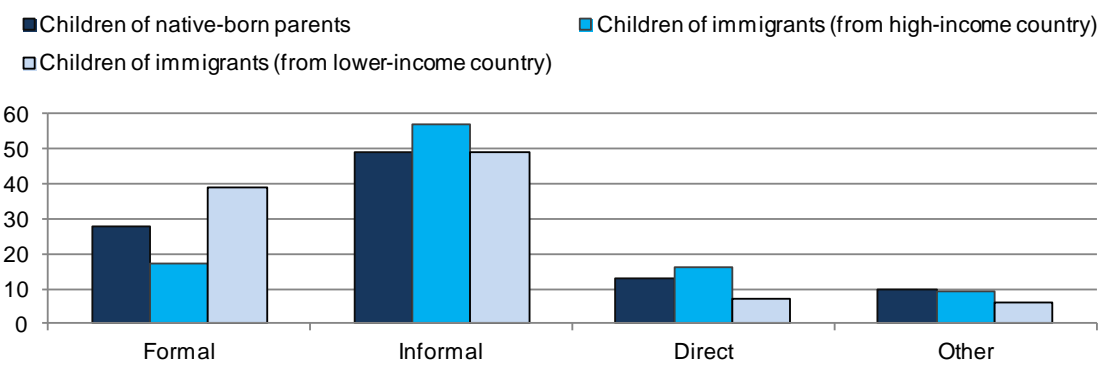

Note: Native-born immigrant offpring and young immigrants are grouped together due to restrictions in the sample size. "Formal" refers to the use of the employment office or private employment agency; "informal" refers to personal networks; "direct" refers to applications to employers without intermediation of a third agent.

Source: TREE.

169. In addition to networks, other factors may hamper the school-to-work transition of children of immigrants such as discrimination (see above) and lack of knowledge about labour market functioning. All of these could lead to a longer duration of job search. In this case, the children of immigrants could be expected to take more time than the children of natives to find employment after having obtained their highest degree. This actually seems to be the case, as participants in the TREE panel whose parents came from lower-income countries needed on average almost twice as long to find a first job and this difference remains relatively robust, even after controlling for education and PISA scores. ${ }^{72}$

170. Turning to the employment of the 20-29 year olds who are not currently in full-time education, native-born children of immigrants from high-income countries seem to be integrating rather well into the Swiss labour market, having even slightly better outcomes than children of the native-born (see Table 14). More than $90 \%$ of the 20-29 year olds have successfully made their way into employment. Unemployment is slightly lower than for the children of natives. The picture is different for native-born offspring of parents from lower-income countries, in particular for young men. They have substantially lower employment and higher unemployment rates. Both figures differ by 15 to 20 percentage points from the rates observed for the children of natives. For women, in turn, only small disadvantages are observed.

Table 14: Employment-population ratios and unemployment rates by migration background and gender, aged 20-29, not in education, 2009

\begin{tabular}{|l|cc|cc|}
\hline & \multicolumn{2}{|c|}{ Employment rate } & \multicolumn{2}{|c|}{ Unemployment } \\
& Men & Women & Men & Women \\
\hline $\begin{array}{l}\text { Children of native-born } \\
\text { Native-born children of immigrants with parents from.... }\end{array}$ & 89 & 87 & 7 & 7 \\
$\quad$ & 4 & 5 & -1 & -2 \\
$\quad$ high-income country & -16 & -2 & 18 & 4 \\
\hline
\end{tabular}

Note: The figures for the children of immigrants display the percentage-points difference relative to the children of native-born. A negative figure for the employment rate means that children of immigrants have a lower employment rate than the children of natives.

Source: Swiss Labour Force Survey, Swiss Federal Statistical Office.

72 These results should be interpreted with caution: Not only are the samples small, but there is also a problem with sample selectivity. It could, for instance, be assumed that individuals who searched longer simply did not enter the labour market at all. Persons in tertiary education could be more likely to have had shorter search times and immigrant offspring are under-represented in this group. Such a bias could lead to an overestimation of the difference. Note also that the duration of job search is rather short in Switzerland: it is on average only about three months for the children of natives. 
171. As seen above, the much less favourable employment outcomes of male native-born immigrant offspring with parents from lower-income countries cannot be fully explained by their higher risk of not completing upper-secondary education. Even among those who had attained a qualification at upper secondary level or higher within seven years after the end of obligatory schooling, children with parents from lower-income countries of origin were still much more likely to be neither in education nor employment (see Table 13 above).

\section{Policy intervention to support the school-to-work transition}

172. Given the precarious employment prospects of youth without an upper-secondary degree in Switzerland and the overrepresentation of immigrant offspring in this group, policy intervention that helps to master the step from lower- to upper-secondary education appears to be of particular importance. Indeed, Switzerland maintains a broad framework to support youth in this transition process. The framework has been overhauled by the OFFT since 2002, to better account for the needs of youth having particular difficulties to integrate into regular apprenticeships. In all of these, children of immigrants are among the target groups.

173. The federal government and the cantons have committed to raising the share of 25-year-olds holding an upper-secondary degree from $90 \%$ in 2004 to $95 \%$ by 2015 . To this end, most cantons are currently in the process of developing a case management programme that is funded by the OFFT with CHF 35.5 million until 2015. The cantons are expected to establish case management bodies to better coordinate already existing measures of career guidance. Moreover, case managers are to identify youth with particular difficulties when they are still in lower-secondary education and to assure that they obtain an upper secondary qualification. Although no data on participant characteristics is available yet, immigrant offspring can be expected to be strongly represented in the target group which is defined as youth confronting "multiple problems" during the transition into upper-secondary education. ${ }^{73}$

174. In the course of the recent overhaul of Swiss regulations for vocational education and training, the cantons have been engaged in establishing a low-threshold alternative to regular three-to-four-year apprenticeships (see OECD, 2009). These apprenticeship programmes take only two years and lead to a certificate that qualifies for lesser-skilled occupations. For apprentices at the risk of dropping out of this measure, individual counselling is available that is partly funded from federal resources. In exceptional cases, it is also possible to extent the duration of apprenticeships.

175. Finally, the OFFT also funds so-called transformational measures that are implemented by the Cantons to bridge the transition from lower-secondary education into vocational training for youth who could not find an apprenticeship right after the end of obligatory schooling. The programmes usually take up to one year and either focus on school-based general education or on practical training that involves an internship (pré-apprentissage). Within this framework, special language and integration courses are offered to young immigrants with substantial language deficits. All these measures aim to prepare for a transition into regular apprenticeships.

176. Apart from the support framework provided by the OFFT, there are also measures of active labour market policy available to youth, financed by the unemployment insurance. However, young immigrants who completed part of their education abroad may not be eligible for the whole range of ALMP measures. ${ }^{74}$ The unemployment insurance, however, makes an exception for youth who have spent

\footnotetext{
73 Across cantons there is some variety in the definition of these "multiple problems" (see OFFT, 2010b). As the programme is still in its initial phase, there has not yet been any rigorous evaluation of its success or the group of participants. An evaluation of the project development and implementation has been conducted by Landert (2011).
} 
at least their final year of schooling in the Swiss education system and allows them to take part in the Motivation Semester programme (Box 6). ${ }^{75}$ Nevertheless, the cantons are required to contribute $50 \%$ to the costs of these "exceptional participants" and the latter do not receive any unemployment support during programme participation. They may thus be tempted to take up (low-skilled) jobs to earn some money quickly rather than invest into a better education, which increases their risk to become NEET thereafter. The above analysis suggests that this seems to be a rather widespread phenomenon among children of immigrants from a disadvantaged background.

\section{Box 6. The Motivation Semester}

The Motivation Semesters are a Swiss active labour market programme, running since 1994. They are targeted at young persons (aged 15-25 years) who have finished or left school and are unemployed, either because they have not found a place in the apprenticeship system, have abandoned an apprenticeship or have no career plans whatsoever. While the programme is not designed specifically for immigrants, many of those meeting the criteria for participation are children of immigrants.

The Motivation Semester aims to fill in gaps in formal training, to restore confidence and to prepare participants for regular employment. This may include language training. The focus is less on technical skills - such as operating machinery - than on softer skills such as punctuality, attention to quality and the ability to work in a team. The programmes are designed to run six months on a full-time basis (40 hours a week), although they may be extended. While apprenticeships generally start in August, enrolment in the Motivation Semester can occur throughout the year. Participants who are eligible to receive unemployment benefits continue to receive them during the Motivation Semester, while those who do not fulfill the eligibility criteria do not receive financial support during the measure.

In 2011, there are 70 such programmes across Switzerland (49 in German-speaking Switzerland, 18 in Frenchspeaking Switzerland, and 3 in Ticino). Roughly 2000 persons (i.e., almost $2.5 \%$ of a youth cohort) participate each year and expenses per participant amounted to almost 40000 Swiss Francs in 2009, making the measure rather costly. The Motivation Semesters are financed by the unemployment insurance. ${ }^{76}$ They are tendered to third-sector organisations - generally training organisations or social enterprises. The success of the Motivation Semester relies partly on the relationship of trust between the training institute and local employers. Individual casework is involved to place and support each student in the internships which are meant to lead to an apprenticeship. The structure of each Motivation Semester varies, as does the individual training and placement offered to participants.

In Thun (in the Canton of Bern), for instance, a foundation has been running a Motivation Semester since 2003. Participants are referred by the public employment service - generally those with a poor educational background - if they have no prior work experience. Out of 53 places and 100 participants (due to the six-month duration) annually, about half are children of immigrants. The programme consists of two days of schoolwork, covering language, mathematics, social studies, sports and general knowledge. The other three days are spent in a PVC fabric cutting workshop. Students are pushed to start an internship of 2-6 months with a company as soon as possible. After completion of the internship, companies are requested to take on the intern as an apprentice. In Thun, about $60 \%$ of participants end up in an apprenticeship, $15 \%$ are rejected, and $25 \%$ drop out of the programme.

The Motivation Semester thus represents a significant investment and seems to prevent unemployed youth from falling out of the system. It reflects the need for individual support during coursework and the internship. The success rates for the programmes vary, depending on the local economic situation and the characteristics of the youth involved, but on average, around two-thirds of participants start an apprenticeship or another type of further education after the end of the programme (Duell et al., 2010). The measure thus appears to be rather effective in this respect.

Switzerland for a period of ten years. This reflects the objective of promoting early family migration, but also has the effect of excluding young immigrants who have arrived at the end of primary schooling or thereafter.

While the Motivation Semester targets unemployed youth in general, many cantons run additional pre-motivation semesters targeting beneficiaries of social assistance who have substantial language and integration problems and who are not yet ready or eligible to participate in the regular Motivation Semester (Spycher et al,. 2007).

76 Like other measures in the realm of active labour market policy, the motivation semester springs from article 59d of the Unemployment Insurance Law. The Motivation Semester is meant, however, to lead to an apprenticeship rather than job placement. 
177. In summary, the good overall performance of the children of immigrants in the past has masked significant problems faced by the children of immigrants from lower-income countries, and the number of these is growing rapidly. There are a number of well-designed programmes in place, but too little attention is paid to early intervention which is crucial for education outcomes and the school-to-work transition. 


\section{Assessment and recommendations}

Switzerland has a

large share of immigrants, and the overall picture for labour market integration is favourable.

This reflects both relatively full employment in Switzerland and the fact that most immigrants have come from neighbouring countries.

\section{There are many recent migrants from the $E U$, and these are generally well integrated into the Swiss labour market.}

\section{There are some signs of a worsening of the labour market situation of immigrant women from lower-income countries, and this should be watched closely.}

About $27 \%$ of Switzerland's population is foreign-born, which is - together with Luxembourg and Australia - one of the largest shares in the OECD. On the aggregate, the key labour market integration indicators for immigrants are quite favourable in international comparison. Both immigrant men and women in Switzerland have among the highest employment rates in the OECD, and this holds also for the native-born offspring of immigrants. Nevertheless, and in spite of the low overall unemployment rate in Switzerland, unemployment for some immigrant groups is non-negligible.

The broadly favourable integration picture compared with other OECD countries seems to be essentially due to two factors. First, overall labour market conditions in Switzerland are good. Second, in contrast to most other OECD countries, the bulk of migration - both in the past and recently - has been from high-income countries, in particular from the neighbouring countries of Germany and Italy which are the two most important origin countries. Within the group of the lower-income countries of origin, the former Yugoslavia and its successor countries account for almost half of all immigrants, with Turkey accounting for an additional 12\%. The bulk of migration has been for work and subsequent family migration, whereas humanitarian migrants - who tend to have particular difficulties in integrating into the labour market in all countries - accounted for a smaller part than elsewhere. However, this latter group is non-negligible in terms of numbers, and indeed Switzerland has been one of the main destination countries for asylum seekers in the OECD over the past two decades.

Since 2002, when it gradually introduced freedom of movement with the EU member countries, Switzerland experienced a large influx of immigrants from the EU. Today, more than five percent of the Swiss resident population at working age consists of recent arrivals, defined as immigrants with less than five years of residence. Within this group, there is considerable diversity in the socio-demographic composition of the flows across origin countries, and immigrants from Portugal in particular also face high unemployment. Generally, however, recent migrants from the enlarged EU have highly favourable labour market outcomes. In particular, they are on average more often found in jobs which match their formal qualification level than the native-born, which suggests that their skills match well with labour demand.

One group for which labour market outcomes are not only unfavourable but have also deteriorated in recent years are immigrant women from lower-income countries, in particular recent arrivals. This is a worrying development which requires careful monitoring. Indeed, immigrant women tend to be out of the focus of integration efforts, as they are often out of the labour market and not benefit-dependent. For this group, the recent reduction in the co-financing (through the unemployment insurance) of active labour market policy measures for persons not receiving unemployment aid could well have the effect of a further reduction in the already limited provision of integration measures unless social assistance steps in. In contrast to humanitarian migrants, family migrants generally do not receive standard integration support after arrival, although they may obtain some support regarding basic language training. In 
The poor outcomes of recent humanitarian migrants call for more structured integration measures.

Cantons' incentives for the rapid labour market integration of humanitarian migrants need to be strengthened...

...and remaining legal obstacles for labour market access removed.

\section{The framework for integration is relatively complex and opaque...}

contrast, in other OECD countries, introduction measures are increasingly made available to all new arrivals, and/or activities by non-governmental organisations compensate for the lack of mainstream offers. Both of these are less prominent in scale and scope in Switzerland. Since a better integration of immigrant women from lower-income countries in the Swiss labour market can also have important spill-over effects on their children, extending integration measures to them is worthy of serious and urgent consideration.

One group which has much lower labour market outcomes currently than in the past and which also has poor outcomes in international comparison are recently-arrived humanitarian migrants. The reasons for this are not entirely clear. In any case, this is a group which needs targeted integration measures, and other OECD countries have implemented structured integration programmes for this group. These last for up to three years and seem to have met with some success. The better outcomes of recent humanitarian arrivals in countries like Denmark and Norway with structured programmes targeted at labour market integration suggest that much could be gained if Switzerland were to follow such an approach.

Although social assistance is a sub-federal competence, it is funded by the Confederation to the cantons for refugees during the first five years of residence. For the large and growing group of the provisionally admitted, the Confederation pays during the first seven years before persons in this group come under cantonal/communal responsibility. In addition, provisionally admitted persons receive less than the regular social assistance, and it appears that this has sometimes been accompanied with less effort to integrate this group. This implies that cantons have little incentive to integrate humanitarian migrants into the labour market during the first five to seven years. But if immigrants are not adequately prepared by then, they find it extremely difficult to enter the labour market successfully and empirical evidence from other OECD countries suggests that early labour market entry is a crucial determinant for integration in the long term. Incentives for rapid labour market integration of humanitarian migrants thus need to be strengthened.

Since 2008, provisionally admitted humanitarian migrants have access to the labour market without a labour market test. However, and in contrast to other migrant groups, they still need a work permit which they generally obtain if they manage to find an employer willing to hire them. Abolishing the requirement of a separate work permission procedure would thus serve to reduce red tape and facilitate labour market integration. In any case, employers should be better informed about the possibilities to hire these migrants.

As federal action in the domain of integration has been very limited until recently, most integration measures were implemented at the cantonal and municipal levels, reflecting the principle of subsidarity. While this has contributed to a flexible approach to integration, it has also led to strongly differing levels of service provision between cantons. While this is true for many policies in Switzerland, and indeed also concerns many services for nonimmigrants, for humanitarian migrants this raises questions of horizontal equity since they cannot freely choose their canton of residence and have limited mobility within Switzerland. 
...and this is mainly due to the fact that access to integration services depends on many factors.

The unequal level of service provision across cantons calls for more policy coordination.

Wage subsidies seem to be a particularly effective integration measure for immigrants, but they rarely benefit from them.

\section{As better data are now available, tackling the research deficit should be part of a coherent integration policy.}

Language training needs to be stepped up, with a clearer focus on the labour market.
The rather complex and opaque nature of the Swiss integration framework is perhaps its single most important shortcoming. It is mainly due to the fact that access to integration services depends on a great variety of factors - the canton of residence, the type of permit and the duration of residence, receipt (or not) of social insurance payments and the pillar of social insurance (unemployment, invalidity or social assistance) under which the migrant eventually falls.

The apparently unequal levels of integration service provision across cantons and the fact that some groups of migrants are not eligible for mainstream services call for more policy co-ordination, both within and across cantons. Common minimum standards should be implemented to make sure that immigrants receive measures according to their needs, independent of their location in Switzerland, of their permit type and of the type and degree of benefit/insurance payment which they may receive or not. In addition, exchanges of good practices between cantons and municipalities should be strengthened.

For such an exchange to make sense, an evaluation of what works and what does not is a precondition, which implies that research and evaluation have to be built into new programmes. Indeed, in spite of a well-developed overall evaluation culture in Switzerland, there has been little specific evaluation of labour market policy regarding immigrants and their children. This reflects mainstreaming of integration policies, but neglects that the effect of active labour market policy on immigrants may differ from that on the native-born. One rather solid result of past evaluations - both in Switzerland and in other OECD countries - has been that wage subsidies are particularly beneficial for immigrants. Yet, they rarely benefit from this measure in Switzerland.

The lack of specific programme evaluation regarding immigrants also holds for research on integration more generally, which is surprising given the significant and longstanding presence of immigrants and their children in Switzerland. The lack of quantitative research has been partly due to a lack of data. As more and better datasets - including longitudinal ones - are now gradually becoming available, tackling the deficit in research and programme evaluation regarding the labour market integration of immigrants and their children should be an important element for a better informed and targeted policy making.

There is international evidence that language training can facilitate the integration of immigrants. It is difficult to assess language training in Switzerland, since most of it is provided by a range of different services at the cantonal level, with little interaction between them. The limited information which is available on language training suggests that this is less frequently provided than in other OECD countries and is not associated with good labour market outcomes for those who have followed it. The reasons for this merit closer scrutiny and corresponding policy action should be taken. In any case, there seems to be a case for both increasing coverage of language training and for more targeted job- or vocation-specific language training. In order to standardise language training throughout Switzerland, a common framework for language training should be considered. 
Naturalisation should be facilitated, as this promotes immigrants' integration.

To promote mobility cantonal and municipal residence requirements should be reviewed.

\section{Integration measures need to account better for the skills of immigrants.}

\section{The transparency of the assessment and recognition of foreign credentials has to be improved, and all professions need to be covered.}

The creation of a one-
stop-shop for all
assessment and
recognition requests
would help in this
respect.

Switzerland has one of the most restrictive naturalisation policies in the OECD, reflecting the view that naturalisation is a certification of a successfully completed integration process rather than an instrument to promote it. Yet, empirical evidence suggests that naturalisation is associated with better labour market outcomes for immigrants and their children in Switzerland, in particular for immigrants from lower-income countries regarding access to higher-skilled jobs and the public sector. These findings and further longitudinal evidence from other OECD countries suggest that much could be gained from facilitating access to Swiss nationality. In any case, there are costs involved in maintaining the current restrictions and awareness about this and about the benefits of obtaining Swiss citizenship for those migrants who are eligible for it should be raised.

In addition to the federal duration-of-residence requirement of twelve years for the ordinary naturalisation procedure, there are cantonal and municipal residence requirements. These make acquisition of nationality more difficult and can be a disincentive to migrants' mobility within Switzerland. A reform of the Swiss naturalisation law is in preparation which should remove some of the most significant shortcomings, namely through an overall harmonisation of duration-of-residence criteria at cantonal and municipal levels and a reduction of the Federal residence requirement to eight years. However, even if the planned reform goes through, the Swiss system would still remain restrictive in international comparison, in particular for the many native-born children of immigrants of whom currently only few have Swiss nationality.

Most available integration measures are targeted at lesser-skilled employment. The incidence of "overqualification", that is, of migrants working in jobs below their formal education levels, is high for migrants who have obtained their degrees in lower-income countries, and this also seems to hold after controlling for objective skills measures.

The assessment and recognition of foreign qualifications seems to be one of the weak points of the Swiss system. Although the fees involved are low and the process is rather quick, the system lacks transparency, and knowledge about it is limited even among integration service providers. In addition, for a number of occupations it is currently not possible at all to obtain assessment and recognition of foreign qualifications and work experience, and these gaps in the system should be fixed. Improving the assessment and recognition system is important, since the vast majority of immigrants with degrees have obtained these abroad. The process outcome seems to be accepted on the labour market, since immigrants who have obtained formal recognition have better labour market outcomes. However, few immigrants with tertiary degrees from non-EEA countries actually seek assessment and recognition. It is unclear if this is because they are not aware of the offer or whether they are discouraged from applying because they are unlikely to obtain recognition.

The Federal Office for Professional Education and Technology already accepts "preliminary applications" for recognition in all domains and levels and provides information on the competent bodies. A further step would be the creation of a one-stopshop which formally accepts all applications and hands over those outside of its domain to the competent authorities rather than returning them back to the applicant with advice as to which office he or she needs to apply to. This would be an important move towards enhancing transparency. In addition, the finding that recognition helps in getting good jobs should be made more widely known to immigrants. 
Bridging offers and mentorship for skilled migrants should be implemented more broadly, in cooperation with employers.

\section{There is a high incidence of discrimination in Switzerland, and awareness of this should be raised.}

\section{The legal and institutional framework for anti- discrimination lags greatly behind that in other OECD countries...}

...and strengthening the framework should be complemented with other measures.

The apprenticeship system appears to be working well for the children of immigrants, but their low completion rates merit further attention.
There are few bridging courses for immigrants and the focus on rapid labour market integration for both refugees and the unemployed in general conflicts with bridging offers. Access in particular to highly-skilled employment is often provided through networks, of which immigrants have less. Here, mentorship programmes seem to be an effective tool, but their scale and scope is limited to date. Immigrants would also seem to benefit disproportionally from a wider provision of accreditation of prior learning (APL), which is now gradually developing in Switzerland. Care should be taken that the APL measures which are currently being developed will actually reach immigrants and meet their needs. Such tools should be provided more broadly, in co-operation with employers.

Testing studies have pointed to a high incidence of discrimination in hiring. They suggest that to get invited to a job interview, children of immigrants educated in Switzerland may have to submit up to five times as many applications as children of natives with otherwise identical CVs. The relatively low incidence of unemployment among immigrant offspring suggests that the latter compensate for this discrimination by submitting more applications. The high degree of discrimination is also partly masked by overall good labour market conditions; and in the public debate, there is little concern about the possibility of discrimination in hiring. Nevertheless, children of immigrants need twice as long to find a job as natives with the same educational outcomes. It is thus important to raise awareness of this issue.

The legal and institutional framework against discrimination lags greatly behind that of most other OECD countries, and nationality-based discrimination is currently not illegal, except for immigrants from the EU. In addition, the counselling and advice structures are currently less well equipped than in other countries, and they may only provide legal advice but cannot take legal action. As a result, the number of cases that they treat is negligible compared to the level of discrimination revealed in testing studies.

It is thus important that both the legal and the institutional framework against discrimination be strengthened, and then be made more widely known to immigrants. Such a reform could be complemented by more pro-active diversity measures aimed at the diversification of recruitment channels by employers, which are currently lacking in Switzerland. The public sector, where immigrants are underrepresented, also needs to be involved in this. Diversity tools such as anonymous CVs, diversity labels and diversity consultants have recently been implemented in a number of OECD countries.

The OECD's Programme for International Student Assessment (PISA) has shown that at the age of 15 , children of immigrants have much lower educational outcomes in Switzerland than children of natives, and the differences are larger than in many other OECD countries. Longitudinal analysis suggest that the school and training system manages to provide these children of immigrants still with relatively good qualifications at a later stage, and the apprenticeship system seems to be working particularly well for them. However, the children of immigrants are less likely to complete an apprenticeship. The reasons for this should be investigated further, and subsequent remedial action taken. 
Children of loweducated immigrants seem to have more integration difficulties now than previous cohorts of immigrant offspring, and tackling this should become a priority for policy.

All young immigrants need to get equal access to active labour market policy measures for youth.
Although the school-to-work mechanism works well for most children of immigrants, there are some signs that more recent cohorts of children of immigrants have more difficulties now than previous ones, and the many children of immigrants born abroad also have less favourable outcomes. This particularly concerns children of immigrants with parents from lower-income countries, who find themselves often neither in employment nor in education or training a few years after having left school. As children of immigrants from lower-income countries are now entering the labour market in large numbers, it is important that improving their outcomes becomes a priority for policy.

There is an extensive framework in place to smoothen the school-to-work transition process for youth in need of support. However, regarding most active labour market policy measures, youth are often only eligible if they have resided in Switzerland for at least ten years. In addition, such immigrant children benefiting from exempted programmes, notably the so-called "Motivation Semester", do not receive unemployment benefits - unlike native children - and may thus be tempted to enter the labour market directly and then take up low-skilled employment instead. They then run the risk of being NEET (neither in employment nor in education or training) at a later stage, and the incidence of NEET is indeed high for this group. A first step in tackling this important challenge would be to ensure that all immigrant children have the same incentives to participate as native children.

One area which seems to entail particular benefits for the children of immigrants is pre-primary education, as research from a number of OECD countries suggests. However, pre-school education is currently greatly underdeveloped in Switzerland, in particular at the ages of three and four which are a critical first stage for integration. A wider and better targeted provision of pre-school education at these ages, along with early language support measures, would seem to entail important benefits. Beneficiaries would not only be the children of immigrants themselves, but also their mothers whose employment is much more strongly linked with childbearing than for native mothers. 


\section{BIBLIOGRAPHY}

Avenir Suisse (ed.) (2008), Die neue Zuwanderung. Die Schweiz zwischen Brain-Gain und Überfremdungsangst, Verlag Neue Zürcher Zeitung, Zürich.

BASS (2006), Ausländer/innen, Erwerbslosigkeit und Arbeitslosenversicherung, Seco Publikation Arbeitsmarktpolitik No. 16., State Secretariat for Economic Affairs, Bern.

Becker, L., T. Liebig and A. Sousa-Poza (2006), "Migration Policy and Industrial Structure: The Case of Switzerland”, International Migration, Vol. 46, No. 2, pp. 81-107.

Caille, J.P. (2001), "Scolarisation à 2 ans et réussite de la carrière scolaire au début de l'école élémentaire", Éducation \& formations, Vol. 60, pp. 7-18.

Card, D. (2004), “Is the New Immigration Really so Bad?", The Economic Journal, Vol. 115, No. 507, pp. 300-323.

CFR (1996), Stelllungnahme der Eidg. Kommission gegen Rassismus zum Drei-Kreise-Modell des Bundesrats über die schweizerische Ausländerpolitik, Bern.

Cueni, D. and G. Sheldon, (2011), Arbeitsmarktintegration von EU/EFTA-Bürgerinnen und Bürgern in der Schweiz. Studie im Auftrag des Bundesamtes für Migration. Forschungsstelle für Arbeitsmarkt- Und Industrieökonomik, Bâle.

de Coulon, A. and Y. Flückiger (2000), "Analyse économique de l'intégration de la population étrangère sur le marché suisse du travail", in P. Centlivres and I. Girod (eds.), Les défis migratoires: actes du colloque CLUSE. Les défis migratoires à l'aube du troisième millénaire, Seismo, Zurich, pp. 109 119.

de Coulon, C. and K. Gäuman (2011), Rapport SOPEMI 2009, Office fédéral des migrations, Berne.

D'Amato, G. (2009), "Switzerland: A Multicultural Country Without Multicultural Policies?", in S. Vertovec and S.Wessendorf (eds.), The Multiculturalism Backlash, Routledge, London.

Duell, N., P. Tergeist, U. Bazant and S. Cimper (2010), Activation Policies in Switzerland, OECD Social, Employment and Migration Working Paper No. 112, Paris.

Federal Council (2010), Bericht zur Weiterentwicklung der Integrationspolitik des Bundes, Bern.

Fibbi, R. (2005), “Mesures de lutte contre les discriminations à l'embauche“, Forum suisse pour l'étude des migrations et de la population, Neuchâtel.

Fibbi, R., et al. (2010), "Les Portugais en Suisse”, Study commissioned by the Swiss Federal Office for Migration.

Fibbi, R., M. Lerch and P. Wanner (2006), "Unemployment and Discrimination against Youth of Immigrant Origin in Switzerland - When the Name Makes a Difference“, Journal of International Migration and Integration, No. 7, pp. 351-366. 
Fibbi, R., B. Kaya and E. Piguet (2004), Nomen est omen: Quand s'appeler Pierre, Afrim ou Mehmet fait la différence, Direction du programme PNR43 - FNRS, Bern.

Fibbi, R., B. Kaya and E. Piguet (2003), «Le passeport ou le diplôme ? » Étude des discriminations à l'embauche des jeunes issus de la migration. Neuchâtel: Forum suisse pour l'étude des migrations Rapport de Recherche 31.

Fritschi, T. and T. Oesch (2008), «Volkswirtschaftlicher Nutzen von frühkindlicher Bildung in Deutschland. Eine ökonomische Bewertung langfristiger Bildungseffekte bei Krippenkindern», Study commissioned by the Bertelsmann Foundation.

Gerfin, M. and M. Lechner (2002), “A Microeconometric Evaluation of the Active Labour Market Policies in Switzerland“, Economic Journal, No. 112, pp. 854-893.

KEK-CDC Consultants and Federal Office for Migration (2008), Arbeitsmarktintegration von Flüchtlingen und Vorläufig Aufgenommenen - Studie über erfolgversprechende Faktoren, Bern.

Körner, H. (1990), Internationale Mobilität der Arbeit, Wissenschaftliche Buchgesellschaft, Darmstadt.

Krause, K. and T. Liebig (2011), The Labour Market Integration of Immigrants and their Children in Austria. OECD Social, Employment and Migration Working Paper No. 127, Paris.

Lalive, R., J.C. van Ours and J. Zweimueller (2002), The Impact of Active Labour Market Programs on the Duration of Unemployment, Institute of Empirical Research in Economics, University of Zurich, Working Paper No. 41.

Landert, Charles (2011), Projet national case management «Formation professionnelle » : Rapport sur l'évaluation de la mise en œuvre, Bern.

Liebig, T. (2009), Jobs for Immigrants: Labour Market Integration in Norway. OECD Social, Employment and Migration Working Paper No. 94, Paris.

Liebig, T. (2002), Switzerland's immigration experiences: lessons for Germany?, Research Institute for Labour Economics and Labour Law, University of St. Gallen, Discussion Paper No. 76, St. Gallen.

Liebig, T. and F. von Haaren (2011), "Citizenship and the Socioeconomic Integration of Immigrants and their Children: An Overview across EU and OECD Countries". In OECD (ed.), Naturalisation: A Passport for the Better Integration of Immigrants? OECD Publishing, Paris.

Liebig, T. and S. Widmaier (2010), "Overview - Children of Immigrants in the Labour Markets of OECD and EU Countries", in OECD (ed.), Equal Opportunities? The Labour Market Integration of the Children of Immigrants, OECD Publishing, Paris.

Mahnig, H. (ed.) (2005), Histoire des politiques d'immigration, d'intégration et d'asile en Suisse, Seismo, Zurich.

Nekby, L. (2008), Active Labor Market Programs for the Integration of Youths and Immigrants into the Labor Market - The Nordic Experience, Report for the UN Economic Commission for Latin America and the Caribbean (ECLAC), mimeograph. 
Niederberger, J.M. (2005), "Le développement d'une politique d'intégration suisse“, in H. Mahnig (ed.), Histoire des politiques d'immigration, d'intégration et d'asile en Suisse, Seismo, Zurich, pp. 255-287.

Niederberger, J.M. (2004), Ausgrenzen, Assimilieren, Integrieren - Die Entwicklung einer schweizerischen Integrationspolitik, Seismo, Zurich.

OECD (forthcoming), Economic Survey Switzerland 2011, OECD Publishing, Paris.

OECD (2011a), Naturalisation: A Passport for the Better Integration of Immigrants? OECD Publishing, Paris.

OECD (2011b), International Migration Outlook 2011, OECD Publishing, Paris.

OECD (2010a), Equal Opportunities? The Labour Market Integration of the Children of Immigrants, OECD Publishing, Paris.

OECD (2010b), Economic Survey Switzerland 2009, OECD Publishing, Paris.

OECD (2009), Learning for Jobs: Switzerland, OECD Publishing, Paris.

OECD (2008a), International Migration Outlook, OECD Publishing, Paris.

OECD (2008b), Jobs for Immigrants (Vol. 2), OECD Publishing, Paris.

OECD (2008c), OECD Employment Outlook, OECD Publishing, Paris.

OECD (2007), Jobs for Immigrants (Vol. 1), OECD Publishing, Paris.

OECD (2006a), Starting Strong II: Early Childhood Education and Care, OECD Publishing, Paris.

OECD (2006b), Economic Survey Switzerland 2007, OECD Publishing, Paris.

OECD (2000), PISA - Measuring Student Knowledge and Skills: The PISA 2000 Assessment of Reading, Mathematical and Scientific Literacy, OECD Publishing, Paris.

ODM (2007), Report Integration Measures, Bern.

OFFT (2010a), Validation of Achievements in Education, Bern.

OFFT (2010b), Case management «Formation professionnelle » : Rapport de monitorage 2010 : état du projet, Bern.

OFIAMT and OFE (1991), Rapport sur la conception et les priorités de la politique suisse des étrangers pour les années 1990, Bern.

Piguet, E. (2009), L'immigration en Suisse - soixante ans d'entrouverture, $2^{\text {nd }}$ edition, Presse polytechniques romandes - Collection "Le Savoir Suisse", Lausanne.

Raymann, U. (2003), Meinungen und Einstellungen gegenüber Ausländerinnen und Ausländern in der Schweiz, Trend- und Vertiefungsbericht, GfS-Forschungsinstitut, Zürich. 
Sancar-Flückiger, A. (1999), "Integrationsleitbilder und Integrationspolitik: zur kontroversen LeitbildDebatte in Zürich, Bern und Basel”, in H. Dietrich (ed.), Flüchtlinge, Migration und Integration, Widerspruch, Zürich, pp. 137-145.

Schönenberger, S. and R. Fibbi (2010), Lutte contre les discriminations à l'embauche - Les mesures volontaires mises en oeuvre en Suisse, Forum suisse pour l'étude des migrations, Neuchâtel (Working document commissioned by the Federal Department of the Interior).

Schulte-Haller, M. (2009), Frühe Förderung: Forschung, Praxis und Politik im Bereich der Frühförderung: Bestandsaufnahme und Handlungsfelder, in Swiss Federal Commission for Migration (CFM, ed.), Materialien zur Migrationspolitik, Bern.

Schwarz, H. (1988), Volkswirtschaftliche Wirkungen der Ausländerbeschäftigung in der Schweiz. Rüegger, Chur.

Sheldon, G. (2001), "Foreign Labor Employment in Switzerland: Less Is Not More“, Schweizerische Zeitschrift für Politikwissenschaft, Vol. 7, No. 1, pp. 104-112.

Simeone, L. (2005), Discrimination Testing Based on ILO Methodology, International Labor Office, Geneva, mimeographed.

Swiss National Fund (2005), Familienergänzende Kinderbetreuung in der Schweiz: Aktuelle und zukünftige Nachfragepotenziale, Zürich.

Spycher, S., T. Egger and E. Hüttner (2007), Die Möglichkeiten der sozialen Sicherung bei der Integration von Ausländerinnen und Ausländern, Centre for Labour and Social Policy Studies (BASS, ed.), Final report for Project No. 405140-69220 in the context of the National Research Programme 51 "Integration and Social Exclusion", Bern.

Steiner, P. (2007), Chronique d'une commission: 37 ans CFE, Commission fédéral des étrangers, Bern.

Steinhardt, M.F., T. Straubhaar and J. Wedemeier (2010), Studie zur Einbürgerung und Integration in der Schweiz: Eine arbeitsmarktbezogene Analyse der Schweizerischen Arbeitskräfteerhebung, Study commissioned by Swiss Federal Office for Migration, Bern.

Swiss Federal Statistical Office (2008), Familien in der Schweiz, Statistischer Bericht, Bern.

Tripartite Agglomeration Conference (2009), Avenir de la politique suisse d'intégration des étrangers, Conférence des gouvernements cantonaux, Bern.

UNICEF (2008), The child care transition. A league table of early childhood education and care in economically advanced countries, UNICEF Innocenti Research Centre (ed.), Innocenti Report Card 8 , Florence.

Van de Voorde, M. and H. de Bruijn (2010), "Mainstreaming the Flemish Employment Equity and Diversity Policy", in OECD (ed.): Equal Opportunities? The Labour Market Integration of the Children of Immigrants, Paris: OECD Publishing, pp. 229-242.

Weins, C. (2010), "Kompetenzen oder Zertifikate? Die Entwertung ausländischer Bildungsabschlüsse auf dem Schweizer Arbeitsmarkt", Zeitschrift für Soziologie, Vol. 39, No. 2, pp. 124-139. 


\section{GLOSSARY}

ALL

ALMP

APL

CFE

CFM

CFR

CRUS

DFE

DIOC

EEA

ECEC

EFTA

ENIC

ESPA

ISCED

ISEI

NEET
Adult Literacy and Life Skills Survey

Active Labour Market Policy

Accreditation of Prior Learning

Commission fédérale des étrangers

Eidgenössische Ausländerkommission, EKA

(Federal Commission for Foreigners)

Commission fédérale pour les questions de migration

Eidgenössische Kommission für Migration, EKM

(Federal Migration Commission )

Commission fédérale contre le racisme

Eidgenössische Kommission gegen Rassismus, EKR

(Federal Commission against Racism)

Conférence des Recteurs des Universités Suisses

Rektorenkonferenz der Schweizer Universitäten

(Rectors' Conference of Swiss Universities)

Département fédéral de l'économie

Eidgenössisches Volkswirtschaftsdepartement, EVD

(Federal Department of Economic Affairs)

OECD Database on Immigrants and Expatriates in OECD Countries

European Economic Area

Early Childhood Education and Care

European Free Trade Association

European Network of National Information Centers on Academic Recognition and Mobility

Enquête suisse sur la population active

Schweizerische Arbeitskräfteerhebung, SAKE

(Swiss Labour Force Survey)

EU Survey of Income and Living Conditions

International Standard Classification of Education

International Socio-Economic Index of Occupational Status

Neither in Employment nor in Education or Training 
NGO

ODM

OFFT

OFIAMT

OIE

ORP

PES

PET

PISA

PSM

SECO

SESAM

UAS

UNHCR

VET
Non-Governmental Organisation

Office fédéral des migrations

Das Bundesamt für Migration, BFM

(Federal Office for Migration)

Office fédéral de la formation professionnelle et de la technologie

Bundesamt für Berufsbildung und Technologie, BBT

(Federal Office for Professional Training and Technology)

Office fédéral de l'industrie des arts et métiers et du travail

Bundesamt für Industrie, Gewerbe und Arbeit, BIGA

(Federal Office for Economic Development and Labour)

Ordonnance du 24 octobre 2007 sur l'intégration des étrangers

Verordnung über die Integration von Ausländerinnen und Ausländern, VIntA

(Ordinance on the Integration of Foreigners)

Offices régionaux de placement

Regionale Arbeitsvermittlungszentren, RAV

(Local Employment Offices)

Public Employment Service

Professional Education and Training

OECD Programme for International Student Assessment

Panel suisse de ménages

Schweizer Haushalt-Panel, SHP

(Swiss Household Panel)

Secrétariat d'Etat à l'économie

Staatssekretariat für Wirtschaft

(State Secretariat for Economic Affairs)

Protection sociale et marché du travail (Enquête)

Soziale Sicherheit und Arbeitsmarkt, SESAM (Erhebung)

(Social protection and labour market (Survey))

Système d'information central sur la migration, SYMIC

Zentrales Migrations-Informationssystem, ZEMIS

(Central Information Service on Migration)

Transition from Education to Employment

Universities of Applied Sciences

United Nations High Commissioner for Refugees

Vocational Education and Training 
ANNEX 1.

\section{Annex Figure 1: Distribution of the gross hourly wage for the full-time employed in Switzerland, aged 15-64 and not in education, 2009}

(median hourly wage of the total employed population=100)

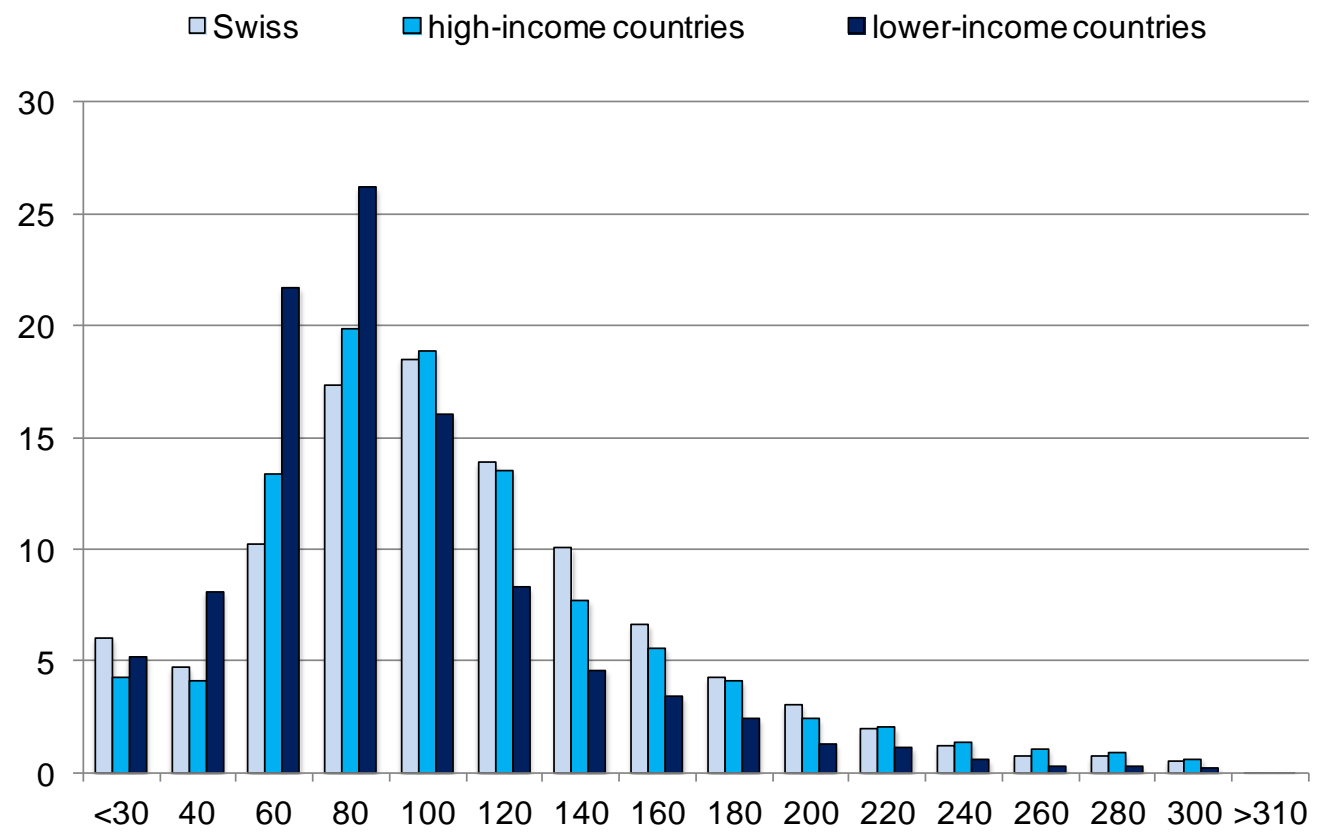

Note: The figures on the $x$-axis indicate the middle of each respective interval (e.g. $100=90 \%-110 \%$ of the hourly median wage). Source: Data from the Swiss Labour Force Survey linked with administrative data on wages (SESAM). 
Annex Figure 2: Main origin countries of the current migrant population, 2008

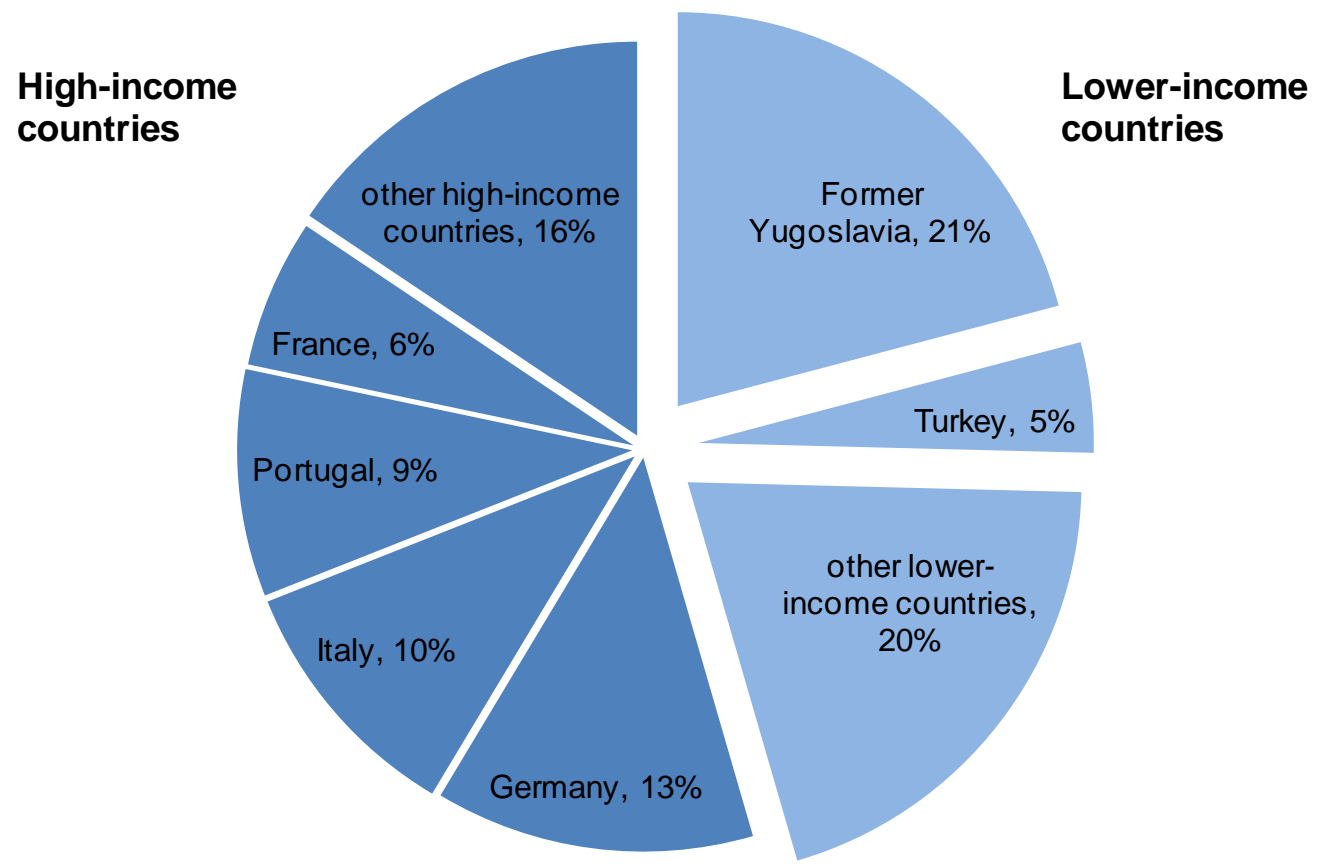

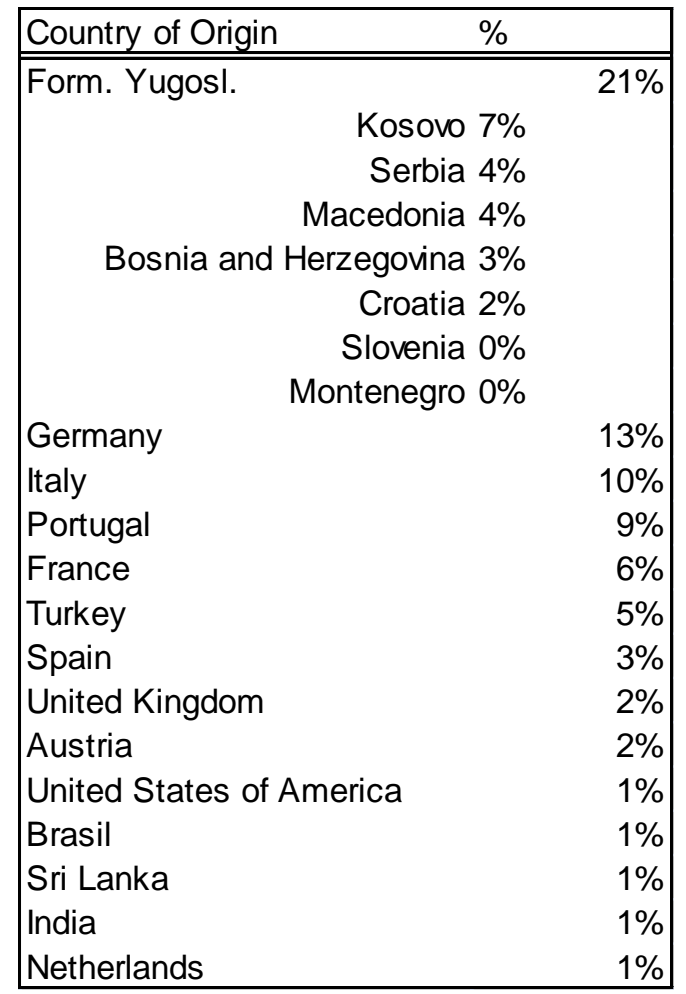

Source: Swiss Labour Force Survey, Swiss Federal Statistical Office. 
Annex Figure 3: Immigrant population by region and main migrant groups, as a percentage of total population, 2009

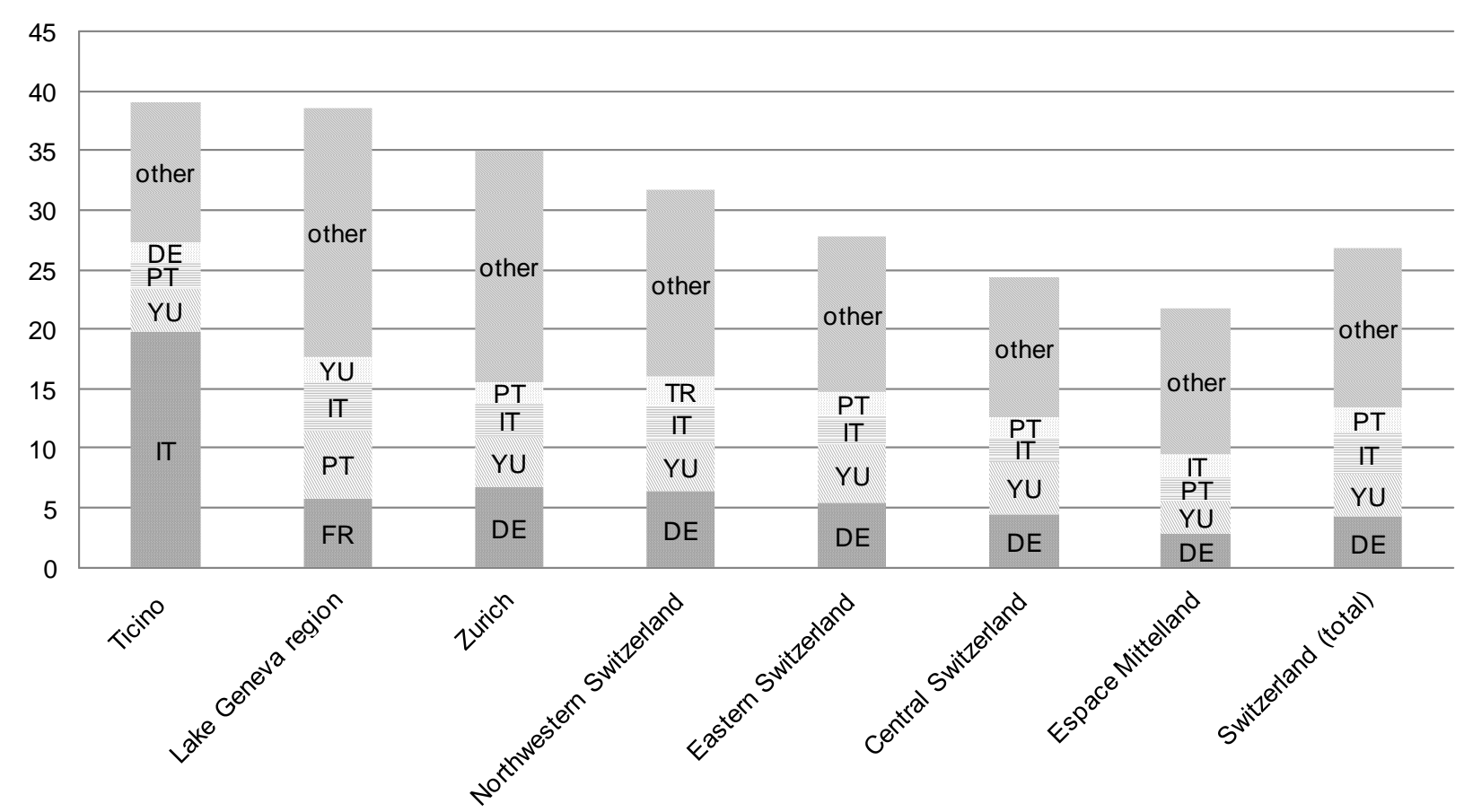

Source: Swiss Labour Force Survey, Swiss Federal Statistical Office.

Note: The classification of the regions is as follows:

\section{Region}

Lake Geneva region

Espace Mittelland

Northwestern Switzerland

Zurich

Eastern Switzerland

Central Switzerland

Ticino

\section{Cantons}

Vaud, Valais, Geneva

Berne, Fribourg, Solothurn, Neuchâtel, Jura

Basel-City, Basel-Country, Aargau

Zurich

Glarus, Schaffhausen, Appenzell Ausserrhoden, Appenzell Innerrhoden, St. Gallen, Grisons, Thurgau

Lucerne, Uri, Schwyz, Obwalden, Nidwalden, Zug

Ticino 
Annex Figure 4: Distribution of immigrants from the former Yugoslavia by year of arrival and region of residence, 15-64, 2009

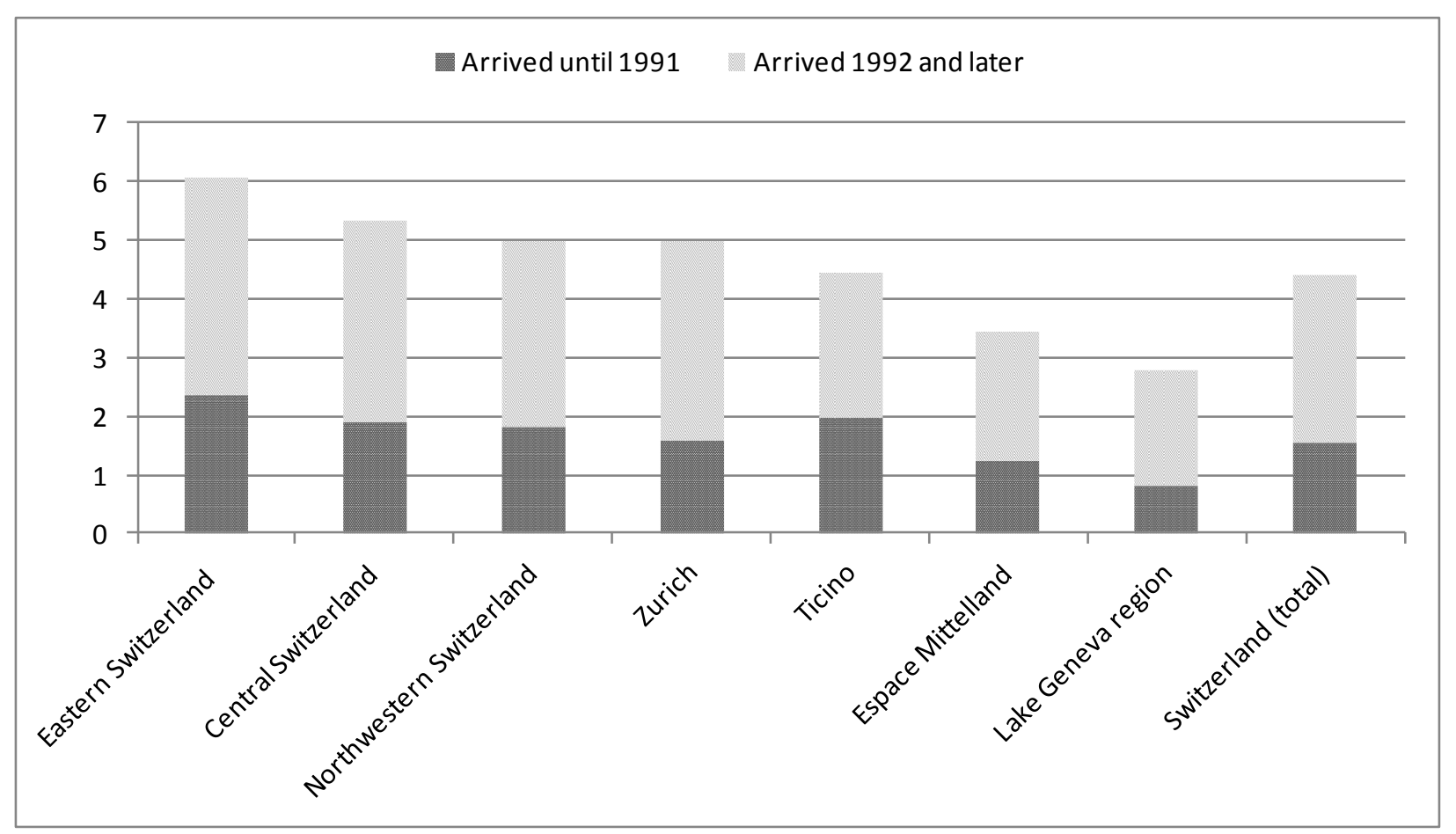

Note: For the classification of the regions, see Note to Annex Figure 3.

Source: Swiss Labour Force Survey, Swiss Federal Statistical Office.

Annex Figure 5: Employment of foreign-born in the public sector in selected OECD countries, 15-64 years old, 2006/2007

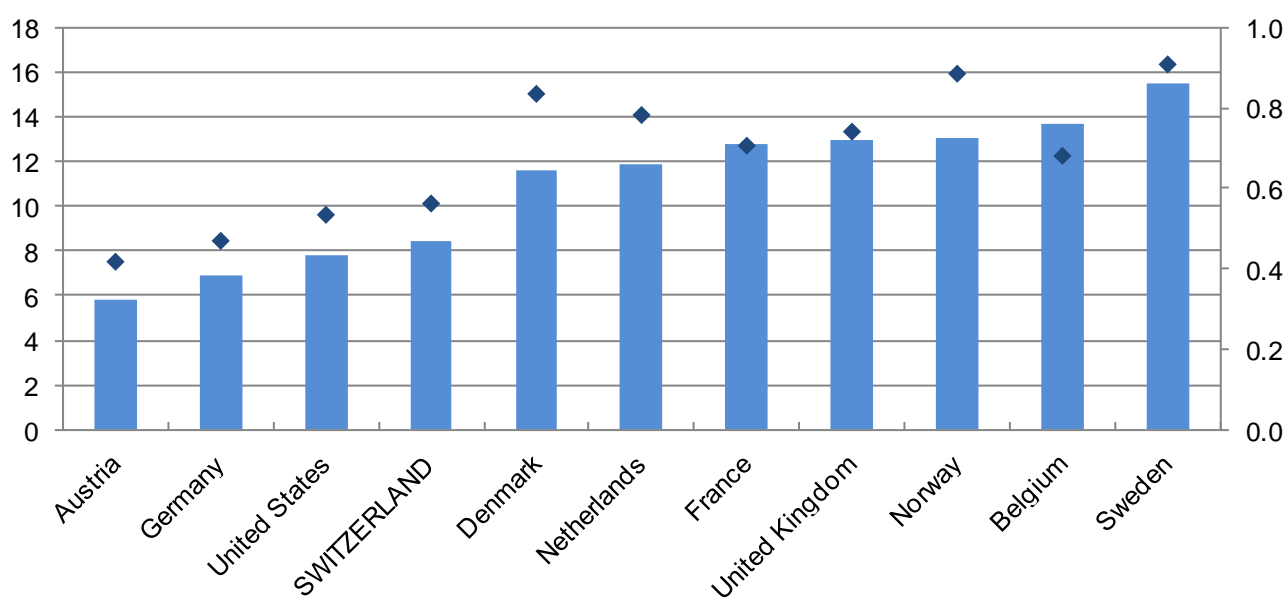

Employment in the public administration as a \% of total foreign-born employment (left scale)

- Relative to share among native-born employment (right scale) 
Annex Table 1: Wages of recent arrivals by origin compared with the native-born, by gender, aged 15-64, 2008

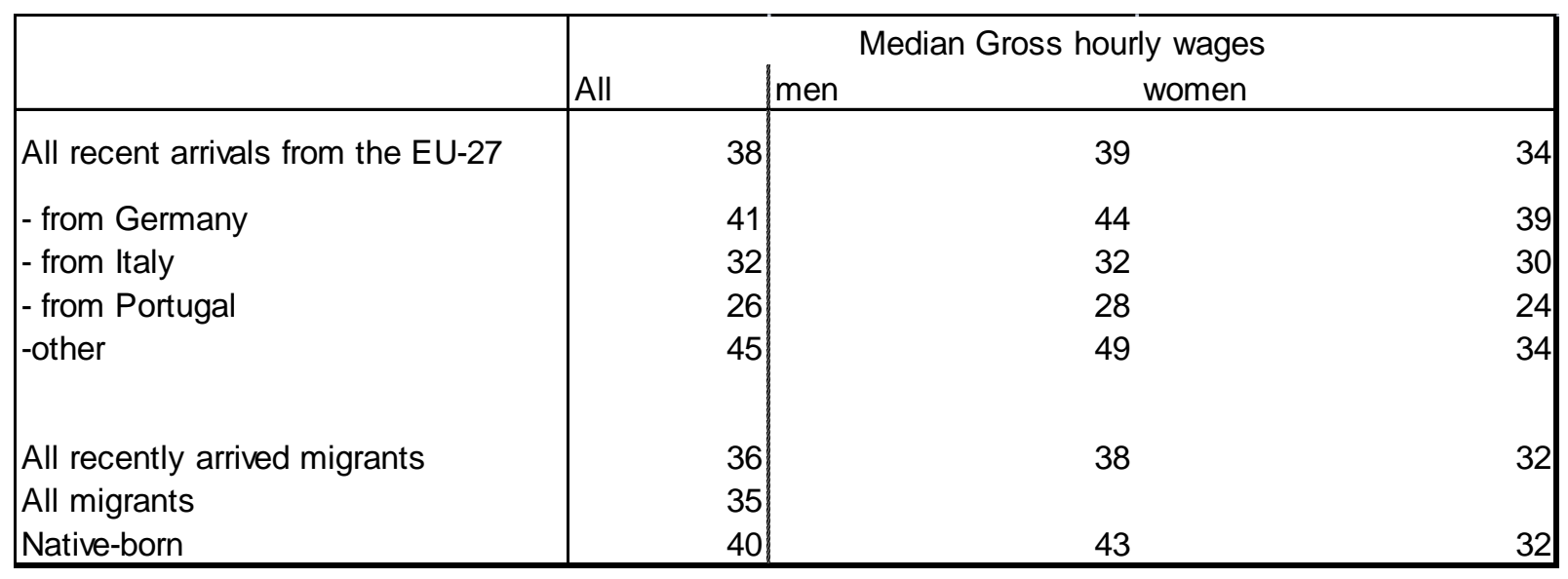

Note: Only full-time employees who have been in employment over the last 12 months "without longer interruption".

Source: Swiss Labour Force Survey, Swiss Federal Statistical Office, SESAM.

\begin{tabular}{|c|c|c|c|c|c|c|}
\hline & \multicolumn{3}{|c|}{ Men } & \multicolumn{3}{|c|}{ Women } \\
\hline & $\begin{array}{l}\text { (1) raw } \\
\text { difference }\end{array}$ & $\begin{array}{l}\text { (2) controlling for work } \\
\text { experience, education, } \\
\text { region }\end{array}$ & $\begin{array}{l}\text { (3) (2) plus occupation, } \\
\text { region }\end{array}$ & $\begin{array}{l}\text { (1) raw } \\
\text { difference }\end{array}$ & $\begin{array}{l}\text { (2) controlling for } \\
\text { work experience, } \\
\text { education, region }\end{array}$ & $\begin{array}{l}\text { (3) (2) plus occupation, } \\
\text { region }\end{array}$ \\
\hline All recent arrivals from the EU-27 & & & & & & \\
\hline - from Germany & $5.7^{\star \star \star}$ & $4.3^{\star *}$ & $3.7^{\star *}$ & $8.3^{\star \star \star}$ & $5.0^{\star \star \star}$ & $4.5^{\star * *}$ \\
\hline - from Italy & $-7.8^{\star \star}$ & 2.4 & 2.2 & 0.1 & 2.0 & 1.7 \\
\hline - from Portugal & $-18.6^{\star * \star}$ & 1.3 & $3.6^{\star *}$ & $-8.6^{\star \star \star}$ & 0 & 2.1 \\
\hline -other & $29.6^{* \star *}$ & $22.1^{* \star *}$ & $21.2^{\star \star \star}$ & $6.5^{\star \star *}$ & 2.6 & 2.9 \\
\hline EU27 $>5$ years & $2.9^{\star \star \star}$ & $2.4^{\star \star}$ & $2.8^{\star \star}$ & $3.7^{\star \star \star}$ & 0.2 & 1.0 \\
\hline Non-EU-27 recent arrivals & 3.3 & $8.2^{\star \star \star}$ & $9.8^{\star \star \star}$ & -1.0 & 0.1 & 1.6 \\
\hline Non-EU-27 >5 years & $-10.7^{\star \star *}$ & $-5.6^{\star \star}$ & -3.0 & $-6.1^{\star * *}$ & $-5.4^{\star \star \star}$ & $-3.8^{\star \star \star}$ \\
\hline constant & 48.0 & 22.5 & 17.9 & 32.9 & 18.0 & 11.7 \\
\hline
\end{tabular}

Note: The dependent variable is the hourly wage, which has been derived from the total gross salary of the respondents of the last 12 months using the average working hours per year in Switzerland (1926 hours according to the Federal Statistical Office). Only people who stated that they have been employed without "longer interruption" during this period are included. Migrants from the USA, Canada, Japan, Korea, Australia and New Zealand as well as respondents who earned $0 €$ or more than $1000 €$ per hour were excluded. Reference group are the native-born. * ${ }^{* *},{ }^{* \star *}$ significant at the $1 \%, 5 \%$ and $10 \%$ level, respectively.

Source: Swiss Labour Force Survey, Swiss Federal Statistical Office, SESAM. 
Annex Table 2: Labour market outcomes of highly-educated population in selected OECD countries, aged 15-64, 2008/2009

\begin{tabular}{|c|c|c|c|c|c|c|}
\hline \multicolumn{7}{|c|}{ Percentage of persons aged $15-64$ working in... } \\
\hline & & $\begin{array}{l}\text { Highly-skilled } \\
\text { employment }\end{array}$ & $\begin{array}{c}\text { Medium-skilled } \\
\text { employment }\end{array}$ & $\begin{array}{c}\text { Low-skilled } \\
\text { employment }\end{array}$ & Unemployment & Inactive \\
\hline \multicolumn{7}{|l|}{ Austria } \\
\hline & native-born & 70 & 17 & (1) & (2) & 10 \\
\hline & foreign-born & 55 & 16 & (5) & (4) & 19 \\
\hline & foreign-born, high-income & 65 & 14 & $\ldots$ & $\ldots$ & 17 \\
\hline & foreign-born, lower-income & 40 & 20 & (11) & $\ldots$ & 23 \\
\hline \multicolumn{7}{|l|}{ Belgium } \\
\hline & native-born & 65 & 18 & 1 & 3 & 13 \\
\hline & foreign-born & 51 & 19 & 3 & 8 & 19 \\
\hline & foreign-born, high-income & 60 & 17 & $\ldots$ & 5 & 17 \\
\hline & foreign-born, lower-income & 41 & 20 & 5 & 12 & 21 \\
\hline \multicolumn{7}{|l|}{ Denmark } \\
\hline & native-born & 76 & 11 & (1) & 3 & 9 \\
\hline & foreign-born & 57 & 16 & $\ldots$ & (8) & 14 \\
\hline & foreign-born, high-income & 68 & $(12)$ & $\ldots$ & $\ldots$ & (12) \\
\hline & foreign-born, lower-income & 39 & (25) & $\ldots$ & $\ldots$ & $\ldots$ \\
\hline \multicolumn{7}{|c|}{ the } \\
\hline & native-born & 64 & 16 & 1 & 4 & 14 \\
\hline & foreign-born & 51 & 15 & 3 & 8 & 22 \\
\hline & foreign-born, high-income & 59 & 11 & $\ldots$ & (7) & 21 \\
\hline & foreign-born, lower-income & 49 & 17 & 4 & 8 & 22 \\
\hline \multicolumn{7}{|l|}{ Germany } \\
\hline & native-born & 71 & 17 & 1 & 3 & 14 \\
\hline & foreign-born & 54 & 20 & 5 & 7 & 14 \\
\hline & foreign-born, high-income & $\ldots$ & $\ldots$ & $\ldots$ & $\ldots$ & $\ldots$ \\
\hline & foreign-born, lower-income & $\ldots$ & $\ldots$ & $\ldots$ & $\ldots$ & $\ldots$ \\
\hline \multicolumn{7}{|c|}{ Netherlands } \\
\hline & native-born & 77 & 10 & 1 & 2 & 10 \\
\hline & foreign-born & 58 & 15 & (3) & 4 & 19 \\
\hline & foreign-born, high-income & 69 & 13 & $\ldots$ & $\ldots$ & 12 \\
\hline & foreign-born, lower-income & 52 & 16 & (3) & (5) & 23 \\
\hline \multicolumn{7}{|l|}{ Norway } \\
\hline & native-born & 80 & 9 & $\ldots$ & 1 & 8 \\
\hline & foreign-born & 61 & 18 & $\ldots$ & $\ldots$ & 14 \\
\hline & foreign-born, high-income & 73 & $\ldots$ & $\ldots$ & $\ldots$ & $\ldots$ \\
\hline & foreign-born, lower-income & 49 & 25 & $\ldots$ & $\ldots$ & 17 \\
\hline \multicolumn{7}{|l|}{ Sweden } \\
\hline & native-born & 79 & 9 & 1 & 3 & 8 \\
\hline & foreign-born & 52 & 20 & 4 & 9 & 15 \\
\hline & foreign-born, high-income & 67 & 16 & $\ldots$ & (5) & 10 \\
\hline & foreign-born, lower-income & 41 & 22 & 6 & 13 & 18 \\
\hline \multicolumn{7}{|c|}{ United Kingdom } \\
\hline & native-born & 65 & 18 & 2 & 4 & 12 \\
\hline & foreign-born & 58 & 19 & 3 & 5 & 15 \\
\hline & foreign-born, high-income & 65 & 15 & 3 & 5 & 12 \\
\hline & foreign-born, lower-income & 55 & 21 & 2 & 6 & 17 \\
\hline \multicolumn{7}{|c|}{ Switzerland } \\
\hline & native-born & 72 & 18 & 1 & 2 & 7 \\
\hline & foreign-born & 69 & 14 & (1) & 4 & 12 \\
\hline & foreign-born, high-income & 76 & 12 & $\ldots$ & 3 & 10 \\
\hline & foreign-born, lower-income & 53 & 18 & (3) & 7 & 18 \\
\hline \multicolumn{7}{|c|}{ United States } \\
\hline & native-born & 53 & 26 & 3 & 3 & 15 \\
\hline & foreign-born & 49 & 25 & 4 & 4 & 18 \\
\hline & foreign-born, high-income & 53 & 23 & 3 & 3 & 18 \\
\hline & foreign-born, lower-income & 48 & 26 & 5 & 4 & 17 \\
\hline \multicolumn{7}{|c|}{$O E C D$ average (1) } \\
\hline & native-born & 70 & 15 & 1 & 3 & 11 \\
\hline & foreign-born & 56 & 18 & 4 & 6 & 16 \\
\hline & foreign-born, high-income & 65 & 15 & 3 & 4 & 15 \\
\hline & foreign-born, lower-income & 47 & 21 & 4 & 8 & 20 \\
\hline
\end{tabular}

Note: The OECD average refers to the average of the countries included in this table and for which data are available.

Source: European Community Labour Force Survey 2009 and Current Population Survey March Supplement 2009 for the United States. 
Annex Table 3: Employment and unemployment rates of migrants from the former Yugoslavia, by gender and arrival, aged 15-64, 2009

\begin{tabular}{lcccccccc} 
& \multicolumn{3}{c}{ Employment rates [\%] } & & \multicolumn{4}{c}{ Unemployment rates [\%] } \\
\cline { 2 - 4 } \cline { 7 - 9 } Arrival & total & \multicolumn{3}{c}{ before 92 } & 92 and later & & total & \multicolumn{3}{c}{ before 92 } & 92 and later \\
\hline Men & 73.1 & 75.8 & 71.3 & & 8.1 & 5.8 & 9.7 \\
\hline Women & 55.3 & 59.1 & 53.6 & & 10.7 & 8.1 & 11.9 \\
\hline Total & 64.3 & 68.7 & 61.9 & & 9.2 & 6.7 & 10.7
\end{tabular}

Source: Swiss Labour Force Survey, Swiss Federal Statistical Office, 
DELSA/ELSA/WD/SEM(2012)2

\section{ANNEX 2.}

\section{ZUSAMMENFASSUNG}

Die Schweiz ist innerhalb der OECD eines der Länder mit dem höchsten Immigrantenanteil - 27 \% der Personen im erwerbsfähigen Alter sind im Ausland geboren - und das Thema Einwanderung nimmt sowohl in der politischen Agenda als auch in der öffentlichen Diskussion einen wichtigen Platz ein. In Anbetracht der zahlreichen Debatten, die das Thema im Land auslöst, könnte man versucht sein zu glauben, die Immigranten seien in der Schweiz weniger gut integriert als in anderen Ländern.

Die Fakten zeigen jedoch, dass die Integration in der Schweiz im Grossen und Ganzen relativ gut funktioniert. Auf dem Arbeitsmarkt ist die Lage der zugewanderten Bevölkerung insgesamt bedeutend besser als in anderen Ländern,. Sowohl bei den Männern als auch bei den Frauen ist die Beschäftigungsquote der Immigranten höher als in den anderen Ländern der OECD.

Diese guten Ergebnisse lassen sich hauptsächlich durch die insgesamt gute Lage auf dem Schweizer Arbeitsmarkt erklären, aber auch durch eine spezielle Konstellation bei den Herkunftsländern. Der Grossteil der Migranten (mehr als $60 \%$ ) stammen aus OECD-Ländern mit hohen Einkommensniveau, mehr als die Hälfte davon aus den Nachbarländern, in denen eine der Schweizer Landessprachen gesprochen wird. Die anderen Immigranten stammen hauptsächlich aus den Ländern Ex-Jugoslawiens und der Türkei.

Im Laufe der letzten Jahre sind als Folge der schrittweisen Einführung des freien Personenverkehrs mit den Mitgliedländern der Europäischen Union aussergewöhnlich viele Zuwanderer in die Schweiz gekommen. Ungefähr $5 \%$ der Wohnbevölkerung sind Menschen, die erst seit kurzem, d.h. seit weniger als fünf Jahren, in der Schweiz wohnen. Diese neuen Einwanderer stammen mehrheitlich aus Nachbarländern, insbesondere aus Deutschland. Alle konventionellen Indikatoren zeigen, dass sie sich gut auf dem Arbeitsmarkt integrieren.

Trotz diesem im Ganzen positiven Bild ist die Lage für gewisse Einwanderergruppen schwieriger, beispielsweise für Frauen mit kleinen Kindern. Es wird wenig unternommen, um die Integration der eingewanderten Frauen zu fördern, die häufig nicht Zugang zu allen Massnahmen der aktiven Arbeitsmarktpolitik haben. Gewisse Elemente scheinen ausserdem darauf hinzuweisen, dass die Beschäftigungsquote dieser Bevölkerungsgruppe seit einigen Jahren sinkt.

Eine weitere Gruppe verzeichnet schlechte Beschäftigungsquoten, und dies auch im internationalen Vergleich: Personen, die vor kurzem aus humanitären Gründen eingewandert sind, scheinen bei der Integration in den schweizerischen Arbeitsmarkt mehr Mühe zu bekunden als frühere Kohorten humanitärer Migranten. Im Gegensatz zu anderen Ländern gibt es in der Schweiz noch kein allgemeines Programm für die Integration dieser Kategorie von Neuankömmlingen. Dies kann zum Teil deren schlechte Leistungen erklären. Angesichts der ermutigenden Erfahrungen, die andere OECD-Länder mit strukturierten und auf den Arbeitsmarkt ausgerichteten Integrationsprogrammen gemacht haben, wäre es wünschenswert, dass die Schweiz ernsthaft erwägt, ebenfalls solche Programme umzusetzen.

Die allgemein hohe Beschäftigungsquote der Immigranten in der Schweiz ist auch mit einer häufigen Überqualifizierung derjenigen Migranten verbunden, die in Nicht-OECD-Ländern ein Diplom erworben haben. Qualifikationen, die im Ausland erworben wurden, werden auf dem schweizerischen Arbeitsmarkt ungenügend anerkannt, und es gibt nur wenige Brücken- bzw. Passerelle-Kurse. Im Gegensatz zu anderen 
Ländern der OECD gibt es in der Schweiz auch nur wenige Patenschaftsprogramme oder ähnliche Initiativen die es den Immigranten ermöglichen würden, die unabdingbaren Kontakte zu in der Schweiz geborenen Personen und zu Arbeitgebern zu knüpfen und sich gleichzeitig mit den Abläufen des Arbeitsmarkts vertraut zu machen; zwei Aspekte, die entscheidend sind, um Zugang zu hochqualifizierten Stellen zu erhalten. Solche Massnahmen sollten stärker verbreitet werden, in Zusammenarbeit mit den Arbeitgebern.

In der Integrationspolitik zeigt sich klar der föderalistische Charakter des Landes. Verschiedene Massnahmen wurden auf lokaler und kantonaler Ebene entwickelt, um die Integration zu fördern. Die Anwendung des Subsidiaritätsprinzips hat einerseits dazu geführt, dass punktuelle und flexible Massnahmen zugunsten vieler Immigranten getroffen wurden, sie hat jedoch gleichzeitig die Entwicklung einer Integrationspolitik des Bundes verzögert. Infolgedessen ist die allgemeine Architektur in Bezug auf die Integration weiterhin unterentwickelt, trotz einer deutlichen Verbesserung in den letzten zehn Jahren. Die Integrationspolitik des Bundes ist alles in allem bescheiden, wenn man sie mit der anderer OECDLänder vergleicht, von denen die meisten einen niedrigeren Einwandereranteil haben als die Schweiz. Mit Ausnahme einiger Instrumente wie beispielsweise dem vom Bundesamt für Migration finanzierten sprachlichen Grundkurs sind in der Schweiz nur wenige Integrationsmassnahmen spezifisch auf Immigranten ausgerichtet. Man geht allgemein davon aus, dass die Immigranten von den allen zugänglichen Massnahmen profitieren werden, anstatt spezifisch auf Immigranten ausgerichtete Politiken zu gestalten. Um die Mängel des aktuellen Systems etwas zu mildern, haben Bund, Kantone und lokale Behörden kürzlich einige Vorschläge formuliert, wie der allgemeine Rahmen für die Integration verbessert werden könnte. Sie haben sich zudem verpflichtet, die Mittel für die Integration aufzustocken.

Auf kantonaler Ebene sind die Massnahmen bei der Integrationshilfe sehr unterschiedlich, was teilweise auf die Unterschiede in der Grösse und der Zusammensetzung der zugewanderten Bevölkerung zurück zu führen ist. Wohl haben zahlreiche Kantone in den letzten Jahren die Integrationsmassnahmen verstärkt, dies jedoch häufig nur in kleinem Umfang und im Rahmen von Beispielprojekten, was eine Evaluation deren Wirksamkeit schwierig macht. Die Bundesbehörden sollten Minimalnormen festlegen, damit alle Immigranten unabhängig vom Wohnkanton von den von ihnen benötigten Massnahmen profitieren können.

Für die Immigranten ist es schwierig, das Schweizer Bürgerrecht zu erwerben. Die erforderliche Aufenthaltsdauer ist in der Tat besonders lang - 12 Jahre für ein normales Verfahren, die längste Frist innerhalb der OECD - und das Verfahren für den Erwerb läuft auf drei Ebenen: Der Kandidat muss sowohl den Anforderungen des Bundes als auch denjenigen des Kantons und der Gemeinde genügen. Eine Reform der Gesetzgebung ist im Gang, sie sollte einige der wichtigsten Lücken im Bürgerrechtsgesetz schliessen und die Mobilität der Migranten innerhalb der Schweiz verbessern. Forschungsergebnisse deuten darauf hin, dass dies eine starke Dynamisierung der Integration benachteiligter Immigrantengruppen bewirken könnte.

Insgesamt erzielen die Kinder von Immigranten im internationalen Vergleich gute Resultate auf dem Arbeitsmarkt, was zum Teil auf die allgemein guten Bedingungen auf dem Arbeitsmarkt zurück zu führen ist. Andere Faktoren spielen ebenfalls eine Rolle, wie beispielsweise die starke Verbreitung der Berufslehre, die sich für Immigrantenkinder im Übergang von der Schule in die Arbeitswelt besonders positiv auszuwirken scheint. Es wurden auch einige innovative Programme lanciert, um niedrigqualifizierte Jugendliche (von denen ein Grossteil Immigrantenkinder sind) auf die Berufslehre vorzubereiten. Diese Programme scheinen eine positive Wirkung gehabt zu haben.

Immigrantenkinder, deren Eltern ein tiefes Bildungsniveau haben, erzielen in der Schule schlechte Leistungen. Gegenwärtig treten diese Immigrantenkinder in steigender Zahl in den Arbeitsmarkt ein. Es scheint, dass diese weniger befriedigenden Leistungen zumindest teilweise darauf zurück zu führen sind, 
dass das Bildungssystem keine Betreuung ab einem genügend frühen Alter vorsieht. Die Einschulung der Kleinkinder ist in der Schweiz noch nicht sehr weit entwickelt. Es sollte dringend eine Priorität des staatlichen Handelns werden, den Immigrantenkindern ab dem entscheidenden Alter von drei oder vier Jahren einen angepassten und zielgerichteten Unterricht sowie Möglichkeiten zum Erlernen der Sprache anzubieten.

In einem Bereich weist die Schweiz einen klaren Rückstand auf andere OECD-Länder auf, und zwar im Kampf gegen Diskriminierung. Den Arbeitgebern ist das Problem, das ausserdem nicht öffentlich diskutiert wird, zu wenig bewusst. Studien haben jedoch gezeigt, dass Immigrantenkinder, insbesondere wenn die Eltern aus Ex-Jugoslawien stammen, bei gleichen Qualifikationen bis zu fünf Mal mehr Bewerbungen schreiben müssen als Kinder ohne Migrationshintergrund, um zu einem Vorstellungsgespräch eingeladen zu werden. Es ist wichtig, die erforderlichen Massnahmen zu treffen, um dieser Ungleichbehandlung entgegenzuwirken.

Auch wenn die Schweiz im Grossen und Ganzen im internationalen Vergleich insgesamt gute Resultate erzielt bei der Integration der zugewanderten Bevölkerung in den Arbeitsmarkt, gibt es dennoch mehrere Anzeichen dafür, dass die Situation für gewisse Gruppen von Migranten divergiert. Einige benachteiligte Gruppen stehen in der Gefahr, auf der Strecke zu bleiben. Es ist daher wichtig, dass sofort gehandelt wird, solange die Resultate gesamthaft noch positiv sind. Dies ist erkannt worden, und die Integrationsbemühungen werden auf allen drei staatlichen Ebenen verstärkt. In vielerlei Hinsicht bleibt die Integrationspolitik der Schweiz jedoch hinter dem zurück, was in anderen OECD-Ländern geleistet wird. Es sollten Massnahmen ins Auge gefasst werden, um diese Situation zu verbessern und zu erreichen, dass die Resultate in Zukunft für alle Gruppen von Immigranten zufriedenstellend sind.

\section{Zusammenfassung der wichtigsten Politikempfehlungen}

\section{A) Den übergeordneten Rahmen für die Integration stärken}

- Gemeinsame Minimalnormen für Integrationsmassnahmen entwickeln, die für alle Kantone gelten.

- Den Austausch von guten Praktiken zwischen Kantonen und Gemeinden erleichtern.

- Sicherstellen, dass alle Immigranten, die Integrationshilfe benötigen, diese auch erhalten, unabhängig vom Bewilligungstypus und der Art und Höhe von Leistungen, die sie beziehen. Dies ist besonders für Immigrantinnen wichtig.

- Allen Immigranten, die eine sprachliche Förderung benötigen, entsprechende Möglichkeiten anbieten, unter Berücksichtigung ihrer Kenntnisse und Qualifikationen.

- Den Zugang zum Schweizer Bürgerrecht vereinfachen, indem insbesondere die Anforderungen der Kantone und Gemeinden bezüglich Aufenthaltsdauer reduziert werden, um Migranten die geographische Mobilität zu erleichtern.

- Auf die Vorteile aufmerksam machen, welche der Erwerb des Schweizer Bürgerrechts für eine bessere Integration der Immigranten und ihrer Kinder mit sich bringt.

B) Bei Migranten, die aus humanitären Gründen eingewandert sind, eine schnelle Integration in den Arbeitsmarkt fördern

- $\quad$ Stärkere Anreize für die Kantone, um Migranten, die aus humanitären Gründen eingewandert sind, innerhalb der ersten fünf Aufenthaltsjahre schnell in den Arbeitsmarkt zu integrieren.

- Umsetzen eines strukturierten Integrationsprogramms zugunsten aller Migranten, die vor kurzem aus humanitären Gründen eingewandert sind (Asylbewerber, deren Antrag angenommen wurde oder die vorläufig aufgenommen sind), je nach den Bedürfnissen der Einzelnen. Der Schwerpunkt sollte klar auf der Integration in den Arbeitsmarkt liegen.

- Eine bessere Information der Arbeitgeber über den Zugang zum Arbeitsmarkt von Personen, die vorläufig aufgenommen sind. 


\section{Zusammenfassung der wichtigsten Politikempfehlungen (Fortsetzung)}

\section{C) Die Fähigkeiten der Migranten besser nutzen}

- $\quad$ Sicherstellen, dass der gegenwärtige Schwerpunkt aktuell auf wenig qualifizierter Arbeit bei Migranten, die aus humanitären Gründen eingewandert sind, nicht ein Hindernis darstellt für eine bestmögliche Nutzung ihrer Fähigkeiten.

- Unter den Immigranten die Angebote für Evaluation und Anerkennung von im Ausland erworbenen Qualifikationen besser bekannt machen. Die Vorteile einer solchen Anerkennung stärker aufzeigen.

- Brückenkurse bzw. Passerellen-Angebote und andere Unterstützungsprogramme einrichten, um Immigranten mit im Ausland erworbenen Diplomen bei der Suche nach einer besser qualifizierten Stelle zu helfen.

- Eine auf Migranten ausgerichtete behutsame Ausdehnung von zeitlich befristeten Lohnsubventionen in Erwägung ziehen.

\section{D) Die Anstrengungen für eine rasche Integration der Immigrantenkinder verstärken}

- Die vorschulische Erziehung ausbauen und besonders darauf achten, dass Kinder von Immigranten aus benachteiligten Verhältnissen ab dem Alter von 3 oder 4 Jahren daran teilnehmen.

- Die sprachliche Förderung der Immigrantenkinder, verstärken, insbesondere im vorschulischen Bereich.

- Untersuchen, warum bei Immigrantenkindern der Prozentsatz der Lehrabschlüsse offenbar niedrig ist, und Massnahmen treffen, um dies zu ändern. 


\section{BEURTEILUNG UND EMPFEHLUNGEN}

Die Schweiz weist einen hohen Anteil an Immigranten auf, und die Gesamtbilanz hinsichtlich der Integration in den Arbeitsmarkt ist positiv.

Dies ist teilweise darauf zurück zu führen, dass in der Schweiz nahezu Vollbeschäftigung herrscht und die meisten Immigranten aus Nachbarländern stammen.
Die Schweiz verzeichnet einen hohen Anteil vor kurzem eingewanderter Personen aus der EU. Diese Bevölkerungsgruppe hat sich im Allgemeinen gut in den Arbeitsmarkt integriert.
Ungefähr 27 \% der in der Schweiz wohnhaften Personen sind im Ausland geboren. Das ist, neben Luxemburg und Australien, einer der höchsten Anteile der OECD-Zone. Im internationalen Vergleich sind die zentralen Indikatoren für die Integration der Immigranten in den Arbeitsmarkt insgesamt durchaus positiv. Die Schweiz ist innerhalb der OECD eines der Länder, in dem Immigranten beider Geschlechter die höchsten Beschäftigungsquoten aufweisen. Dies gilt ebenso für die in der Schweiz geborenen Kinder eingewanderter Eltern. Dennoch, und trotz der allgemein tiefen Arbeitslosenquote im Land, ist die Arbeitslosigkeit gewisser Immigrantengruppen nicht unbedeutend.

Das im Vergleich zu anderen OECD-Ländern recht positive Bild der Integration in der Schweiz dürfte sich im Wesentlichen auf zwei Faktoren zurück führen lassen. Erstens ist die Lage auf dem schweizerischen Arbeitsmarkt gesamthaft gesehen gut. Zweitens stammten und stammen die meisten Immigranten in der Schweiz, im Gegensatz zu anderen OECD-Ländern, aus Hocheinkommensländern, insbesondere aus den Nachbarländern Deutschland und Italien, den beiden häufigsten Herkunftsländern. In der Gruppe der Herkunftsländer mit tiefem Einkommensniveau stellen Ex-Jugoslawien und seine Nachfolgestaaten fast die Hälfte aller Immigranten. $12 \%$ der Migranten stammen aus der Türkei. Gründe für die Einwanderung waren im Wesentlichen die Arbeitsmigration und der damit zusammen hängende Familiennachzug. Der Anteil an Migranten, die aus humanitären Gründen eingewandert sind (und die in allen Ländern oft besondere Schwierigkeiten haben bei der Integration in den Arbeitsmarkt) ist jedoch kleiner als in anderen Ländern. Allerdings ist auch diese Gruppe zahlenmässig nicht unbedeutend, da die Schweiz in den letzten zwei Jahrzehnten eines der Hauptzielländer für Asylbewerber innerhalb der OECD war.

Seit 2002 sind in Folge der schrittweisen Einführung der Freizügigkeit mit der EU und ihren Mitgliedstaaten sehr viele Personen aus der Europäischen Union in die Schweiz eingewandert. Mehr als $5 \%$ der Bevölkerung des Landes sind in diesem Zeitraum eingewandert. Innerhalb dieser Gruppe ist die soziodemographische Zusammensetzung je nach Herkunftsland sehr unterschiedlich. Besonders viele Immigranten aus Portugal sind arbeitslos. Im Allgemeinen erzielen jedoch die neu zugewanderten Migranten aus der erweiterten EU sehr gute Resultate auf dem Arbeitsmarkt. Insbesondere entspricht ihre Arbeitsstelle im Durchschnitt eher ihrer formellen Qualifikation, als dies bei den Nichtzuwanderern der Fall ist. Dies legt die Vermutung nahe, dass ihre Kompetenzen in hohem Masse mit der Nachfrage nach Arbeitskräften übereinstimmen. 
Es gibt gewisse Anzeichen einer Verschlechterung der Beschäftigungssituation für Frauen aus Ländern mit niedrigen Einkommensniveau. Diese Entwicklung gilt es im Auge zu behalten.
Immigrantinnen aus Ländern mit niedrigen Einkommensniveau, insbesondere neu eingewanderte Frauen, sind eine Gruppe, deren Resultate bezüglich der Beschäftigung nicht nur unvorteilhaft sind, sondern sich in den letzten Jahren noch verschlechtert haben. Dies ist eine beunruhigende Entwicklung, die aufmerksam verfolgt werden muss. In der Tat erreichen die Integrationsbemühungen der Schweiz die Immigrantinnen oft nicht, da die Frauen häufig nicht im Arbeitsmarkt sind und von keinen Leistungen profitieren können. Für diese Gruppe könnte die kürzlich erfolgte Reduktion der Mitfinanzierung (über die Arbeitslosenversicherung) der aktiven arbeitsmarktlichen Massnahmen für Personen ohne Arbeitslosengeld zur Folge haben, dass das bereits eingeschränkte Angebot an Integrationsmassnahmen weiter eingeschränkt wird, wenn nicht die Sozialdienste diese Reduktion auffangen. Im Gegensatz zu Migranten, die aus humanitären Gründen eingewandert sind, können Migranten, die durch Familiennachzug in die Schweiz gekommen sind, bei ihrer Ankunft nicht von einer einheitlichen Integrationshilfe profitieren. Sie können jedoch eine gewisse Unterstützung in der Form einer sprachlichen Grundausbildung erhalten. In den anderen OECD-Ländern hingegen werden Massnahmen zunehmend auf alle neu Ankommenden ausgeweitet, und/oder die Tätigkeiten von Nichtregierungsorganisationen kompensieren den Mangel an allgemeinen Angeboten. Beide Ansätze sind in der Schweiz eher unbedeutend. Da eine bessere Integration der Immigrantinnen in den schweizerischen Arbeitsmarkt auch den Kindern dieser Frauen wichtige Impulse geben kann, sollte eine Ausdehnung der Integrationsmassnahmen auf diese Bevölkerungsgruppe dringend und ernsthaft in Betracht gezogen werden.

Personen, die vor kurzem aus humanitären Gründen eingewandert sind, erzielen heute auf dem Arbeitsmarkt viel weniger gute Resultate als früher, zudem schneiden sie auch im internationalen Vergleich schlecht ab. Es ist nicht ganz klar, welche Gründe zu dieser Situation geführt haben. Auf jeden Fall handelt es sich hier um eine Gruppe, die gezielte Integrationsmassnahmen benötigt. Andere OECD-Länder haben strukturierte Integrationsprogramme für diese Gruppe umgesetzt. Diesen Massnahmen, die bis zu drei Jahren dauern können, scheint ein gewisser Erfolg beschieden zu sein. In Ländern wie Dänemark oder Norwegen, die über strukturierte, auf die Integration in den Arbeitsmarkt ausgerichtete Programme verfügen, haben sich die Resultate der Personen, die vor kurzem aus humanitären Gründen eingewandert sind, verbessert. Dies deutet darauf hin, dass die Schweiz stark profitieren könnte, wenn sie sich an diesem Ansatz orientieren würde. 
Die Anreize der Kantone für eine rasche Integration der aus humanitären Gründen eingewanderten Personen in den Arbeitsmarkt müssen verstärkt werden...
... und die weiterhin bestehenden juristischen Hindernisse für den Zugang zum Arbeitsmarkt sollten beseitigt werden.
Der Rahmen für die Integration ist ziemlich komplex und undurchsichtig ...
Für die Sozialhilfe ist zwar nicht der Bund zuständig, auf Ebene der Kantone wird sie jedoch während den ersten fünf Aufenthaltsjahren der Flüchtlinge vom Bund bezahlt. Für die auch zahlenmässig immer wichtigere Gruppe der vorläufig aufgenommenen Personen bietet der Bund sogar eine Finanzierung während der ersten sieben Jahre, bevor die Kantone /Gemeinden für diese Personen zuständig sind. Vorläufig aufgenommene Personen erhalten zudem weniger als die ordentliche Sozialhilfe, und diese Tatsache scheint manchmal mit einer Verminderung der Integrationsbemühungen für diese Gruppe einher zu gehen. Dies bringt mit sich, dass für die Kantone Anreize fehlen, um die aus humanitären Gründen eingewanderten Personen während der ersten fünf bis sieben Jahre in den Arbeitsmarkt $\mathrm{zu}$ integrieren. Wenn die Immigranten jedoch während dieser Zeit nicht richtig vorbereitet werden, werden sie beim Eintritt in den Arbeitsmarkt grosse Schwierigkeiten haben. Gemäss Analysen aus anderen OECD-Ländern ist ein schneller Eintritt in den Arbeitsmarkt jedoch ein entscheidender Faktor für eine langfristige Integration. Die Anreize für eine rasche Integration der aus humanitären Gründen eingewanderten Personen in den Arbeitsmarkt sollten daher verstärkt werden.

Seit 2008 haben aus humanitären Gründen eingewanderte, vorläufig aufgenommene Migranten Zugang zum Arbeitsmarkt, ohne Prüfung der Arbeitsmarktsituation. Sie benötigen jedoch eine Arbeitsbewilligung, im Gegensatz zu den anderen Gruppen von Migranten. Diese erhalten sie im Allgemeinen, wenn sie einen Arbeitgeber finden, der bereit ist, sie einzustellen. Eine Abschaffung der Pflicht zum Erwerb einer separaten Arbeitsbewilligung würde dazu beitragen, dass der Papierkrieg vermindert und die Integration in den Arbeitsmarkt vereinfacht würde. Auf jeden Fall müssen die Arbeitgeber besser über die Möglichkeit der Anstellung solcher Migranten informiert werden.

Da die Tätigkeit des Bundes im Bereich der Integration bis vor kurzem eingeschränkt war, wurden die meisten Integrationsmassnahmen auf kantonaler oder kommunaler Ebene umgesetzt, was das Subsidiaritätsprinzip widerspiegelt. Dies hat zwar zu einer Flexibilität bei der Integration geführt, aber auch zu grossen Unterschieden bei den Dienstleistungen zwischen den einzelnen Kantonen. Auch wenn diese Tatsache in der Schweiz für viele Politiken gilt und auch zahlreiche Massnahmen und Programme für Nicht-Immigranten davon betroffen sind, stellt sich für Personen, die aus humanitären Gründen eingewandert sind, trotzdem die Frage nach der horizontalen Gerechtigkeit. Schliesslich können sie ihren Wohnkanton nicht frei wählen und sind auch in ihrer Mobilität eingeschränkt. 
... was hauptsächlich darauf zurück Komplexität und Intransparenz des schweizerischen zu führen ist, dass der Zugang zu den Integrationsmassnahmen von vielen Faktoren abhängt. Integrationsrahmens sind vielleicht dessen grösster Mangel. Dies ist im Wesentlichen darauf zurück zu führen, dass der Zugang zu den Integrationsdiensten von zahlreichen Faktoren abhängt - von Wohnkanton, Aufenthaltsstatus und Dauer des Aufenthalts, Erhalt (oder nicht) von Sozialversicherungsleistungen und davon, welche Sozialversicherung (Arbeitslosigkeit, Invalidität oder Sozialhilfe) gegebenenfalls für den Migranten zuständig ist.

Die Unterschiede im Angebot der Die Tatsache, dass das Angebot an Integrationsdiensten in den Dienstleistungen erfordern eine verschiedenen Kantonen offenbar unterschiedlich ist und viele bessere Koordination des staatlichen Migranten nicht von den allgemeinen Massnahmen profitieren Handelns.

Lohnsubventionen scheinen eine besonders wirksame Integrationsmassnahme für Immigranten zu sein, diese profitieren jedoch nur selten davon. können, erfordert eine bessere Koordination des staatlichen Handelns, sowohl innerhalb der Kantone als auch zwischen den Kantonen. Es sollten gemeinsame Minimalnormen angewendet werden, um sicher $\mathrm{zu}$ stellen, dass die Immigranten von Massnahmen profitieren können, die ihren Bedürfnissen entsprechen, und dies unabhängig vom Wohnort, dem Aufenthaltsstatus und der Art und Höhe von Versicherungsleistungen oder -beihilfen, auf die sie Anspruch haben oder nicht. Ausserdem wäre es wichtig, den Austausch guter Praktiken zwischen den Kantonen und Gemeinden zu verstärken.

Damit ein solcher Austausch Sinn macht, muss vorgängig evaluiert werden, welche Massnahmen funktionieren und welche nicht. Dies bedeutet, dass Forschung und Evaluation in die neuen Programme integriert werden müssen. Obwohl in der Schweiz die allgemeine Evaluationskultur gut entwickelt ist, gibt es praktisch keine spezifische Evaluation der Arbeitsmarktpolitik bezüglich der Immigranten und ihrer Kinder. Dies widerspiegelt den Ansatz einer Integrationspolitik über die allgemeinen Programme und Massnahmen, lässt jedoch die Tatsache beiseite, dass die Auswirkungen der aktiven Arbeitsmarktpolitik für Immigranten anders sein können als für Personen ohne Migrationshintergrund. Frühere Evaluationen (sowohl in der Schweiz als auch in anderen OECDLändern) haben ein ziemlich robustes Ergebnis gebracht: Lohnsubventionen wirken sich besonders bei Immigranten sehr positiv aus. In der Schweiz profitieren diese jedoch nur selten von dieser Massnahme. 
Da die heute verfügbaren Daten von Eine spezifische Evaluation fehlt nicht nur bezüglich der besserer Qualität sind, sollte es Teil Programme für Immigranten, sondern auch allgemein in der einer kohärenten Integrationspolitik Forschung über Integration. Dies ist erstaunlich, wenn man sein, das Forschungsdefizit zu beheben.

\section{Die Sprachförderung muss ausgebaut und stärker auf den Arbeitsmarkt ausgerichtet werden.}

Die Einbürgerung sollte erleichtert werden, da sie die Integration der Immigranten fördert. bedenkt, wie viele Immigranten und ihre Kinder seit langem in der Schweiz leben. Das Fehlen quantitativer Forschung ist teilweise auf einen Mangel an Daten zurück zu führen. Da nun nach und nach mehr und bessere Datensammlungen verfügbar werden (auch Längsschnittdaten), sollte das Beheben des Defizits in Forschung und Evaluation der Programme zur Integration der Immigranten und ihrer Kinder in den Arbeitsmarkt ein wichtiges Element beim Erarbeiten einer besser informierten und zielgerichteteren Politik Sein.

Internationale Studien zeigen, dass das Erlernen der Sprache die Integration der Immigranten erleichtern kann. Eine Evaluation der Sprachförderung in der Schweiz ist schwierig, da sie grösstenteils von verschiedenen Diensten auf kantonaler Ebene angeboten wird, die kaum miteinander in Kontakt stehen. Die wenigen vorhandenen Informationen über die sprachliche Förderung weisen darauf hin, dass entsprechende Kurse weniger häufig durchgeführt werden als in anderen OECD-Ländern, und der Besuch solcher Kurse nicht mit guten Resultaten in Bezug auf die Beschäftigung einhergeht. Es würde sich lohnen, die Gründe dafür vertieft zu untersuchen und die entsprechenden Massnahmen zu treffen. Auf jeden Fall scheint es vernünftig, das Feld der sprachlichen Ausbildung sowohl zu erweitern als auch stärker auf das Berufsleben auszurichten. Auch wäre es wünschenswert, die Schaffung eines allgemeinen Rahmens für die sprachliche Ausbildung ins Auge zu fassen und diese so gesamtschweizerisch $\mathrm{zu}$ vereinheitlichen.

Die Schweiz ist in Sachen Einbürgerungspolitik eines der restriktivsten Länder innerhalb der OECD. Diese Tatsache widerspiegelt die Idee, dass die Einbürgerung nicht ein Instrument für die Förderung der Integration ist, sondern vielmehr die Bestätigung einer gelungenen Integration. Gemäss den empirischen Daten geht die Einbürgerung Hand in Hand mit besseren Resultaten im Bereich der Beschäftigung der Immigranten und ihrer Kinder in der Schweiz. Dies gilt besonders für Immigranten aus Ländern mit niedrigen Einkommensniveau, die so Zugang erhalten zu besser qualifizierten Tätigkeiten und zum öffentlichen Dienst. Diese Feststellungen und weitere Längsschnittdaten aus OECD-Ländern legen nahe, dass mit einem erleichterten Zugang zum Schweizer Bürgerrecht offenbar viel zu gewinnen wäre. Auf jeden Fall hat das Beibehalten der geltenden Einschränkungen seinen Preis. Es wäre wichtig, dass diesbezüglich eine Sensibilisierung stattfinden würde und die Vorteile aufgezeigt würden, welche der Erwerb des Schweizer Bürgerrechts den dazu berechtigten Migranten bringt. 
Die Wohnsitzkriterien in Kanton und Gemeinde sollten überarbeitet werden, um die Mobilität zu fördern.

Die Integrationsmassnahmen müssen die Kompetenzen der Immigranten stärker berücksichtigen.

Die Transparenz in Bezug auf Evaluation und Anerkennung der ausländischen Diplome sollte verbessert werden und das Verfahren muss alle Berufe umfassen.
Neben der eidgenössischen Wohnsitzfrist von 12 Jahren für die ordentliche Einbürgerung gibt es Wohnsitzfristen des Kantons und der Gemeinde. Dies erschwert den Erwerb des Bürgerrechts und kann auf die Mobilität der Immigranten innerhalb der Schweiz bremsend wirken. Eine Reform der Schweizerischen Gesetzgebung über das Bürgerrecht ist in Vorbereitung. Sie sollte mittels einer umfassenden Harmonisierung der kantonalen und kommunalen Wohnsitzfristen einige der wichtigsten Schwächen des Gesetzes beseitigen und die eidgenössische Wohnsitzfrist auf acht Jahre verkürzen. Selbst wenn die vorgesehene Reform angenommen würde, wäre das schweizerische System im internationalen Vergleich weiterhin restriktiv, insbesondere für die zahlreichen in der Schweiz geborenen Kinder eingewanderter Eltern, von denen gegenwärtig nur wenige das Schweizer Bürgerrecht besitzen.

Die meisten verfügbaren Integrationsmassnahmen sind auf niedrig qualifizierte Arbeit ausgerichtet. Die Zahl der Migranten, die ihr Diplom in einem Land mit niedrigem Einkommensniveau erworben haben und «überqualifiziert» sind (Migranten in einer Anstellung, für die eine niedrigere Qualifikation verlangt wird als die formelle Qualifikation, die sie besitzen) ist jedoch hoch, und diese Feststellung scheint auch nach Berücksichtigung objektiver Kompetenzmessungen ihre Gültigkeit zu behalten.

Evaluation und Anerkennung ausländischer Diplome scheinen einer der Schwachpunkte des schweizerischen Systems zu sein. Die entsprechenden Kosten sind zwar tief und das Verfahren ist relativ schnell, das System ist jedoch nicht transparent und sogar bei Erbringern von Integrationsleistungen nicht sehr bekannt. Ausserdem ist es momentan für gewisse Berufe unmöglich, eine Evaluation und eine Anerkennung der Qualifikation und der im Ausland erworbenen Berufserfahrung zu erhalten. Diese Lücken im System sollten geschlossen werden. Da die überwiegende Mehrheit der Immigranten mit einem Diplom den Titel im Ausland erworben hat, ist es wichtig, das System für die Evaluation und die Anerkennung zu verbessern. Das Ergebnis des Evaluationsverfahrens scheint auf dem Arbeitsmarkt akzeptiert zu sein, weil die Immigranten, die eine formelle Anerkennung erhalten haben, im Bereich der Beschäftigung bessere Ergebnisse erzielen. Es gibt jedoch nur sehr wenige Immigranten mit einem Hochschuldiplom eines Nicht-EWR-Landes, die eine die Evaluation und Anerkennung ihrer Diplome beantragen. Es ist nicht ganz klar, ob dies darauf zurück zu führen ist, dass sie diese Möglichkeit nicht kennen, oder darauf, dass sie ein Gesuch gar nicht erst stellen, weil sie sich nur wenige Chancen auf eine Anerkennung ausrechnen. 
In dieser Hinsicht wäre es nützlich, Das Bundesamt für Berufsbildung und Technologie (BBT) eine zentrale Anmeldestelle für alle akzeptiert bereits «Vorgesuche» für Anerkennungen in allen Evaluations- und Disziplinen und auf allen Ebenen und bietet Informationen über Anerkennungsgesuche zu schaffen. die zuständigen Stellen an. Es wäre nun ein weiterer Schritt, eine zentrale Anmeldestelle zu schaffen, die formell alle Gesuche annimmt, statt sie den Kandidaten zurück zu schicken und ihnen die zu kontaktierende Stelle anzugeben. Ein solches Vorgehen wäre ein wichtiger Fortschritt im Sinn der Transparenz. Ausserdem sollte die Tatsache, dass man mit einer Anerkennung leichter eine gute Stelle findet, unter den Immigranten stärker verbreitet werden.

Die Passerellen-Angebote und das Es gibt nur wenige Passerellen-Ausbildungen für Immigranten, Mentoring für qualifizierte Migranten sollten in grösserem Umfang umgesetzt werden, in und die Tatsache, dass der Schwerpunkt sowohl bei den Flüchtlingen als auch allgemein bei den Arbeitslosen auf eine schnelle Integration in den Arbeitsmarkt gelegt wird, steht im Kooperation mit den Arbeitgebern.

Diskriminierung bei der Anstellung kommt in der Schweiz häufig vor, und eine verstärkte Sensibilisierung für dieses Problem ist erforderlich.
Widerspruch $\mathrm{zu}$ Brückenkursen bzw. Passerellen-Angeboten. Insbesondere der Zugang zu hochqualifizierten Stellen erfolgt oft über Netzwerke, aber über diese verfügt die eingewanderte Bevölkerung kaum. Hier scheinen Mentoring-Programme ein wirksames Instrument zu sein, diese sind jedoch in Umfang und Reichweite bislang begrenzt. Es scheint auch, dass die Immigranten sehr von einem grösseren Angebot für Akkreditierung nicht-formalen Lernens profitieren würden, einem Angebot, das in der Schweiz nach und nach ausgebaut wird. Bei der Ausarbeitung der Massnahmen zur Akkreditierung nichtformalen Lernens sollte sichergestellt werden, dass diese die Immigranten tatsächlich erreichen und auf ihre Bedürfnisse zugeschnitten sind. Diese Massnahmen sollten verstärkt angeboten werden, in Ko-operation mit den Arbeitgebern.

Durch Teststudien konnte gezeigt werden, dass Diskriminierung bei der Stellensuche häufig vorkommt. Um zu einem Vorstellungsgespräch eingeladen $\mathrm{zu}$ werden müssen immigrantenkinder, die ihre Ausbildung in der Schweiz absolviert haben, müssen bis zu fünf mal mehr Bewerbungen schreiben als Kinder ohne Migrationshintergrund mit ansonsten vergleichbarem Lebenslauf,. Die relativ tiefe Arbeitslosigkeit bei Immigrantenkindern lässt darauf schliessen, dass diese die Diskriminierung dadurch kompensieren, dass sie sich mehr bewerben. Die Häufigkeit der Diskriminierung wird auch teilweise dadurch überdeckt, dass die Lage auf dem Arbeitsmarkt allgemein gut ist. In der öffentlichen Debatte wird das Diskriminierung bei der Anstellung zudem kaum thematisiert. Dennoch benötigen Kinder von Immigranten doppelt so viel Zeit wie Kinder ohne Migrationshintergrund und ansonsten gleichen Schulleistungen, um eine Stelle zu finden. Eine stärkere Sensibilisierung für dieses Problem ist daher wichtig. 
Der juristische und institutionelle Rahmen für den Kampf gegen die Diskriminierung liegt im Vergleich mit den anderen OECD-Ländern weit zurück...

... und sollte durch andere Massnahmen ergänzt werden.
Der juristische und institutionelle Rahmen für den Kampf gegen die Diskriminierung liegt im Vergleich mit den meisten anderen OECD-Ländern weit zurück. Zurzeit ist Diskriminierung aufgrund der Nationalität nicht illegal, ausser für Immigranten aus der EU. Ausserdem sind die Beratungsstrukturen häufig weniger gut ausgestattet als in anderen Ländern. Sie können zwar juristische Stellungnahmen abgeben, jedoch keine Klagen einreichen. Dementsprechend ist die Anzahl der behandelten Dossiers unbedeutend angesichts der Häufigkeit von Diskriminierung, wie sie durch die Teststudien ans Licht gebracht worden ist.

Es ist daher wichtig, dass sowohl der juristische als auch der institutionelle Rahmen für den Kampf gegen Diskriminierung verstärkt und bei den Immigranten besser bekannt gemacht werden. Diese Reform könnte ergänzt werden durch entschlossenere Massnahmen zugunsten der Diversität, mit dem Ziel einer grösseren Vielfalt an Rekrutierungswegen für die Arbeitgeber. Dies fehlt momentan in der Schweiz. Der öffentliche Dienst, in dem die Immigranten untervertreten sind, muss bei dieser Bewegung ebenfalls involviert sein. Massnahmen wie beispielsweise anonyme Lebensläufe, «Diversitätslabels» und Beratung zu Diversität wurden vor kurzem in mehreren OECD-Ländern umgesetzt.

Das System der Berufslehre scheint für die Kinder der Immigranten gut zu funktionieren aber der Tatsache, dass der Prozentsatz der Lehrabschlüsse niedrig ist, sollte mehr Beachtung geschenkt werden.

Das internationale Programm der OECD zur Schülerbewertung (PISA) hat gezeigt, dass Immigrantenkinder in der Schweiz im Alter von 15 Jahren bedeutend schlechtere schulische Leistungen erbringen als die Kinder ohne Migrationshintergrund, und dass der Abstand grösser ist als in vielen anderen OECD-Ländern. Eine Längsschnittanalyse mit Schweizer PISA-Daten weist darauf hin, dass das Schul- und Ausbildungssystem diesen Immigrantenkindern später trotzdem relativ gute Qualifikationen ermöglicht. Das System der Berufslehre scheint für sie besonders gut zu funktionieren. Die Wahrscheinlichkeit, dass Immigrantenkinder ihre Lehre auch abschliessen, ist allerdings weniger gross. Die Gründe für dieses Phänomen sollten näher untersucht und anschliessend die nötigen Korrekturmassnahmen getroffen werden.

Immigrantenkinder scheinen heute Die meisten Immigrantenkinder schaffen den Übergang von der mehr Probleme zu haben als früher. Schule ins Erwerbsleben gut. Es gibt jedoch Anzeichen, die darauf Diesem Missstand abzuhelfen, sollte hindeuten, dass die neuen Kohorten von Immigrantenkindern eine Priorität des staatlichen Handelns werden. heute grössere Schwierigkeiten haben als frühere Gruppen, und viele im Ausland geborene Immigrantenkinder erzielen weniger gute Leistungen. Dies betrifft insbesondere Kinder, deren Eltern aus Ländern mit niedrigen Einkommensniveau stammen. Einige Jahre nach Schulabschluss haben sie oft weder eine Stelle noch stehen sie in einer Ausbildung (NEET). Da heute viele Kinder von Immigranten aus Ländern mit niedrigen Einkommensniveau ins Berufsleben eintreten, sollte die öffentliche Hand die Verbesserung ihrer Integrationsergebnisse $\mathrm{zu}$ einer Priorität machen. 
Alle jungen Immigranten müssen gleichberechtigten Zugang zur aktiven Arbeitsmarktpolitik für Jugendlichehaben.
Die Förderung und Betreuung der Kleinkinder muss verbessert werden mit einem Schwerpunkt auf Kinder benachteiligter Immigranten.
Es existiert eine breite Palette an Massnahmen, um Jugendlichen, die Unterstützung brauchen, den Übergang von der Schule ins Erwerbsleben zu erleichtern. Da der Zugang zu den meisten Massnahmen der aktiven Arbeitsmarktpolitik jedoch häufig auf Personen beschränkt ist, die sich seit mehr als 10 Jahren im Land befinden, sind viele junge Immigranten davon ausgeschlossen. Ausserdem erhalten die jungen Immigranten, die von diesen Programmen, insbesondere dem «Motivationssemester» profitieren, keine Arbeitslosenbeiträge (im Gegensatz zu den in der Schweiz geborenen Kindern). Sie können daher versucht sein, direkt in den Arbeitsmarkt einzutreten und sich mit einer wenig qualifizierten Arbeit zufrieden zu geben. So stehen sie in der Gefahr, später ohne Stelle und ohne Ausbildung dazustehen, was offenbar häufig der Fall ist. Es wäre eine erste Massnahme, um diese wichtige Herausforderung anzugehen, wenn sicher gestellt würde, dass Immigrantenkinder dieselben Anreize für die Teilnahme an den Programmen haben wie Kinder ohne Migrationshintergrund.

Die vorschulische Erziehung ist offenbar ein Bereich, der für , Immigrantenkinder besondere Vorteile mit sich bringt. Dies zeigen Forschungen aus mehreren OECD-Ländern. Die vorschulische Erziehung ist jedoch in der Schweiz gegenwärtig stark unterentwickelt, insbesondere für Kinder im für die Integration entscheidenden Alter von drei und vier Jahren. Ein grösseres und zielgerichteteres Angebot vorschulischer Erziehung für diese Altersgruppe sowie Massnahmen für eine frühe sprachliche Unterstützung würden offenbar viele Vorteile bringen. Profitieren würden nicht nur die Kinder der Immigranten, sondern auch deren Mütter, für welche die Tatsache, Kinder zu haben, einen viel grösseren Einfluss auf den Bereich der Erwerbstätigkeit hat als für Mütter, die in der Schweiz geboren sind. 
DELSA/ELSA/WD/SEM(2012)2

\section{ANNEX 3.}

\section{SINTESI}

La Svizzera è uno dei Paesi dell'OCSE con la maggiore percentuale di immigrati (il 27\% delle persone in età lavorativa è nato all'estero) e in cui il tema dell'immigrazione occupa un posto di rilievo sia nell'agenda politica sia nel dibattito pubblico. Se si tiene conto delle numerose discussioni sollevate da questo problema a livello nazionale, si potrebbe essere tentati di pensare che in Svizzera le persone immigrate siano meno bene integrate che in altri Paesi.

I fatti dimostrano invece che, nell'insieme, l'integrazione in Svizzera funziona piuttosto bene. In genere, per quanto riguarda il mercato del lavoro, la popolazione immigrata si trova in una situazione complessivamente molto favorevole rispetto a quanto si osserva in altri Paesi. Il tasso di occupazione degli immigrati di ambedue i sessi è più elevato che negli altri Paesi dell'OCSE.

Questi ottimi risultati sono da ricondurre soprattutto alla situazione del mercato del lavoro svizzero globalmente buona e a una combinazione particolare di Paesi d'origine. La maggior parte dei migranti (più del 60\%) è originaria di Paesi dell'OCSE ad alto reddito, e più della metà di loro proviene dai Paesi limitrofi, le cui lingue nazionali sono le stesse di quelle parlate in Svizzera. Gli altri immigrati provengono soprattutto dai Paesi dell'ex Jugoslavia e dalla Turchia.

Negli ultimi anni, dopo l'introduzione progressiva della libera circolazione delle persone con gli Stati membri dell'Unione europea, la Svizzera ha assistito all'arrivo di un numero insolitamente elevato di stranieri. Circa il 5\% della popolazione residente è composto da immigrati recenti ossia da persone che si sono stabilite in Svizzera da meno di cinque anni. La maggior parte dei nuovi arrivati è originaria dei Paesi limitrofi, soprattutto dalla Germania e, secondo tutti gli indicatori convenzionali, si integra bene nel mercato del lavoro.

Tuttavia, nonostante un quadro globalmente positivo, la situazione è più delicata per certe categorie di immigrati, come per esempio le donne con bambini piccoli. Infatti, sono poche le iniziative a favore dell'integrazione delle donne immigrate, le quali non hanno accesso a tutte le misure di politica attiva del mercato del lavoro. Del resto, alcuni elementi denotano un calo del tasso d'attività di questo gruppo di popolazione da qualche anno a questa parte.

Vi è un altro gruppo con un tasso d'occupazione mediocre, anche nel confronto internazionale: i migranti titolari di un permesso di soggiorno per motivi umanitari recentemente arrivati che, rispetto ai gruppi precitati, sembrano avere maggiori difficoltà a integrarsi nel mercato del lavoro svizzero. Contrariamente ad altri Paesi, la Svizzera non ha ancora predisposto un programma d'integrazione specifico destinato a questa categoria di nuovi arrivati, il che può spiegare in parte tali risultati insoddisfacenti. Sulla scorta delle esperienze incoraggianti maturate dai Paesi dell'OCSE che propongono programmi d'integrazione strutturati e incentrati sul mercato del lavoro, sarebbe auspicabile che la Svizzera prendesse seriamente in considerazione l'adozione di simili iniziative.

In Svizzera, il tasso d'occupazione generalmente elevato degli immigrati è legato anche al fatto che i migranti titolari di un diploma provenienti da Paesi non membri dell'OCSE spesso sono sovraqualificati. Le qualifiche acquisite all'estero sono insufficientemente valorizzate sul mercato del lavoro svizzero, e l'offerta di corsi "passerella" è alquanto limitata. Contrariamente ad altri Paesi dell'OCSE, la Svizzera ha realizzato pochi programmi di mentorato o iniziative analoghe atti a fornire agli immigrati i contatti 
indispensabili con gli autoctoni e i datori di lavoro, familiarizzandoli al tempo stesso con il funzionamento del mercato del lavoro. Vista la cruciale importanza di questi due aspetti per accedere a impieghi altamente qualificati, simili interventi meriterebbero di essere ampiamente diffusi in collaborazione con i datori di lavoro.

Il carattere federale del Paese si riflette chiaramente nella politica d'integrazione. Infatti, diverse misure volte a promuovere l'integrazione sono state sviluppate a livello locale e cantonale. L'applicazione del principio della sussidiarietà ha comportato l'attuazione di misure puntuali e flessibili destinate a numerosi immigrati. Ma al tempo stesso ha ritardato lo sviluppo di una politica integrativa a livello federale. Di conseguenza, e nonostante un netto miglioramento durante l'ultimo decennio, l'architettura generale in materia d'integrazione rimane sottosviluppata. Paragonandola alle azioni condotte in altri Paesi dell'OCSE, nella maggior parte dei quali la popolazione immigrata è meno numerosa che in Svizzera, la politica integrativa federale è abbastanza modesta. Salvo qualche strumento come la formazione linguistica elementare finanziata dall'Ufficio federale della migrazione, le misure specifiche destinate agli immigrati in Svizzera sono poche. Invece di concepire politiche destinate ai soli immigrati, l'approccio globale all'integrazione parte dall'idea che gli immigrati possono beneficiare dei servizi offerti a tutti. Per colmare le lacune del sistema attuale, la Confederazione, i Cantoni e le autorità locali hanno formulato recentemente un certo numero di suggerimenti volti a migliorare il quadro generale dell'integrazione, impegnandosi inoltre ad aumentare le risorse destinate all'integrazione.

A livello cantonale, le misure volte a favorire l'integrazione variano molto, in parte a causa delle differenze per quanto riguarda entità e composizione delle popolazioni immigrate. Sebbene negli ultimi anni numerosi Cantoni abbiano intensificato le loro misure integrative, spesso lo hanno fatto su piccola scala e nell'ambito di progetti modello, il che non permette di valutarne facilmente l'efficacia. Occorrerebbe che le autorità federali stabilissero alcune norme minime affinché tutti gli immigrati possano beneficiare delle misure di cui hanno bisogno, a prescindere dal loro Cantone di residenza.

Per gli immigrati è difficile accedere alla cittadinanza svizzera: in effetti, la durata di soggiorno richiesta è particolarmente lunga - 12 anni per la procedura ordinaria, ossia il periodo più lungo dell'OCSE -, inoltre il processo d'acquisizione si svolge a tre livelli e il candidato deve soddisfare le esigenze federali, cantonali e comunali. $\mathrm{E}$ in atto una riforma della legislazione, volta a ovviare alle maggiori lacune della legge sulla cittadinanza e a migliorare la mobilità dei migranti sul territorio svizzero. Le osservazioni empiriche suggeriscono che ciò potrebbe dare una forte spinta all'integrazione dei gruppi di immigrati svantaggiati.

Nel confronto internazionale, le performance occupazionali dei figli d'immigrati sono generalmente buone. Ciò è dovuto in parte alle buone condizioni generali del mercato del lavoro nonché ad altri fattori quali il ruolo importante dell'apprendistato che, a quanto pare, avrebbe un effetto particolarmente benefico per i figli di immigrati durante il processo di transizione dalla scuola al lavoro. Per preparare all'apprendistato i giovani poco scolarizzati (tra cui anche molti figli d'immigrati) sono altresì stati sviluppati alcuni programmi innovativi, che sembra abbiano avuto un effetto benefico.

I figli d'immigrati i cui genitori hanno un basso livello d'istruzione conseguono risultati mediocri a scuola; al momento, questi giovani sono sempre più numerosi ad accedere al mercato del lavoro. Queste performance meno soddisfacenti sembrerebbero riconducibili, almeno in parte, alla mancanza di interventi di sostegno sufficientemente precoci da parte del sistema educativo. Offrire ai figli d'immigrati dall'età di tre o quattro anni in poi un insegnamento adeguato e mirato, parallelamente all'apprendimento della lingua, dovrebbe dunque imporsi urgentemente come una priorità dell'azione pubblica.

Un settore in cui la Svizzera accusa un certo ritardo rispetto ad altri Paesi dell'OCSE è quello della lotta alla discriminazione. I datori di lavoro non si rendono sufficientemente conto del problema, che del resto è assente anche dal dibattito pubblico. Eppure, alcuni studi hanno dimostrato che prima di essere 
invitato a un colloquio di assunzione, un figlio d'immigrati, soprattutto se i suoi genitori sono originari dell'ex Jugoslavia, deve presentare un numero di candidature pari al quintuplo di quelle inoltrate da un figlio di autoctoni. Occorrerebbe dunque adottare le misure che s'impongono per ovviare a questo tipo di ineguaglianza.

Sebbene, per quanto riguarda l'integrazione nel mercato del lavoro della popolazione immigrata, i risultati conseguiti dalla Svizzera nel confronto internazionale siano in genere buoni, alcuni segni rivelano una situazione diversa per determinate categorie di migranti, ossia per certi gruppi svantaggiati che corrono il rischio di restare indietro. È importante agire subito, mentre i risultati globali sono ancora positivi. Il problema è stato individuato e sono già in atto misure volte a intensificare l'integrazione ai tre livelli del governo. Per molti versi, le politiche integrative della Svizzera non reggono tuttavia il confronto con quelle adottate da altri Paesi dell'OCSE. Occorrerebbe pertanto considerare un certo numero di misure per rimediare a questa situazione e fare in modo che d'ora in poi i risultati siano soddisfacenti per tutte le categorie d'immigrati.

\section{Sintesi delle principali raccomandazioni per le politiche}

\section{A) Potenziare il quadro globale d'integrazione}

- Sviluppare norme minime comuni affinché le misure volte a favorire l'integrazione sia applicate in tutti i Cantoni.

- $\quad$ Facilitare lo scambio di buone pratiche tra i Cantoni e i Comuni.

- Assicurarsi che tutti gli immigrati che necessitano di un aiuto all'integrazione vi possano accedere in modo appropriato, a prescindere dal tipo di permesso di cui sono titolari nonché dalla natura e dalla rilevanza delle prestazioni di cui beneficiano, specialmente trattandosi di donne immigrate.

- Offrire una formazione linguistica a tutti gli immigrati che ne hanno bisogno, tenendo conto delle loro competenze e delle loro qualifiche.

- $\quad$ Facilitare l'acquisizione della cittadinanza svizzera, in particolare riducendo le esigenze dei Cantoni e dei Comuni in termini di durata del soggiorno, così da agevolare la mobilità geografica dei migranti.

- Sensibilizzare ai vantaggi derivanti dall'acquisizione della cittadinanza svizzera per una migliore integrazione degli immigrati e dei loro figli.

\section{B) Favorire l'integrazione rapida nel mercato del lavoro dei migranti per motivi umanitari}

- Rafforzare gli incentivi dei Cantoni a favore dell'integrazione rapida nel mercato del lavoro dei migranti per motivi umanitari durante i primi cinque anni di soggiorno.

- Realizzare un programma d'integrazione strutturato destinato a tutte le persone immigrate di recente per motivi umanitari (i richiedenti la cui domanda è stata accolta o che beneficiano dell'ammissione provvisoria), tenendo conto dei bisogni individuali e ponendo chiaramente l'accento sull'integrazione nel mercato del lavoro.

- Informare meglio i datori di lavoro circa l'accesso al mercato del lavoro delle persone che beneficiano dell'ammissione provvisoria. 


\section{Sintesi delle principali raccomandazioni per le politiche (cont.)}

\section{C) Utilizzare al meglio le competenze dei migranti}

- Assicurarsi che l'accento attualmente posto sull'occupazione poco qualificata dei migranti per motivi umanitari non impedisca di utilizzare al meglio le loro competenze.

- Far meglio conoscere agli immigrati le offerte disponibili in materia di valutazione e di riconoscimento delle qualifiche acquisite all'estero e spiegare quali sono i vantaggi derivanti da tale riconoscimento.

- $\quad$ Predisporre corsi passerella e altri programmi di sostegno per aiutare gli immigrati titolari di diplomi conseguiti all'estero ad accedere a impieghi più qualificati.

- Considerare la possibilità di estendere con discernimento il beneficio delle sovvenzioni salariali temporanee agli immigrati.

\section{D) Intensificare gli sforzi a favore di una rapida integrazione dei figli d'immigrati}

- Sviluppare l'educazione prescolare e rivolgere un'attenzione particolare alla partecipazione dei figli d'immigrati provenienti da ambienti svantaggiati a partire dall'età di $3 \circ 4$ anni.

- Potenziare la formazione linguistica dei figli d'immigrati, segnatamente dei più giovani.

- Esaminare le cause dei tassi apparentemente deboli di completamento della formazione da parte dei figli d'immigrati, adottare misure per porre rimedio a questa situazione.

\section{E) Stabilire un quadro solido per combattere la discriminazione}

- Rendere illegale la discriminazione fondata sulla nazionalità al momento dell'assunzione.

- Sensibilizzare soprattutto i datori di lavoro e la società in generale alla questione della discriminazione.

- $\quad$ Prendere in considerazione l'introduzione di misure più incisive per combattere la discriminazione. 


\section{VALUTAZIONE E RACCOMANDAZIONI}

La Svizzera presenta un'elevata percentuale di immigrati e, per quanto riguarda l'integrazione nel a una delle percentuali più elevate registrate nella zona dell'OCSE. mercato del lavoro, il bilancio globale è positivo.

Ciò è dovuto in parte alla situazione di quasi pieno impiego in Svizzera e inoltre al fatto che la maggior parte degli immigrati proviene dai Paesi limitrofi.

In Svizzera, le persone nate all'estero rappresentano circa il 27\% della popolazione, il che corrisponde, come nel Lussemburgo e in Australia, Nel confronto internazionale, i principali indicatori dell'integrazione degli immigrati nel mercato del lavoro sono in genere abbastanza favorevoli. La Svizzera si colloca tra i Paesi dell'OCSE con il più alto tasso d'occupazione degli immigrati di ambedue i sessi. Lo stesso vale anche per i figli nati in Svizzera da genitori immigrati. Tuttavia, nonostante il basso tasso di disoccupazione generale registrato nel Paese, la disoccupazione di certi gruppi di immigrati non è trascurabile, in particolare trattandosi in molti casi di donne immigrate con bambini piccoli.

Pare che la situazione piuttosto favorevole dell'integrazione in Svizzera rispetto agli altri Paesi dell'OCSE sia sostanzialmente dovuta a due fattori. Innanzitutto, la situazione globale del mercato del lavoro svizzero è buona. Inoltre, contrariamente alla maggior parte degli altri Paesi dell'OCSE, una forte proporzione dell'immigrazione passata e presente proviene da Paesi ad alto reddito, soprattutto dalla Germania e dall'Italia (i due maggiori Paesi d'origine). Nel gruppo dei Paesi d'origine a basso reddito, quasi la metà di tutti gli immigrati è originaria dell'ex Jugoslavia e dei suoi Paesi successori, senza dimenticare il $12 \%$ degli immigrati provenienti dalla Turchia. I flussi migratori sono dovuti soprattutto a motivi di lavoro e al ricongiungimento familiare connesso, mentre l'immigrazione per motivi umanitari (che in tutti i Paesi è caratterizzata da maggiori difficoltà di integrazione nel mercato del lavoro) è più bassa rispetto ad altri Paesi. Tuttavia, in termini quantitativi, nemmeno questo gruppo è trascurabile e di fatto, negli ultimi due decenni, la Svizzera è stata uno dei principali Paesi di destinazione dei richiedenti l'asilo dell'OCSE.

La Svizzera annovera numerosi immigrati recenti originari

Dal 2002, in seguito alla progressiva introduzione della libera circolazione delle persone con l'UE e i suoi Paesi membri, la Svizzera dell'UE. In genere, si tratta di una ha assistito all'afflusso di un forte numero di immigrati provenienti fetta della popolazione bene integrata nel mercato del lavoro. dall'UE. Gli immigrati arrivati durante questo periodo rappresentano una percentuale della popolazione del Paese superiore al 5\%. All'interno di questo gruppo si riscontra, secondo il Paese d'origine, una grande diversità sociodemografica dei flussi e segnatamente gli immigrati provenienti dal Portogallo sono confrontati anche con un elevato tasso di disoccupazione. In genere, le persone immigrate di recente in provenienza dall'UE allargata conseguono ottimi risultati sul mercato del lavoro. Rispetto alla media degli autoctoni, queste persone occupano più frequentemente un posto di lavoro equivalente al loro livello di qualifica formale, il che dimostra che le loro competenze corrispondono al fabbisogno di manodopera. 
Vi sono segni di un degrado della situazione occupazionale delle donne immigrate originarie di Paesi a basso reddito. Occorre seguire la cosa con particolare attenzione.

La situazione mediocre delle persone immigrate di recente in Svizzera per motivi umanitari richiede misure più strutturate a favore dell'integrazione.
Le donne immigrate originarie di Paesi a basso reddito, segnatamente le nuove arrivate, non solo conseguono risultati mediocri sul piano occupazionale, ma da alcuni anni vedono la loro situazione addirittura deteriorarsi. Tale evoluzione è inquietante e richiede un attento monitoraggio. Infatti, le donne immigrate tendono in genere a sottrarsi agli sforzi compiuti in Svizzera a favore dell'integrazione, poiché spesso sono lontane dal mercato del lavoro e non beneficiano di alcuna prestazione. La recente riduzione del cofinanziamento (attraverso l'assicurazione contro la disoccupazione) delle misure attive del mercato del lavoro adottate a sostegno delle persone che non beneficiano di un'indennità di disoccupazione potrebbe comportare, a meno che i servizi sociali non si oppongano, una nuova riduzione dell'offerta già limitata di misure integrative, svantaggiando ulteriormente questo gruppo. Contrariamente ai migranti per motivi umanitari, i migranti giunti in Svizzera ai fini del ricongiungimento familiare non possono beneficiare di un aiuto all'integrazione standard all'arrivo, anche se viene offerto loro un certo sostegno sotto forma di una formazione linguistica di base. Gli altri Paesi dell'OCSE prevedono invece sempre più spesso misure d'accoglienza destinate ai nuovi arrivati, e/o le attività di organizzazioni non governative compensano l'assenza di offerte globali in tali Stati. Tali misure e attività occupano un posto meno importante in Svizzera. Siccome l'integrazione riuscita delle donne immigrate nel mercato del lavoro ha ricadute positive sui figli, l'ampliamento delle misure integrative destinate a questa cerchia della popolazione meriterebbe di essere preso seriamente e urgentemente in considerazione.

Le persone immigrate di recente in Svizzera per motivi umanitari conseguono risultati di gran lunga inferiori, sul mercato del lavoro, rispetto al passato e al confronto internazionale. Le ragioni non sono del tutto chiare. A ogni modo, si tratta di un gruppo che necessita di misure integrative mirate. Anche altri Paesi dell'OCSE hanno predisposto programmi strutturati volti a favorire l'integrazione di questo gruppo. Le misure adottate, che possono estendersi sull'arco di tre anni, sembrano dare buoni risultati. Il miglioramento della situazione dei migranti arrivati di recente in Paesi dotati di programmi strutturati incentrati sull'integrazione nel mercato del lavoro, quali la Danimarca e la Norvegia, induce a pensare che la Svizzera avrebbe molto da guadagnare lasciandosi ispirare da tale approccio. 
Occorre potenziare gli incentivi dei Cantoni a una rapida integrazione dei migranti per motivi umanitari nel mercato del lavoro.

... e abbattere gli ostacoli giuridici che si oppongono a loro accesso al mercato del lavoro.

Il contesto dell'integrazione ̀̀ relativamente complesso e poco trasparente...
Sebbene competa alle amministrazioni sub-federali, l'aiuto sociale a livello cantonale è finanziato dalla Confederazione durante i primi cinque anni di soggiorno dei rifugiati. Per questo (viepiù) cospicuo gruppo di persone ammesse a titolo provvisorio, la Confederazione offre addirittura un finanziamento per i primi sette anni, prima ancora che i Cantoni / i Comuni prendano in carico le persone appartenenti a questo gruppo. Inoltre, le persone ammesse a titolo provvisorio beneficiano in minor misura dell'aiuto sociale normalmente previsto e pare che questo fenomeno vada di pari passo con una diminuzione degli sforzi volti a favorire l'integrazione di questo gruppo. $\mathrm{Ne}$ consegue uno scarso incentivo per i Cantoni a integrare nel mercato del lavoro i migranti giunti in Svizzera per motivi umanitari durante i primi cinque-sette anni. Ma se durante questo lasso di tempo non vengono preparati correttamente, per gli immigrati risulta estremamente difficile posizionarsi con successo sul mercato del lavoro. Secondo i dati di altri Paesi dell'OCSE, un'entrata rapida nel mercato del lavoro è determinante per l'integrazione a lungo termine. Occorre dunque potenziare gli incentivi per una rapida integrazione nel mercato del lavoro di questi migranti.

Dal 2008, i migranti per motivi umanitari ammessi a titolo provvisorio possono accedere al mercato del lavoro a prescindere dalla situazione occupazionale. Tuttavia, contrariamente agli altri gruppi, questi migranti necessitano tuttora di un'autorizzazione di lavoro che in genere riescono a ottenere se trovano un datore di lavoro disposto ad assumerli. Abolire l'obbligo di un'autorizzazione di lavoro a parte permetterebbe di ridurre le pratiche burocratiche e di facilitare l'integrazione nel mercato del lavoro. In ogni caso, occorre informare meglio i datori di lavoro della possibilità di assumere questi migranti.

Fino a poco tempo fa, gli interventi della Confederazione a favore dell'integrazione erano limitati, per cui la maggior parte delle misure integrative era realizzata a livello cantonale o comunale, secondo il principio della sussidiarietà. Pur avendo contribuito a un approccio flessibile all'integrazione, ciò ha condotto anche a una differenza rilevante tra i livelli di prestazione dei servizi nei vari Cantoni. Sebbene in Svizzera tale sia il caso in molti ambiti politici e in numerosi servizi destinati ai non immigrati, nel caso dei migranti per motivi umanitari ciò solleva la questione dell'equità orizzontale, visto che non possono scegliere liberamente il loro Cantone di residenza e possono beneficiare soltanto di una mobilità territoriale limitata. 
...il che è dovuto soprattutto al fatto che l'accesso ai servizi volti a dell'integrazione svizzero è forse il suo maggior difetto. Alla base vi è favorire l'integrazione dipende da Sostanzialmente il fatto che l'accesso ai servizi volti a favorire numerosi fattori. dal tipo di permesso e dalla durata del soggiorno, dall'ottenimento (o meno) di prestazioni d'assicurazione sociale nonché dal regime d'assicurazione sociale (disoccupazione, invalidità o aiuto sociale) cui soggiace il migrante. Queste differenze tra Cantoni di residenza riguardano parimenti la popolazione autoctona, ma diversamente da quest'ultima, visto che si tratta soprattutto di migranti titolari di un permesso di soggiorno per motivi umanitari, gli immigrati non hanno la possibilità di scegliere liberamente il loro luogo di residenza a causa delle restrizioni alla mobilità geografica.

La differenza per quanto riguarda L'apparente differenza per quanto riguarda l'offerta di servizi volti a l'offerta di servizi evidenzia la necessità di coordinare maggiormente l'operato pubblico. favorire l'integrazione nei vari Cantoni e il fatto che numerosi migranti non possono beneficiare dei servizi generalmente offerti evidenziano la necessità di un maggiore coordinamento dell'operato pubblico, sia all'interno dei Cantoni sia tra i vari Cantoni. Occorrerebbero norme minime comuni per garantire agli immigrati misure corrispondenti alle loro esigenze, a prescindere dal loro luogo di residenza in Svizzera, dal tipo di permesso nonché dalla natura e dalla rilevanza delle prestazioni/delle indennità assicurative a cui hanno o non hanno diritto. Andrebbe inoltre rafforzato lo scambio di buone pratiche tra i Cantoni e i Comuni.

Apparentemente le sovvenzioni salariali sono una misura integrativa particolarmente efficace destinata agli immigrati, di cui questi tuttavia beneficiano raramente.
Affinché il predetto scambio abbia una sua utilità, occorre valutare preliminarmente le misure che funzionano e quelle che non funzionano, il che implica la necessità di integrare nei nuovi programmi le dimensioni della ricerca e della valutazione. Infatti, nonostante una cultura di valutazione globale ben sviluppata in Svizzera, non vi è stata praticamente nessuna valutazione specifica delle politiche del mercato del lavoro concernente gli immigrati e i loro figli. Ciò riflette l'approccio alla politica d'integrazione attraverso i servizi generalmente offerti, ma non tiene conto del fatto che la politica attiva del mercato del lavoro può avere un impatto differente sugli immigrati e sugli autoctoni. Dalle valutazioni effettuate in passato (sia in Svizzera sia in altri Paesi dell'OCSE) è scaturito un risultato abbastanza concreto: le sovvenzioni salariali sono particolarmente benefiche per gli immigrati. Peccato che in Svizzera questi ultimi beneficino solo raramente di tale misura. 
Dal momento che i dati ora disponibili sono di migliore qualità, una politica d'integrazione coerente dovrebbe dunque colmare la lacuna della ricerca.

\section{La formazione linguistica va sviluppata e orientata più} chiaramente al mercato del lavoro.

L'assenza di una valutazione specifica dei programmi concernenti gli immigrati vale anche, sebbene in un'ottica più generale, per la ricerca sull'integrazione, il che sorprende vista la forte presenza di lunga data degli immigrati e dei loro figli in Svizzera. L'assenza di una ricerca quantitativa è dovuta in parte a una mancanza di dati. Dal momento che le serie di dati rese progressivamente disponibili sono sempre più numerose e di migliore qualità (compresi i dati longitudinali), cercare di colmare la lacuna della ricerca e rimediare alla mancante valutazione dei programmi concernenti l'integrazione nel mercato del lavoro degli immigrati e dei loro figli dovrebbe costituire un elemento importante per l'elaborazione di strategie politiche più chiare e più mirate.

A livello internazionale è risaputo che l'apprendimento della lingua può facilitare l'integrazione degli immigrati. È difficile valutare la formazione linguistica in Svizzera dal momento che è perlopiù dispensata a livello cantonale, da servizi che praticamente non interagiscono tra loro. Le poche informazioni disponibili sulla formazione linguistica inducono a pensare che in Svizzera l'offerta sia più limitata che negli altri Paesi dell'OCSE e non venga associata a buoni risultati per quanto riguarda l'occupazione di coloro che l'hanno conseguita. Occorrerebbe esaminare in modo più approfondito le ragioni a monte e adottare misure corrispondenti. Ad ogni modo sarebbe d'uopo ampliare il campo della formazione linguistica e improntare maggiormente l'insegnamento alla professione. Per standardizzare la formazione linguistica su tutto il territorio svizzero sarebbe auspicabile un quadro globale.

Occorrerebbe facilitare la Tra i Paesi dell'OCSE, la Svizzera si è dotata di una delle politiche di naturalizzazione in quanto fattore d'integrazione dei migranti. naturalizzazione più restrittive, rispecchiando in questo l'idea della naturalizzazione intesa come garanzia di un'integrazione riuscita e non come uno strumento atto a promuoverla. Secondo i dati empirici, la naturalizzazione viene associata a migliori risultati per quanto riguarda la situazione occupazionale degli immigrati e dei loro figli in Svizzera, in particolare trattandosi di persone originarie di Paesi a basso reddito che in tal modo possono accedere a impieghi più qualificati e svolgere funzioni pubbliche. Partendo da tali constatazioni e da altri dati longitudinali forniti dai Paesi dell'OCSE, si può ipotizzare che ci sarebbe molto da guadagnare facilitando l'acquisizione della cittadinanza svizzera. Il mantenimento delle restrizioni in vigore ha comunque un costo e pertanto sarebbe opportuno intraprendere un'azione di sensibilizzazione in merito, dimostrando i vantaggi connessi all'ottenimento della cittadinanza svizzera per i migranti che vi hanno diritto. 
Per promuovere la mobilità occorrerebbe rivedere i requisiti di residenza cantonali e comunali.
Oltre al requisito federale di 12 anni di soggiorno per la naturalizzazione ordinaria, esistono requisiti di residenza a livello cantonale e comunale. Ciò rende più difficile l'acquisizione della cittadinanza e può essere un freno alla mobilità degli immigrati all'interno del Paese. È in preparazione una riforma della legislazione svizzera sulla naturalizzazione. L'obiettivo è di eliminare alcuni dei maggiori punti deboli della legge grazie a un'armonizzazione globale dei requisiti relativi alla durata di residenza stabiliti a livello cantonale e comunale e di ridurre a otto anni la durata di soggiorno richiesta a livello federale. Anche se la riforma prevista sarà votata, nel confronto internazionale il sistema svizzero resterà comunque restrittivo, soprattutto per quanto riguarda i numerosi bambini nati in Svizzera da genitori immigrati di cui attualmente solo alcuni hanno la cittadinanza svizzera.
Le misure volte a favorire l'integrazione devono tenere maggiormente conto delle competenze degli immigrati.

La maggior parte delle misure volte a favorire l'integrazione sono incentrate sul lavoro poco qualificato. Molti migranti che hanno conseguito un diploma in un Paese a basso reddito sono sovraqualificati e svolgono mansioni corrispondenti a una qualifica inferiore a quella formalmente conseguita. Questa constatazione sembra mantenersi anche se si tiene conto di una valutazione obiettiva delle competenze.

Occorre accrescere la trasparenza La valutazione e il riconoscimento dei diplomi esteri sembrano uno della valutazione e del riconoscimento dei diplomi esteri e considerare tutte le professioni.

dei punti deboli del sistema svizzero. Sebbene i relativi costi siano bassi e il processo abbastanza veloce, il sistema manca di trasparenza ed e inoltre poco conosciuto anche dai fornitori di prestazioi integrative. Del resto, per un certo numero di professioni è tuttora impossibile ottenere una valutazione e un riconoscimento delle qualifiche e dell'esperienza lavorativa acquisite all'estero. Proprio qui risiedono le lacune del sistema che andrebbero colmate. È importante migliorare il sistema di valutazione e di riconoscimento, poiché la stragrande maggioranza degli immigrati diplomati ha conseguito il proprio titolo all'estero. A quanto pare, il risultato di tale procedura è bene accetto sul mercato del lavoro, giacché gli immigrati che hanno ottenuto un riconoscimento formale dei loro titoli mostrano risultati migliori sul piano occupazionale. Comunque, sono rari gli immigrati in possesso di diplomi d'insegnamento superiore rilasciati da Paesi non membri dello SEE che chiedono la valutazione e il riconoscimento dei loro titoli. Non si capisce bene se ciò sia dovuto alla loro ignoranza di tale possibilità o se sono semplicemente scoraggiati all'idea di dover presentare la richiesta, ritenendo di avere poche probabilità di ottenere il riconoscimento. 
Sarebbe utile creare uno sportello unico per la presentazione di tutte le richieste di valutazione e di riconoscimento.

\section{Occorrerebbe un'offerta più ampia di corsi passerella $e$ mentorato per i migranti qualificati.}

\section{L'alta incidenza della discriminazione nelle assunzioni in Svizzera meriterebbe una maggiore sensibilizzazione al problema.}

L'Ufficio federale della formazione professionale e della tecnologia (UFFT) accetta già le «domande preliminari» di riconoscimento in tutte le discipline e a tutti i livelli e fornisce informazioni sugli organi competenti. In una prossima tappa, si potrebbe creare uno sportello unico che accetti formalmente tutte le richieste anziché rinviarle ai candidati indicando il nome dell'organo competente al quale rivolgersi. Si tratterebbe di un passo importante verso una maggiore trasparenza e presenterebbe altresì il vantaggio di diffondere maggiormente la pratica di riconoscimento, prerequisito utile per trovare un buon impiego.

Esistono pochi corsi passerella destinati agli immigrati. Peraltro, l'accento su un'integrazione rapida nel mercato del lavoro sia dei rifugiati sia delle persone disoccupate in generale è in contraddizione con le offerte passerella. Va altresì rilevato che la popolazione immigrata è raramente associata alle reti che danno accesso agli impieghi altamente qualificati. I programmi di mentorato sembrerebbero uno strumento efficace, ma la loro rilevanza e la loro entità sono tuttora limitate. A quanto pare, anche gli immigrati trarrebbero enorme beneficio da un'offerta più vasta di validazione degli apprendimenti acquisiti, dispositivo che in Svizzera si sta sviluppando gradualmente. Occorrerebbe assicurarsi che le misure di validazione degli apprendimenti acquisiti in fase di elaborazione raggiungano effettivamente gli immigrati e corrispondano alle loro esigenze.

Da pertinenti studi di valutazione è emersa una forte incidenza della discriminazione nelle assunzioni. Per essere convocati a un colloquio, i figli di immigrati che hanno compiuto i loro studi in Svizzera devono talvolta presentare un numero di candidature pari addirittura al quintuplo rispetto ai figli di autoctoni con un CV peraltro identico. L'incidenza relativamente debole della disoccupazione tra $\mathrm{i}$ figli d'immigrati induce a pensare che questi ultimi compensino la discriminazione presentando un numero superiore di candidature. L'elevato grado di discriminazione è in parte mascherato dalla condizione globalmente favorevole del mercato del lavoro; va detto inoltre che, nel dibattito pubblico, il rischio di discriminazione nelle assunzioni non viene praticamente menzionato. Tuttavia, rispetto agli autoctoni che hanno conseguito gli stessi risultati a scuola, i figli degli immigrati ci mettono il doppio di tempo per trovare un impiego. Di qui l'importanza di una maggiore sensibilizzazione al problema.

Il quadro giuridico e istituzionale della lotta alla discriminazione è nettamente insufficiente rispetto alla maggior parte degli altri Paesi dell'OCSE. Attualmente, la discriminazione basata sulla nazionalità non è illegale, tranne che per gli immigrati provenienti dall'UE. Inoltre, nel confronto con altri Paesi risulta che le strutture di consulenza e di orientamento sono spesso meno ben dotate e sebbene possano fornire assistenza legale, non sono autorizzate a intraprendere azioni legali. Di conseguenza, il numero di casi trattati è trascurabile se si considera il livello di discriminazione evidenziato dagli studi di valutazione. 
...e il potenziamento del quadro dovrebbe essere completato da altre misure.

Il sistema d'apprendistato sembra funzionare bene per i figli degli immigrati, ma i bassi tassi di completamento della formazione meritano una maggiore attenzione.
Pertanto è importante potenziare sia il quadro giuridico sia il quadro istituzionale della lotta alla discriminazione e portarli maggiormente a conoscenza degli immigrati. Tale riforma potrebbe essere completata da misure più incisive a favore della diversità, finalizzate alla diversificazione dei canali di reclutamento da parte dei datori di lavoro, elemento che attualmente manca in Svizzera. Il settore pubblico, nel quale gli immigrati sono sottorappresentati, deve parimenti partecipare a tale innovazione. Strumenti al servizio della diversità quali i CV anonimi, le etichette « diversità » e le consulenze in materia di diversità sono stati recentemente implementati in un certo numero di Paesi dell'OCSE.

Il Programma dell'OCSE per la valutazione internazionale delle competenze degli studenti (PISA) ha dimostrato che in Svizzera i figli d'immigrati conseguono all'età di 15 anni risultati scolastici nettamente inferiori rispetto ai figli di autoctoni e che queste differenze superano quelle osservate in molti altri Paesi dell'OCSE. L'analisi longitudinale tende a indicare che il sistema scolastico e di formazione riesce comunque a fornire successivamente qualifiche relativamente buone a questi figli d'immigrati e che nel loro caso il sistema di apprendistato sembra funzionare particolarmente bene. I figli d'immigrati hanno comunque meno probabilità di riuscire a portare a termine il loro apprendistato. Occorrerebbe studiare più a fondo tale fenomeno e adottare le corrispondenti misure correttive.

A quanto pare i figli d'immigrati Il meccanismo del passaggio dalla scuola all'impiego funziona bene hanno più problemi che in passato, per la maggior parte dei figli d'immigrati. Vi sono però anche segni per cui porvi rimedio dovrebbe essere una priorità dell'operato pubblico. secondo i quali i figli d'immigrati nuovamente arrivati riscontrano maggiori difficoltà che in precedenza e secondo cui molti dei figli d'immigrati nati all'estero conseguono risultati meno favorevoli. Quest'osservazione riguarda in particolar modo i figli d'immigrati i cui genitori sono originari di Paesi a basso reddito, che alcuni anni dopo aver lasciato la scuola, spesso non lavorano, non studiano e non si aggiornano (NEET). Siccome oggigiorno i figli d'immigrati provenienti da Paesi a basso reddito che accedono alla vita attiva sono numerosi, è importante i poteri pubblicio considerino prioritario migliorare i loro risultati. 
Tutti i giovani immigrati devono beneficiare della parità d'accesso alle politiche attive del mercato del lavoro destinate ai giovani.
Esiste una vasta gamma di misure volte a facilitare ai giovani che necessitano di un sostegno il passaggio dalla scuola all'impiego. Tuttavia, l'ammissibilità alla maggior parte delle misure di politica attiva del mercato del lavoro è spesso limitata alle persone presenti sul territorio da più di 10 anni, il che esclude numerosi giovani immigrati. Inoltre, i giovani immigrati che beneficiano di questi programmi, soprattutto del cosiddetto «semestre di motivazione", non percepiscono indennità di disoccupazione (a differenza dei giovani nati in Svizzera), e possono quindi essere tentati di entrare direttamente nel mercato del lavoro accontentandosi di un'occupazione poco qualificata. Rischiano così di essere esclusi da lavoro, studi e formazione (NEET), il che sembra accadere spesso. Assicurarsi che i figli d'immigrati e i figli di autoctoni abbiano gli stessi incentivi a partecipare ai programmi costituirebbe un primo passo per affrontare questa sfida rilevante.

Occorre migliorare l'educazione e l'accoglienza dei bambini Secondo le ricerche effettuate in un certo numero di Paesi dell'OCSE, il settore dell'educazione prescolare comporterebbe vantaggi piccoli, concentrandosi soprattutto particolari per i figli di immigrati. Tuttavia, in Svizzera l'educazione sui figli degli immigrati svantaggiati. prescolare è attualmente largamente sottosviluppata, soprattutto per quanto riguarda i bambini dai tre ai quattro anni, un'età critica per l'integrazione. Fornire un'educazione prescolare più ampia e più mirata ai bambini di quest'età e attuare precocemente misure di sostegno linguistico avrebbe importanti vantaggi. Non ne beneficerebbero solamente i figli d'immigrati, ma anche le loro madri per le quali, rispetto alle madri autoctone, il legame tra il lavoro e il fatto di avere dei figli è molto più forte. 


\section{OECD SOCIAL, EMPLOYMENT AND MIGRATION WORKING PAPERS}

Most recent releases are:

No. 127 THE LABOUR MARKET INTEGRATION OF IMMIGRANTS AND THEIR CHILDREN IN AUSTRIA Karolin Krause and Thomas Liebig (2011)

No. 126 ARE RECENT IMMIGRANTS DIFFERENT? A NEW PROFILE OF IMMIGRANTS IN THE OECD BASED ON DIOC 2005/06 Sarah Widmaier and Jean-Christophe Dumont (2011)

No. 125 EARNINGS VOLATILITY AND ITS CONSEQUENCES FOR HOUSEHOLDS Danielle Venn (2011)

No. 124 CRISIS, RECESSION AND THE WELFARE STATE Willem Adema, Pauline Fron and Maxime Ladaique (2011)

No. 123 AGGREGATE EARNINGS AND MACROECONOMIC SHOCKS Andrea Bassanini (2011)

No. 122 REDISTRIBUTION POLICY AND INEQUALITY REDUCTION IN OECD COUNTRIES: WHAT HAS CHANGED IN TWO DECADES? Herwig Immervoll, Linda Richardson (2011)

No. 121 OVER-QUALIFIED OR UNDER-SKILLED Glenda Quintini (2011)

No. 120 RIGHT FOR THE JOB Glenda Quintini (2011)

No.119 THE LABOUR MARKET EFFECTS OF UNEMPLOYMENT COMPENSATION IN BRAZIL Alexander Hijzen (2011)

No. 118 EARLY MATERNAL EMPLOYMENT AND CHILD DEVELOPMENT IN FIVE OECD COUNTRIES Maria del Carmen Huerta, Willem Adema, Jennifer Baxter, Miles Corak, Mette Deding, Matthew C. Gray, Wen-Jui Han, Jane Waldfogel (2011)

No. 117 WHAT DRIVES INFLOWS INTO DISABILITY?EVIDENCE FROM THREE OECD COUNTRIES Ana Llena-Nozal and Theodora Xenogiani (2011)

No. 116 COOKING, CARING AND VOLUNTEERING: UNPAID WORK AROUND THE WORLD Veerle Miranda (2011)

No. 115 THE ROLE OF SHORT-TIME WORK SCHEMES DURING THE 2008-09 RECESSION Alexander Hijzen and Danielle Venn (2010)

No. 114 INTERNATIONAL MIGRANTS IN DEVELOPED, EMERGING AND DEVELOPING COUNTRIES: AN EXTENDED PROFILE Jean-Christophe Dumont, Gilles Spielvogel and Sarah Widmaier (2010)

No. 113 ACTIVATION POLICIES IN JAPAN Nicola Duell, David Grubb, Shruti Singh and Peter Tergeist (2010)

No. 112 ACTIVATION POLICIES IN SWITZERLAND

Nicola Duell and Peter Tergeist with contributions from Ursula Bazant and Sylvie Cimper (2010)

No. 111 ECONOMIC DETERMINANTS AND CONSEQUENCES OF CHILD MALTREATMENT Lawrence M. Berger, Jane Waldfogel (forthcoming)

No. 110 DISTRIBUTIONAL CONSEQUENCES OF LABOR DEMAND ADJUSTMENTS TO A DOWNTURN: A MODEL-BASED APPROACH WITH APPLICATION TO GERMANY 2008-09 Herwig Immervoll, Olivier Bargain, Andreas Peichl, Sebastian Siegloch (2010)

No. 109 DECOMPOSING NOTIONAL DEFINED-CONTRIBUTION PENSIONS: EXPERIENCE OF OECD COUNTRIES' REFORMS

Edward Whitehouse (2010) 
No. 108 EARNINGS OF MEN AND WOMEN WORKING IN THE PRIVATE SECTOR: ENRICHED DATA FOR PENSIONS AND TAX-BENEFIT MODELING

Anna Cristina D'Addio and Herwig Immervoll (2010)

No. 107 INSTITUTIONAL DETERMINANTS OF WORKER FLOWS: A CROSS-COUNTRY/CROSS-INDUSTRY APPROACH

Andrea Bassanini, Andrea Garnero, Pascal Marianna, Sebastien Martin (2010)

No. 106 RISING YOUTH UNEMPLOYMENT DURING THE CRISIS: HOW TO PREVENT NEGATIVE LONG-TERM CONSEQUENCES ON A GENERATION?

Stefano Scarpetta, Anne Sonnet and Thomas Manfredi (2010)

No. 105 TRENDS IN PENSION ELIGIBILITY AGES AND LIVE EXPECTANCY, 1950-2050

Rafal Chomik and Edward Whitehouse (2010)

No. 104 ISRAELI CHILD POLICY AND OUTCOMES

John Gal, Mimi Ajzenstadt, Asher Ben-Arieh, Roni Holler and Nadine Zielinsky (2010)

No. 103 REFORMING POLICIES ON FOREIGN WORKERS IN ISRAEL Adriana Kemp (2010)

No. 102 LABOUR MARKET AND SOCIO-ECONOMIC OUTCOMES OF THE ARAB-ISRAELI POPULATION Jack Habib, Judith King, Asaf Ben Shoham, Abraham Wolde-Tsadick and Karen Lasky (2010)

No. 101 TRENDS IN SOUTH AFRICAN INCOME DISTRIBUTION AND POVERTY SINCE THE FALL OF APARTHEID

Murray Leibbrandt, Ingrid Woolard, Arden Finn and Jonathan Argent (2010)

No. 100 MINIMUM-INCOME BENEFITS IN OECD COUNTRIES: POLICY DESIGN, EFFECTIVENESS AND CHALLENGES

Herwig Immervoll (2009)

No. 99 HAPPINESS AND AGE CYCLES - RETURN TO START...? ON THE FUNCTIONAL RELATIONSHIP BETWEEN SUBJECTIVE WELL-BEING AND AGE Justina A.V. Fischer (2009)

No. 98 ACTIVATION POLICIES IN FINLAND

Nicola Duell, David Grubb and Shruti Singh (2009)

No. 97 CHILDREN OF IMMIGRANTS IN THE LABOUR MARKETS OF EU AND OECD COUNTRIES: AN OVERVIEW

Thomas Liebig and Sarah Widmaier (2009)

A full list of Social, Employment and Migration Working Papers is available at www.oecd.org/els/workingpapers.

Other series of working papers available from the OECD include: OECD Health Working Papers. 
DELSA/ELSA/WD/SEM(2012)2

\section{RECENT RELATED OECD PUBLICATIONS:}

NATURALISATION: A Passport for the Better Integration of Immigrants? via OECD Bookshop

SICK ON THE JOB: Myths and Realities about Mental Health and Work (2011), www.oecd.org/els/disability

DIVIDED WE STAND: Why Inequality Keeps Rising (2011), www.oecd.org/els/social/inequality

EQUAL OPPORTUNITIES? The Labour Market Integration of the Children of Immigrants (2010), via OECD Bookshop

OECD REVIEWS OF LABOUR MARKET AND SOCIAL POLICIES: ESTONIA (2010), www.oecd.org/els/estonia2010

JOBS FOR YOUTH: GREECE (2010), www.oecd.org/employment/youth

JOBS FOR YOUTH: DENMARK (2010), www.oecd.org/employment/youth

OECD REVIEWS OF LABOUR MARKET AND SOCIAL POLICIES: ISRAEL (2010), www.oecd.org/els/israel2010

JOBS FOR YOUTH: UNITED STATES (2009), www.oecd.org/employment/youth

JOBS FOR YOUTH: POLAND (2009), www.oecd.org/employment/youth

OECD EMPLOYMENT OUTLOOK: Tackling the Jobs Crisis (2009), www.oecd.org/els/employment/outlook

DOING BETTER FOR CHILDREN (2009), www.oecd.org/els/social/childwellbeing

SOCIETY AT A GLANCE - ASIA/PACIFIC EDITION (2009), www.oecd.org/els/social/indicators/asia

OECD REVIEWS OF LABOUR MARKET AND SOCIAL POLICIES: SLOVENIA (2009), www.oecd.org/els/slovenia2009

INTERNATIONAL MIGRATION OUTLOOK: SOPEMI (2010) www.oecd.org/els/migration/imo

PENSIONS AT A GLANCE 2009: Retirement-Income Systems in OECD Countries (2009),

www.oecd.org/els/social/pensions/PAG

JOBS FOR YOUTH: FRANCE (2009), www.oecd.org/employment/youth

SOCIETY AT A GLANCE 2009 - OECD Social Indicators (2009), www.oecd.org/els/social/indicators/SAG

JOBS FOR YOUTH: AUSTRALIA (2009), www.oecd.org/employment/youth

OECD REVIEWS OF LABOUR MARKET AND SOCIAL POLICIES: CHILE (2009), www.oecd.org/els/chile2009

PENSIONS AT A GLANCE - SPECIAL EDITION: ASIA/PACIFIC (2009),www.oecd.org/els/social/pensions/PAG

SICKNESS, DISABILITY AND WORK: BREAKING THE BARRIERS (VOL. 3) - DENMARK, FINLAND, IRELAND

AND THE NETHERLANDS (2008), www.oecd.org/els/disability

GROWING UNEQUAL? Income Distribution and Poverty in OECD Countries (2008), www.oecd.org/els/social/inequality

JOBS FOR YOUTH: JAPAN (2008), www.oecd.org/employment/youth

JOBS FOR YOUTH: NORWAY (2008), www.oecd.org/employment/youth

JOBS FOR YOUTH: UNITED KINGDOM (2008), www.oecd.org/employment/youth

For a full list, consult the OECD online Bookshop at www.oecd.org/bookshop. 
DELSA/ELSA/WD/SEM(2012)2 